\title{
An Assessment of Gas Void Fraction Prediction Models in Highly Viscous Liquid and Gas Two-Phase Vertical Flows
}

\section{Joseph X. F. Ribeiro ${ }^{1,2,3}$, Ruiquan Liao ${ }^{1,2}$, Aliyu M. Aliyu ${ }^{4}$, Yahaya D. Baba5 ${ }^{5}$ Archibong Archibong-Eso ${ }^{6}$, Adegboyega Ehinmowo ${ }^{7}$ Liu Zilong $^{1,2}$}

1. Petroleum Engineering College, Yangtze University, Wuhan Campus, No. 111, Caidian District, Wuhan City 430100, Hubei Province, China.

2. Laboratory of Multiphase Flow, Gas Lift Innovation Centre, China National Petroleum Corporation, Wuhan, China

3. Kumasi Technical University, P. O. Box 854, Kumasi, Ghana

4. Faculty of Engineering, University of Nottingham, NG7 2RD, UK. (Currently at: School of Computer and Engineering, University of Huddersfield, Queensgate, HD1 3DH, UK).

5. Department of Chemical and Biological Engineering, University of Sheffield, S1 3JD, UK.

6. Department of Mechanical Engineering, University of Birmingham Dubai, Dubai International Academic City PO Box 341799 Dubai, UAE.

7. Department of Chemical Engineering, University of Lagos, Nigeria

Joseph X. F. Ribeiro (Corresponding author), joxaro@yahoo.com,+233244476160; Ruiquan Liao, 1036792057@qq.com; Aliyu M. Aliyu, a.m.aliyu@hud.ac.uk, Yahaya D. Baba, y.baba@sheffield.ac.uk, Archibong Archibong-Eso, a.e.archibong@bham.ac.uk; Adegboyega Ehinmowo, aehinmowo@unilag.edu.ng; Liu Zilong, zilongliu@yahoo.com

Keywords: gas void fraction, highly viscous flow, two-phase flow, vertical pipes,

\section{Abstract}

Gas void fraction plays a significant role in determination of several multiphase flow parameters. Good insight of its behaviour coupled with accurate prediction is imperative for design of efficient equipment which has the potential to translate to higher production rates in the petroleum industry. Against the background of the prevalence of higher viscous and imminent application of highly viscous liquids in the petroleum industry, air-water and air-low viscous liquid mixtures dominate gas void fraction research in vertical pipes. In this work, gas-liquid $\left(\mu_{l}=100-7000 \mathrm{mPas}\right.$ ) mixtures are used to investigate the behaviour of gas void fraction in vertical pipes. The influence of superficial phase velocities and liquid viscosity are observed. Further, a combined database consisting of experimental and the reported data of Schmidt et al. (2008) is employed to evaluate the predictions of 100 existing correlations. The results indicate that the Hibiki and Ishii (2003) and Bestion (1990) correlations are the overall best and secondbest performing correlations. In the absence good performing correlations for churn and annular flows, two correlations each, based on drift flux and slip ratio, are developed respectively. Predictions from these correlations show good agreement with the database and comparable performance with the overall best correlations. 


\section{Introduction}

Simultaneous transportation of gases and liquids is critical to production in many industries. For this reason, gas-liquid two-phase flows are regularly employed in industries including food, civil, chemical, nuclear, power plants (Yin et al., 2018) and petroleum where they are employed in various applications (Wu et al., 2017). For instance, two-phase flow applications are found in process equipment (vapour-liquid contactors and/or absorbers, vapour generators, thermosyphon reboilers, and gas-liquid chemical reactors) in chemical industries (Fernandes et al., 1983). In the petroleum industry, two-phase flows are observed during transportation of oil and gas products through pipes from wells to processing facilities (Hewakandamby et al., 2014; Kim et al., 2018) while its characteristics are employed in the calculation of phase flow rates, pressure loss and liquid holdup in pipelines. Additionally, related parameters are essential to the design of production conduits, sizing of gas lines, gathering and separation systems, heat exchangers and gas condensate pipelines (Alamu, 2010).

Two-phase flows in vertical pipes can be classified on the basis of flow patterns observed. A large number of flow pattern classifications exists partly due to the subjective nature of identification methods and can also be attributed to the effects of flow conditions, pipe geometry, and fluid properties. Additionally, the application of current technologies such as wire mesh sensors is aiding more accurate identification of previously unknown flow characteristics (Abdulkadir et al., 2014a; Aliyu et al., 2017; Almabrok et al., 2016; Ambrose, 2015; Hernandez Perez et al., 2010; Peddu et al., 2018). Common flow patterns reported, however, are bubble, slug, churn (froth), annular (Hewakandamby et al., 2014).

Bubble flow is characterized by individual gas bubbles dispersed in a continuous phase liquid. This flow regime is often observed at low gas and liquid velocities. Some studies (Barnea, 1987; Taitel et al., 1980) have also reported dispersed bubble flow regime at high liquid velocities/flow rates, which can produce large turbulent forces and inhibit bubble coalescence. Slug flow occurs when gas velocity is increased beyond that generating bubble flow. This regime is characterized by the presence of large gas bubbles, known as Taylor bubbles, which occupy the entire cross section of the pipe except for a thin liquid film on the wall. Taylor bubbles form as a result of coalescence smaller bubbles as gas velocity increases. Further increases in the superficial gas velocity lead to the collapse of Taylor bubbles into an unstable flow (Wu et al., 2017). Churn flow is characterized by highly oscillatory, violently mixing of liquid and gas (Hewakandamby et al., 2014) while annular flow is fully developed at sufficiently high gas velocities and is 
characterized by a gas core flowing in the middle of the pipe with thin liquid film flowing at the inner periphery of the wall (Berna et al., 2014; Wu et al., 2017). Details of the flow regimes have been compiled by several authors including Alamu (2010), Bhagwat and Ghajar (2014) and Wu et al. (2017).

Measured flow characteristics such as gas void fraction (Cioncolini and Thome, 2012), liquid holdup and pressure gradient can also be used to categorize two-phase flows. In particular, gas void fraction, defined as the quantification of the in-situ phase fraction for the gas phase, is a dimensionless quantity which plays crucial roles in the accurate determination of several multiphase flow parameters (Parrales et al., 2018) including mixture density, pressure gradient and heat transfer (Azizi et al., 2016 Cioncolini and Thome, 2012). It is also useful in the classification of flow patterns in pipes (Barnea, 1987; Taitel et al., 1980). Indirectly, therefore, gas void fraction influences the accurate design of equipment for safety and enhanced production. Its significance, the need to understand its dynamic behaviour as well as factors which influence it has made it an intense subject of research spanning several decades and resulting in a long list of reported correlations for varied flow conditions and pipe configurations.

Against the backdrop of significant application of highly viscous liquids in industry, the behaviour of gas void fraction in vertical pipes has largely been studied using air-water with a considerable number of studies employing air-low viscosity mixtures. Reports from studies based on air-low viscosity mixtures establish, with evidence, that liquid viscosity influences flow characteristics including gas void fraction (Alamu, 2010; Parsi et al., 2015a). Despite these findings, there is generally a dearth of information and data obtained from highly viscous flow studies, especially for flows in vertical pipes. To successfully model gas void fraction in highly viscous flows, there is the need to understand its behaviour under this influence. Furthermore, most existing correlations were developed based on air-water and air-low viscosity liquid mixtures, hence their prediction capacities in high viscosity liquid systems need investigation to ascertain their reliability.

In an attempt to fill the information gap, this review highlights findings of relevant studies and reports the results of an experimental study with the same focus. Additionally, it also aims to establish the prediction accuracy of existing correlations when applied to highly viscous flows. Results from this study will provide the much need confidence in the application of these correlations and make the case for improvement or development of new ones where necessary.

\subsection{Previous works}

Gas void fraction can be estimated for all flow regimes. Perhaps, this constitutes one of the major reasons for its intense investigation in multiphase flows. Research efforts have yielded several correlations for 
different flow regimes and inclinations. Recent contributions include the works of Vijayan et al.(2000), Coddington and Macain (2002), Woldesemayat and Ghajar (2007), and Godbole et al. (2011) and Cioncolini and Thome (2012). For the majority of reported studies, however, air-water mixtures constitute the main experimental fluids. Detailed information has been covered by Godbole (2009), Godbole et al. (2011), Mathure (2010), Bhagwat (2011), Oyewole (2013), and Tang et al. (2013). The few reported studies on the subject reported using gas-low/higher viscous liquids in vertical pipes are listed in Table 1.

Table 1. Compilation of works focused on the influence of liquid viscosity on gas void fraction in vertical pipes

\begin{tabular}{|c|c|c|c|}
\hline Author & $\begin{array}{l}\text { Liquid viscosity } \\
\text { (mPa s) }\end{array}$ & Experimental fluids & Remarks \\
\hline \multicolumn{4}{|l|}{ Low viscosity } \\
\hline $\begin{array}{l}\text { Sowinski and Dziubinski } \\
\text { (2007) }\end{array}$ & $0.95,4,9.7$ & $\begin{array}{l}\text { Air-Water, Air-aqueous } \\
\text { saccharose solution }\end{array}$ & $\begin{array}{l}I D=0.015 \mathrm{~m}, \mathrm{v}_{\mathrm{sl}}=0.047-2.30 \mathrm{~m} / \mathrm{s} \\
\mathrm{v}_{\mathrm{sg}}=0.011-5.56 \mathrm{~m} / \mathrm{s}\end{array}$ \\
\hline Szalinski et al. (2010) & 5.25 & Air-water, Air-Silicone & $\begin{array}{l}\mathrm{ID}=0.067 \mathrm{~m}, \mathrm{v}_{\mathrm{sl}}=0.2,0.25,0.7 \mathrm{~m} / \mathrm{s} \\
\mathrm{v}_{\mathrm{sg}}=0.05-5.7 \mathrm{~m} / \mathrm{s}\end{array}$ \\
\hline Alamu (2010) & $1,10,12$ & Air-Water, Air-Glycerol & $I D=0.005 m, L=3 m$ \\
\hline Abdulkadir et al. (2014b) & 4.7 & Air-water, Air-Silicone & $\begin{array}{l}\mathrm{ID}=0.067 \mathrm{~m}, \mathrm{v}_{\mathrm{sl}}=0.05-0.38 \mathrm{~m} / \mathrm{s} \\
\mathrm{v}_{\mathrm{sg}}=0.05-4.73 \mathrm{~m} / \mathrm{s}\end{array}$ \\
\hline Parsi et al. (2015a) & $1,10,40$ & $\begin{array}{l}\text { Air-water,Air- } \\
\text { water/carboxyl methyl } \\
\text { cellulose }\end{array}$ & $\begin{array}{l}\mathrm{ID}=0.076 \mathrm{~m}, \mathrm{v}_{\mathrm{sl}}=0.055-1.0 \mathrm{~m} / \mathrm{s} \\
\mathrm{v}_{\mathrm{sg}}=10-40 \mathrm{~m} / \mathrm{s}\end{array}$ \\
\hline Vieira et al. (2015) & $1,10,40$ & $\begin{array}{l}\text { Air-water,Air- } \\
\text { water/carboxyl methyl } \\
\text { cellulose }\end{array}$ & $\begin{array}{l}I \mathrm{I}=0.076 \mathrm{~m}, \mathrm{v}_{\mathrm{sl}}=0.055-1.0 \mathrm{~m} / \mathrm{s} \\
\mathrm{v}_{\mathrm{sg}}=10-40 \mathrm{~m} / \mathrm{s}\end{array}$ \\
\hline \multicolumn{4}{|l|}{ High viscosity } \\
\hline McNeil and Stuart (2003) & $1,50,200,550$ & $\begin{array}{l}\text { Air-water, Air-glycerine- } \\
\text { water }\end{array}$ & $\begin{array}{l}(1 \mathrm{mPa} \mathrm{s}) \mathrm{v}_{\mathrm{g}}(\mathrm{m} / \mathrm{s})=22-120, \mathrm{u}_{\mathrm{lf}}(\mathrm{m} / \mathrm{s})=1.9-4.2 \\
(50 \mathrm{mPa} \mathrm{s}) \mathrm{v}_{\mathrm{g}}(\mathrm{m} / \mathrm{s})=22-100, \mathrm{u}_{\mathrm{lf}}(\mathrm{m} / \mathrm{s})=0.21-2.1 \\
(200 \mathrm{mPa} \mathrm{s}) \mathrm{v}_{\mathrm{g}}(\mathrm{m} / \mathrm{s})=17-96, \mathrm{u}_{\mathrm{lf}}(\mathrm{m} / \mathrm{s})=0.47-2.0 \\
(550 \mathrm{~L} \mathrm{mPa} \mathrm{s}) \mathrm{v}_{\mathrm{g}}(\mathrm{m} / \mathrm{s})=12-87, \mathrm{u}_{\mathrm{lf}}(\mathrm{m} / \mathrm{s})=0.5-2.1 \\
(550 \mathrm{H} \mathrm{mPa} \mathrm{s}) \mathrm{v}_{\mathrm{g}}(\mathrm{m} / \mathrm{s})=17-110, \mathrm{u}_{\mathrm{lf}}(\mathrm{m} / \mathrm{s})=0.37- \\
2.0\end{array}$ \\
\hline Schmidt et al. (2008) & $900-7000$ & $\begin{array}{l}\text { Ai-water, Nitrogen gas- } \\
\text { Luviskol }\end{array}$ & $\begin{array}{l}\mathrm{ID}=0.054 \mathrm{~m}, \mathrm{v}_{\mathrm{sl}}=0.005-3.4 \mathrm{~m} / \mathrm{s} \\
\mathrm{v}_{\mathrm{sg}}=0-30 \mathrm{~m} / \mathrm{s} \text { (nitrogen gas) }\end{array}$ \\
\hline $\begin{array}{l}\text { Hewakandamby et } \\
\text { al.(2014) }\end{array}$ & $1,12.2,16.2$ & & \\
\hline Mohammed et al. (2018) & 3300,3600 & Air-Silicone & $\mathrm{ID}=0.240 \mathrm{~m}, 0.290 \mathrm{~m}$ \\
\hline
\end{tabular}

As a result of intense study of gas void fraction, several correlations have been reported in literature. In this study, correlations which presented satisfactory performance are highlighted to aid comparison and discussion. 
Gas void fraction correlations can be categorized into 4 groups; namely, flow pattern specific correlations, flow pattern independent correlations for vertical upward orientation, flow pattern independent correlations applicable to a variety of the flow orientations including vertical upward flow and correlations not developed for but applicable to vertical upward flow (Godbole,2009). Flow pattern-specific correlations are developed for a specific flow pattern in vertical upward two-phase flow. Flow-regime independent correlations developed for vertical pipes comprise those correlations independent of flow pattern and developed only for upward vertical orientation. Flow regime independent correlations developed for multiple pipe orientations are correlations are independent of flow pattern and developed only for different angles of inclination including upward vertical orientation. Flow regime independent correlations not developed for but applicable to vertical pipes are correlations not developed specifically for vertical flow but are recommended by researchers for prediction of void fraction in vertical flow.

Correlations can further be categorized into four groups based on the approach employed for development; namely, empirical (semi-empirical), $\mathrm{K} \alpha_{\mathrm{H}}$, mechanistic, slip ratio and drift flux. The empirical approach fits curves to data obtained from experiments and makes predictions using the mathematical expressions which describe the fitted curve. The $\mathrm{K}_{\mathrm{H}}$ methods predict void fraction by multiplying the homogenous model $\left(\alpha=v_{s g} / v_{s g}+v_{s l}\right)$ with an empirically determined constant, $\mathrm{K}$ (Cioncolini and Thome, 2012). Mechanistic correlations, on the other hand, are based on mathematical theories which are based on flow phenomena. The drift-flux model, on the other hand, is based on the interaction of two-phase and physics of the flow. It represents the mean value of the local void fraction averaged across the pipe cross-section and in essence, is the same as that of $\alpha$ when measured using the quick closing valve method. Hence, the cross-sectional averaged void fraction $\langle\alpha\rangle$ can be interchangeably used with $\alpha$. Slip ratio correlations specify establish the empirical relationship for predicting the slip between phases (Cioncolini and Thome, 2012). Majority of correlations reported for void fraction prediction are based on the drift-flux approach (Cioncolini and Thome, 2012).

For this study, the first categorization is adopted for analysis. Correlations which presented good performances in this study are briefly discussed. Also, a summarized detail of the correlations discussed is provided in Appendix A.1. Details of these approaches as well as others, not covered in this study, are adequately discussed by the aforementioned authors. 


\subsubsection{Flow regime dependent correlations}

\subsubsection{Bubble flow}

Gomez et al. (2000), as reported by (Godbole, 2009), proposed a mechanistic model for prediction of liquid holdup (gas void fraction) in bubble flow as part of their work to develop a unified model for the prediction of flow pattern, liquid holdup and pressure drop for all flow patterns from horizontal to vertical two-phase flow. They introduced the inclination angle to modify the Hasan and Kabir (1988) bubble flow correlation in order to extend the range of inclinations. The drift velocity proposed by Harmanthy (1960) was adopted. The $\mathrm{C}_{\mathrm{o}}$ value used was 1.15 .

\subsubsection{Slug}

Nicklin and Davidson (1962) studied flow pattern transition in upward vertical slug flow using air and water mixtures as fluids and presented a drift flux correlation for void fraction. The authors estimated a distribution parameter, $\mathrm{C}_{\mathbf{o}}$ of 1.2. Ellis and Jones (Ellis and Jones, 1965; Godbole, 2009) adopted an empirical correlation for void fraction development for the slug flow regime. Bonnecaze et al. (1971) studied void fraction and pressure drop in slug flow using gas and oil in inclined ( $\pm 10^{\circ}$ to horizontal) pipes and used 152 experimental data points to develop a $\mathrm{K} \alpha_{\mathrm{H}}$ correlation for void fraction prediction. Kataoka and Ishii (1987) demonstrated that the conventional drift flux model for pool void fraction to relatively large pipes was only limited to low gas fluxes and proposed a drift flux correlation for larger systems (Aliyu et al., 2017). Their correlation accounted for the effect of the gas and liquid phase properties, diameter and pressure. The authors compared their model with air-water, air-glycerin and steam-water void fraction data of 13 other researchers. Good results were achieved with nearly all predicted data points falling within the $\pm 20 \%$ error index (Godbole, 2009). The proposed mechanistic correlation presented by Gomez et al. (Godbole, 2009) for slug flow is similar to that of Fernandes et al. (1983) and is applicable to inclinations from 0 to $+90^{\circ}$. The correlations of Kataoka and Ishii (1987), Nicklin and Davidson (1962) and Bonnecaze et al. (1971) predicted more than $80 \%$ of entire data used by Godbole (2009) in his study. The correlation of Gomez et al. (2000) (as presented by Godbole, 2009) predicted 80\% of the overall data. Godbole (2009) asserts that the Bonnecaze et al. (1971) and Nicklin and Davidson (1962) correlations are approximately the same for vertical upward orientation. Hence, identical performance is to be expected. These two correlations performed best for overall slug flow data used by Godbole (2009).

\subsubsection{Churn flow}

Kabir and Hasan (1990) applied the drift-flux model to develop a correlation for gas void fraction. The authors used a $\mathrm{C}_{\mathbf{o}}$ value of 1.15 . Godbole (2009) reported a good performance for the correlation when it 
was evaluated. It predicted as high as $91.3 \%$ experimental data points within the $15 \%$ error index. At the suggestion of Mao and Dukler (1993) that slug flow correlations could predict churn flow data, Godbole (2009) evaluated the Nicklin and Davidson (1962) and Orell and Rembrand (Godbole, 2009) correlations with his churn flow data. The authors found that Nicklin and Davidson (1962) performs better than the churn flow correlations, predicting more than $80 \%$ of experimental data in the $10 \%$ error index.

\subsubsection{Annular flow}

Correlations which offered good performances at this flow regime include those of Lockhart and Martinelli (Godbole, 2009), Fauske (1961), Smith (1969), Gomez et al.(Godbole, 2009) and Beggs (1972). The Lockhart and Martinelli correlation, as presented by (Godbole, 2009), is a slip ratio correlation. Woldesemayat (2006) reported the capacity of this correlation to predict void fraction in annular flow. The Fauske (1961) correlation also employed a slip ratio method to develop a gas void fraction correlation based on a steamwater system for a quality range from 0.01 to 1 using diameters of $0.003175 \mathrm{~m}, 0.006833 \mathrm{~m}$ and $0.0127 \mathrm{~m}$. Pressures during the experiment ranged from 0.28 to $2.48 \mathrm{MPa}$ (40 to $360 \mathrm{psia}$ ) respectively. Smith (1969) also proposed a slip ratio correlation for prediction of void fraction in annular flow. For annular flow, the Gomez et al.(2000) correlation (presented by Godbole, 2009) was mechanistic in nature and a similar approach to that of Kabir and Hasan (1990). This correlation accounted for liquid entrainment. The expression for liquid entrainment, proposed by Wallis (1969) was adopted for this correlation. The correlation presented by Beggs (1972) for void fraction prediction was empirical in nature and applicable to all inclinations.

\subsubsection{Flow regime independent}

\subsubsection{Flow pattern independent correlations developed for upward Vertical orientation}

Schmidt et al. (2008) studied flow pattern and gas void fraction by conducting adiabatic experiments using mixtures of nitrogen and solutions of Polyvinylpyrrolidone (Luviskol) in water with dynamic viscosities from 900 to $7000 \mathrm{mPa}$ s and a pipe with ID $0.054 \mathrm{~m}$. Mass flux and quality varied from 8 to $3500 \mathrm{~kg} / \mathrm{m}^{2} / \mathrm{s}$ and 0 to $82 \%$ respectively. Superficial gas and liquid velocities were 0 to $30 \mathrm{~m} / \mathrm{s}$ and 0.005 to $3.4 \mathrm{~m} / \mathrm{s}$ respectively. For comparison, reference measurements were taken for mixtures of Nitrogen and water (1 mPa s). Two new correlations, based on slip ratio and drift flux methodologies respectively, were developed using 87 selected data points. Overall predictions of the correlations for the entire data agreed very well with the experimental data. Thom (1964) suggested a slip correlation for vertical upward flow of boiling water. The author presented the variation of void fraction with quality. Baroczy (1966) formulated a slip ratio correlation using vertical flow data. Czop et al. (1994) conducted experiments using $0.0198 \mathrm{~m}$ diameter 
vertical helical tubes with water and $\mathrm{SF}_{6}$ as the working fluids. They developed a $\mathrm{K} \alpha_{\mathrm{H}}$ correlation based on the data obtained. Predictions of their correlations agreed well with the experimental data (40 data points) within $\pm 10 \%$. The Dimentiev et al. (1959) correlation is a pool void fraction correlation for large diameter pipes and steam-water mixtures. The accuracy of the correlation was not stated by the author. Dix (1971) developed a drift flux correlation based on vertical upward flow data sets from a boiling water reactor. The correlation was one of the top three correlations in a comparative study Chexal et al. (1992) carried out using approximately 1500 data points obtained from a vertical upward steam - water system. The author presented a $C_{o}$ which is a function of phase superficial velocities. Takeuchi et al. (1992) developed a drift flux correlation for vertical two-phase flow. Accuracy of the correlation was not provided by the authors. It also presented good performance when subjected to the air-water data of Sujumnong (1997) (Godbole, 2009) and gave good performance in the 15\% (more than $85 \%$ ) and 10\% (more than $75 \%$ ) error indices respectively.

\subsubsection{Flow pattern independent correlations applicable to multiple orientations including vertical upward flow}

Bhagwat and Ghajar (2014) proposed two separate sets of equations for the distribution parameter and drift velocity for the drift flux correlation for gas void fraction prediction. The new expressions were defined as functions of several two-phase parameters. 8255 data points collected from more than 60 sources consisting of air-water, argon-water, natural gas-water, air-kerosene, air-glycerin, argon-acetone, argonethanol, argon-alcohol, refrigerants (R11, R12, R22, R134a, R114, R410A, R290, and R1234yf), steam-water as well as air and oil mixtures. The authors demonstrated successful prediction of experimental data obtained using hydraulic pipe diameters ranging between 0.5 to $305 \mathrm{~mm}$, pipe orientations of $-90^{\circ} \leq \theta \leq$ $+90^{\circ}$, liquid viscosities ranging from 0.0001 to $0.6 \mathrm{~Pa}$ s, system pressures from 0.1 to $18.1 \mathrm{MPa}$ and twophase Reynolds numbers from 10 to $5 \times 10^{6}$. Further, comparison with existing top performing correlations revealed the correlation gives better performance over the entire range of void fraction. The correlation appears to predict well at various viscosities.

\subsubsection{Correlations not developed for by applicable to vertical upward flow}

Armand (1946) (Godbole, 2009) employed a $\mathrm{K}_{\mathrm{H}}$ approach to develop a gas void fraction. Hart et al. (1989), Flanigan (1958) and Wallis (1969) used a general equation to develop their correlation for predicting gas void fraction. Turner and Wallis (1965) adopted a slip ratio methodology to develop their void fraction correlation.

The rest including Mattar and Gregory (1974), Woldesemayat and Ghajar (2007), Lahey and Moody (1977), Ishii (Godbole, 2009), Ohkawa and Lahey (Godbole, 2009), Jowitt et al. (1984), Bestion (1990), Pearson et 
al. (Azizi et al., 2016), Hughmark (1965), Gregory and Scott (1969), Toshiba (Woldesemayat and Ghajar, 2007), Shipley (Bhagwat and Ghajar, 2014), Hibiki and Ishii (2003), Mishima and Hibiki (1996) presented a new equation for distribution parameter as a function of inner diameter. Clark and Flemmer (Bhagwat and Ghajar, 2014), and Beattie and Sugawara (Bhagwat and Ghajar, 2014) also utilized the drift flux method for correlation development.

Mattar and Gregory (1974) employed air-oil mixtures, the correlation was designed to be capable of predicting gas void fraction (GVF) from horizontal to $\pm 10^{\circ}$ inclined flows (Mathure, 2010; Mattar and Gregory, 1974; Woldesemayat and Ghajar, 2007). Lahey and Moody (Godbole, 2009) presents a drift flux correlation known as the "ramp model". Accuracy of correlation was not determined initially by the authors. Ohkawa and Lahey (Godbole, 2009) proposed a correlation for void fraction in countercurrent flow limited (CCFL) conditions. Accuracy of correlation was not determined initially by the authors. Bestion (1990) presented a drift flux correlation with a modified expression for drift velocity and a distribution parameter of 1. When compared with the experimental data of Coddington and Macain (2002), the author observed overprediction above the value of 0.6. Its absolute error in prediction was 0.049. Shipley (Bhagwat and Ghajar, 2014) presented a drift flux correlation. It can be noticed that the expression for drift velocity does not account for the effect of fluid properties. Ishii (Godbole, 2009) presented a drift flux correlation. Accuracy of correlation was not determined initially by the authors. When compared with the data of Coddington and Macain (2002), it predicted it with an absolute error of 0.048 . The correlation was found to present good performance when subjected to the air-water data of Sujumnong (Godbole, 2009), and gave the best performance in the $15 \%(94.2 \%)$ and $10 \%$ (86.5\%) error indices respectively. It also presented the best performance for $10 \%$ ( $85.7 \%$ data points) and 15\% (92.2\% data points) error bands for air-glycerin mixtures.

Jowitt et al. (Godbole, 2009; Jowitt et al., 1984) suggested a drift flux correlation. The correlation predicted the void fraction data in the study of Coddington and Macain (2002) with an average absolute error of 0.057. It was also observed that the correlation showed overprediction for void fraction data for values equal to and greater than 0.5. Hibiki and Ishii (2003) developed three flow regime dependent correlations for bubble, slug and annular flow respectively. The authors employed drift velocity expressions suitable for slug flow, which captures the effect of pipe diameter and phase densities. Mishima and Hibiki (1996) presented a correlation based on the drift flux methodology. The drift velocity they employed does not account for the effect of fluid properties. Beattie and Sugawara (Bhagwat and Ghajar, 2014) presented a 
drift flux model essentially developed for two-phase flow of steam-water through large diameter pipes and is modelled as a function of two-phase friction factor (ftp).

Hughmark (1965) presented a drift flux correlation with a $C_{o}$ value of 1.2. There is the noticeable absence of drift velocity parameter (as reported by Woldesemayat and Ghajar (2007) and Mathure (2010)). Using carbon dioxide and water mixtures and a pipe ID of 0.75 and 1.5 inches (Nobakht Hassanlouei et al., 2012), Gregory and Scott (1969) developed a drift flux correlation based on the work of Nicklin and Davidson (1962) and determined a $C_{o}$ value of 1.19. The authors presented no drift velocity in their correlation (Mathure, 2010; Woldesemayat and Ghajar, 2007).

Clark and Flemmer (Bhagwat and Ghajar, 2014) analyzed the Zuber and Findlay (1965) drift flux model for both upward and downward flows. Air-water mixtures were used in experiments with a pipe diameter of $0.1 \mathrm{~m}$. The authors performed regression on results using Wallis (1969) equation and found bubble rise velocity approximately equal to $0.25 \mathrm{~m} / \mathrm{s}$ which is in good agreement with Harmanthy (1960) equation. They obtained a $C_{o}$ value of 1.165 the best fit for all data in bubbly flow for downward flow and $C_{o}$ value of 1.07 for bubble upward flow. Their result was found in contrast to that of Zuber and Findlay (1965) who proposed the same value for the different conditions. For slug flow, Clark and Flemmer (Bhagwat and Ghajar, 2014) suggested a drift velocity similar to that of Nicklin et al. (1962). They observed a certain relationship between the distribution parameter and gas void fraction for slug flow. The expression for the distribution parameter $C_{o}$ in terms of void fraction was given as, $\mathrm{C}_{\mathrm{o}}=1.521(1-3.67 \alpha)$. However, they claimed that this linear relation between $C_{o}$ and gas void fraction may not be valid for some pipe geometries since dependence on $C_{o}$ on void fraction may vary for different pipe diameters. The reliability of this expression is open to question since the correlation was not compared with another data and the percentage accuracy of the void fraction correlation was not provided (Bhagwat, 2011).

Two correlations, originally developed by Cai et al. (Bhagwat and Ghajar, 2012) for predicting void fraction for vertically downward flows were evaluated by Bhagwat and Ghajar (2012) using data obtained for vertically upward flows with success. These were also integrated into study for assessment. Though Nicklin et al. (1962) was developed for slug flow, Woldesemayat and Ghajar (2007) observed that it predicted 75\% of their data points for all their data sets, indicating that it has more potential than just to predict for slug flows only.

Detailed information has been covered by Godbole (2009), Godbole et al. (2011), Mathure (2010), Bhagwat (2011), Oyewole (2013), and Tang et al. (2013). 


\subsection{Comparative studies}

A number of comparative studies have been made to evaluate the reliability of correlations at different flow conditions. This has often been the case when new data, obtained at novel conditions, become available.

Majority of the comparative studies have been implemented for horizontal pipes (Dukler et al.,1964; Marcano, 1973; Abdul-Majeed, 1996; Hoogendoorn, 1959). Dukler et al. (1964) implemented the first comparison. In their investigation, 706 void fraction data points of Hoogendorn (1959) which had viscosities range between 3 and $20 \mathrm{mPa}$ s were used for the exercise. Void fraction correlations considered included Hoogendorn (1959), Hughmark (1962) and Lockhart and Martinelli (1949). Using statistical tools such as arithmetic mean deviation and standard deviation, the authors showed that the Hughmark (1962) correlation performed better than the others. Marcano (1973) performed a similar exercise on the correlations of Lockhart and Martinelli (1949), Hughmark (1962), Dukler et al. (1969), Eaton et al. (1967), Guzhov et al. (1967) and Beggs (1972) using the reported data of Eaton (1966) and Beggs (1972). The authors found that correlations of Eaton et al. (1967) and Beggs (1972) performed well due to the fact the data used for the comparison was the data from which these correlations were developed. Further, the correlations of Dukler et al. (1969) and Lockhart and Martinelli (1949) were found to present satisfactory results.

Palmer (1975) compared the correlations of Beggs (1972), Flanigan (1958) and Guzhov et al. (1967) for inclinations between 4.2 and 7.5 degrees. Using the percent error, average percent error and standard deviation, the authors concluded that the Beggs (1972) correlation presented good prediction of the void fraction for uphill flow.

Mandhane et al. (1975) utilized the 2700-point void fraction data hosted in the University of Calgary multiphase pipe flow data bank to evaluate 12 correlations: Lockhart and Martinelli (1949), Hoogendorn (1959), Eaton et al. (1967), Hughmark (1962), Guzhov et al. (1967), Chawla (1969), Beggs (1972), Dukler et al. (1969), Scott (1962), Agrawal et al. (1973), Hughmark (1965) and Levy (1960). Root mean-square error (RMSE), mean absolute error (MAE), simple mean error, mean-percentage absolute error (MPAE) and mean percentage error (MPE) were the statistical tools used for the assessment. Best performing correlations were identified for the various flow regimes.

Spedding et al. (Woldesemayat and Ghajar, 2007) evaluated 60 correlations using the data of Spedding and Nguyen (1976) for an upward angle of 2.75 degrees from the horizontal. 30\% of data points predicted within the error was the criteria for satisfactory performance. Nicklin et al. (1962) was found to give 
satisfactory predictions for bubble and slug flows at all inclined angles. The correlations of Bonnecaze et al. (1971), Premoli et al. (1970) and Lockhart and Martinelli (1949) were reported to give satisfactory predictions for some flow patterns independent of inclination angle. Lockhart and Martinelli (1949) and Spedding and Chen (1984) performed well for slug and annular flow respectively.

Abdul-Majeed (1996) simplified the mechanistic model of Taitel and Dukler (1976) thereby obtaining a new correlation. He compared the predictions of 12 correlations with the experimental data obtained from his 51-mm diameter horizontal pipe. Statistical tools used for the comparison were the average percent error (APE), absolute average percent error (AAPE) and the standard deviation. He demonstrated that the correlation satisfactorily predicts void fraction in stratified, slug and annular flow regimes better compared to the Taitel and Dukler(1976) correlation specifically developed for stratified flow.

Spedding (1997) implemented an extensive comparison on more than 100 void fraction correlations using the air-water data of Spedding et al. $(1989 ; 1979 ; 1993 ; 1991 ; 1976)$ for all inclinations $\left(-90^{\circ}\right.$ to $\left.+90^{\circ}\right)$. The authors concluded that no correlation could handle all flow regimes and angle of inclination satisfactorily. Different void fraction correlations were recommended for the various flow regimes and inclinations.

To implement a horizontal and upward vertical comparison, Diener and Friedel (1998) used 24,000 experimental data points to evaluate 13 correlations. The average predictive accuracy of the correlations was established the scatter logarithmic ratios, scatter of absolute deviations, average logarithmic ratios and mean density. The first correlation of Rouhani and Axelsson (1970) was recommended as exhibiting an accurate predictive capability.

For vertical pipes, comparison of predictions for gas void fraction has been investigated by a few researchers including Godbole (2009), Woldesemayat and Ghajar (2007) and in recent times, Bhagwat and Ghajar (2012). Godbole (2009) comprehensively evaluated 52 existing correlations using experimental data and data obtained from literature. He observed that no correlation was could predict the data of Schmidt et al. (2008) satisfactorily. He attributed this failure to the fact that all the correlations were developed based on low viscosities. Woldesemayat and Ghajar (2007) compared the performance of 68 void fraction correlations using a dataset of 2845 data points covering a wide range of parameters. The analysis showed that most of the correlations developed are very restricted in terms of handling a wide variety of data sets. Based on the observations made, an improved void fraction correlation which could acceptably handle all data sets regardless of flow patterns and inclination angles was suggested. In recent times, using a large dataset, a wide range of flow conditions and pipe geometries, Bhagwat and Ghajar(Ghajar and Bhagwat, 
2013) presented a flow pattern independent void fraction correlation. The authors claim the correlation is accurate for all inclinations, diameters from 0.5 to $305 \mathrm{~mm}$ and viscosities from $0.0001 \mathrm{~Pa}$ s to $0.6 \mathrm{~Pa}$ s for system pressures from 0.1 MPa to 18.1 MPa. The correlation was verified with 8255 data points collected from more than 60 sources and was determined to perform consistently accurate and satisfactorily over the collected data. Abdulkadir et al. (2014a) compared 13 correlations with air-silicone data. Morooka et al. (1989) was adjudged the best correlation based on RMS error while Kawanishi et al. (1990) was found to be the best based on percentage error. McNeil and Stuart (2003) as well as Schmidt et al. (2008) reported that the existing correlations compared could not accurately predict their data. However, it should be noted that their conclusion was based on comparison of very few correlations.

In summary, literature remains dominated by studies which employed air-water as well as air-low viscosity liquids as experimental fluids. Data obtained from these experiments have been employed for the development of gas void fraction correlations. This has fueled concerns about the ability of existing correlations to provide accurate prediction for highly viscous gas-liquid flows (Godbole, 2009; McNeil and Stuart, 2003; Schmidt et al., 2008) due to limitations including flow pattern dependency and empiricism (Godbole et al., 2011). Empiricism comes into play because some of correlations have been developed and validated with data limited to some specific flow conditions (e.g. pipe configuration and orientation, flow pattern, and gas-liquid combination)(Godbole et al., 2011). Furthermore, the influence of liquid viscosity on gas void fraction has been established with evidence. Research reports of authors whose work has yielded some data and insight to the discussions are listed in Table 1. Due to scarcity of highly viscous data this knowledge is still limited to information obtained with low viscous liquids. Knowledge of the behaviour this important parameter under the influence of high liquid viscosity would translate to more accurate prediction of other equally important flow parameters including pressure gradient and additionally contribute to safe and efficient equipment design. The full extent of its influence needs to be investigated. In addition, there is a plethora of existing correlations for gas void fraction, majority of which were developed based on air-water as well as air/gas - low viscous liquid data. Before improved correlations can be developed for highly viscous flow conditions, there is the need to scrutinize existing ones. Evaluations of such nature provide strong basis and direction for targeted improvements during development of new correlations of modification of old ones.

In this work, the influence of high liquid viscosity on gas void fraction is investigated and reported. In addition, using the combined experimental data and the reported data of Schmidt et al. (2008), predictions of 100 existing correlations are compared with combined experimental data and the best performing 
correlations identified. Further, based on the database employed, two new gas void fraction correlations are developed for churn and annular flows respectively. Results of evaluation indicated that predictions from these correlations agree very well with the experimental data and their performances is observed to rival than the top performing existing correlations.

\subsection{Criteria for comparative study}

In the absence of a universal definition for satisfactory performance for correlations prediction assessment, the user-defined approach adopted Godbole et al. (2011) and Bhagwat and Ghajar (2012) is utilized in this study. The correlations were evaluated against the entire experimental dataset, four specified ranges of the void fraction and the different flow patterns. To identify the best performing correlations, four levels of assessment were pursued. Accuracy of correlations were judged in terms of percentage of experimental data predicted within a selected error index and RMS error.

The first level of assessment, which is assessment of the entire data is perfunctory, since it overlooks the strengths and weaknesses of the correlations in specific ranges of void fraction. The number of experimental data points is not uniformly distributed throughout the entire void fraction range of $0<\alpha<$ 1 (in this study, majority are in the annular flow regime) hence, relying solely on overall performances could lead to a biased interpretation. Subsequently, a second level of assessment, which is the analysis of correlations at various viscosities. This is important to gain insight into the reliability of the prediction capacities of the correlations at varied viscosities. The third assessment level was to examine the predictions of correlations at smaller void fraction ranges, by dividing the entire void fraction range into four categories: $0<\alpha \leq 0.25,0.25<\alpha \leq 0.5,0.5<\alpha \leq 0.75,0.75<\alpha \leq 1.0$. Dividing the analysis into specific void fraction ranges would also reveal the most accurate correlations for each specific range, thus allowing access to correlations with higher accuracies in specific void fraction range of interest. The previous authors reported that the void fraction in the range typically $0-0.25$ is sensitive to the increase in the gas flow rate and also the percentage error in the pre- diction is large due to low values of the void fraction. Hence a less restrictive criterion was used for the lowest of the four specified void fraction ranges. Due to the better accuracy involved in the measurement and the high values of the void fraction typically in a range of $0.75<\alpha<1$, the associated percentage error was expected to be small and hence a stringent criterion was set in this range for the satisfactory performance of the void fraction correlations. Finally, the fourth level of assessment is taking the "best" correlation identified from the first three levels of 
assessment and comparing it with the performances of the flow pattern specific void fractions. The criteria for assessment are summarized in Table 2.

Out of the 100 void fraction correlations considered, 47 are mentioned in this article because they were found to compare satisfactorily with the compiled experimental results. It is to be noted that, in the work of the previous authors, only three levels of assessment were investigated because viscosity was not a parameter to be examined.

Table 2. Criteria for satisfactory performance

\begin{tabular}{ll}
\hline Void fraction range & Criteria for satisfactory performance \\
\hline Entire range (0-1) & $\begin{array}{l}\text { At least more than } 85 \% \text { of data points predicted within } \pm 15 \% \text { and more } \\
\text { than } 75 \% \text { of data points predicted within } \pm 20 \% \text { and RMS error } \leq 30 \%\end{array}$ \\
$0-0.25$ & At least $80 \%$ of data points predicted within $\pm 30 \%$ and RMS error $\leq 60 \%$ \\
\hline $0.25-0.5$ & At least $80 \%$ of data points predicted within $\pm 20 \%$ and RMS error $\leq 20 \%$ \\
\hline $0.5-0.75$ & At least $80 \%$ of data points predicted within $\pm 15 \%$ and RMS error $\leq 15 \%$ \\
\hline $0.75-1.0$ & At least $80 \%$ of data points predicted within $\pm 10 \%$ and RMS error $\leq 10 \%$ \\
\hline Flow pattern criteria & At least $80 \%$ of data points predicted within $\pm 20 \%$ and RMS error $\leq 20 \%$ \\
\hline
\end{tabular}

\section{Experimental facility description and data processing}

In order to carry out an effective review of correlations for the prediction of void fraction in vertical twophase flows, especially where liquids with viscosities higher than water are concerned, we carried out experiments to collect data in a vertical air-oil flow loop. This is because many of the models in the open literature were developed for and using data in air - water systems at essentially atmospheric pressure. Significant deviations can result when these are applied to higher viscosity flows or at elevated pressures.

\subsection{Test rig description}

The experiment was implemented on a test rig capable of inclinations from 0 - 90 (Figure 1) at the Gas Lift Innovation Centre, Yangtze University, China. For each experiment, the desired volume of oil is pumped into a mixing tank, and pressurized. After pressure stabilization and measurement, the liquid is mixed with compressed gas and introduced into the test section. The liquid returns to the mixing tank while the air is released into the atmosphere after the gas-liquid mixture has passed through the separator. 
(a)
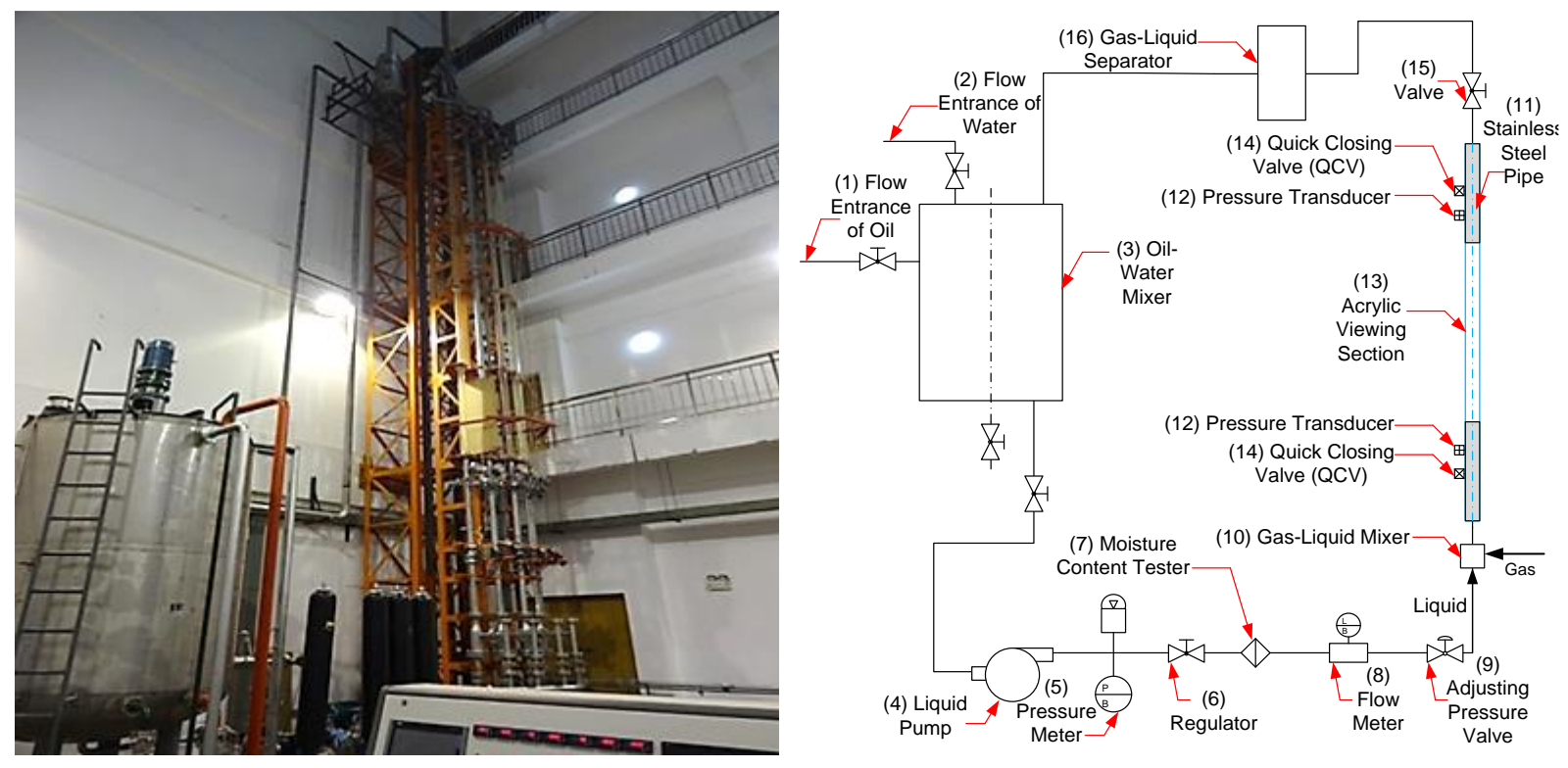

(c)

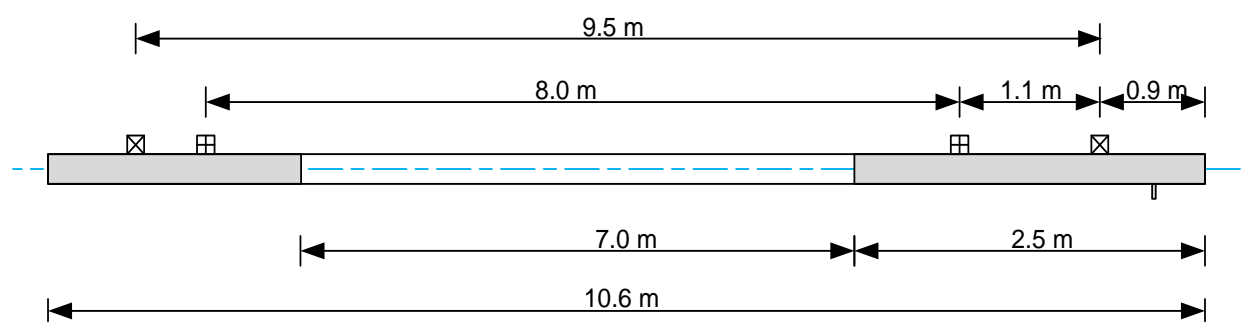

Figure 1. Experimental setup: (a): photo of the experimental rig in vertical position; (b): schematic diagram (c) Dimensions of test section

Table 3. Details of measuring equipment utilized for the experiment

\begin{tabular}{cccc}
\hline Equipment & Parameter measured & Measuring range & Measurement error \\
\hline Rosemount 305 1S & Pressure & $0 \sim 3.5 \mathrm{MPa}$ & $\pm 0.1 \%$ \\
Pressure transducers & Temperature & $0-90^{\circ} \mathrm{C}$ & $\pm 0.5 \%$ \\
Thermocouples & Liquid Flow Rate & $2 \sim 20 \mathrm{~m}^{3} / \mathrm{h}$ & $\pm 0.3 \%$ \\
Endress+Hauser/80E50 & Gas Flow Rate & $160^{\sim} 2000 \mathrm{~m}^{3} / \mathrm{h}$ & $\pm 0.1 \%$ \\
\hline Endress+Hauser/65F1H & Parameter measured & Mode of actuation/ & Uncertainty \\
& Response time & $0.1 \%$ \\
\hline
\end{tabular}


Table 4. Fluid properties used in the two-phase high viscosity experiment

\begin{tabular}{lll}
\hline & Gas & $\begin{array}{l}\text { Liquid } \\
\text { (high viscosity:2phase) }\end{array}$ \\
Fluid & Air & Oil \\
\hline Density $\left(\mathbf{k g} / \mathbf{m}^{\mathbf{3}}\right)$ & 1.205 & 854 \\
Viscosity $(\mathbf{m P a} \mathbf{~ s})$ & $0.0181\left(20^{\circ} \mathrm{C}\right)$ & $100-580\left(20^{\circ} \mathrm{C}\right)$ \\
Surface tension $\mathbf{( N / \mathbf { m } )}$ & - & $0.0287\left(20^{\circ} \mathrm{C}\right)$ \\
\hline
\end{tabular}

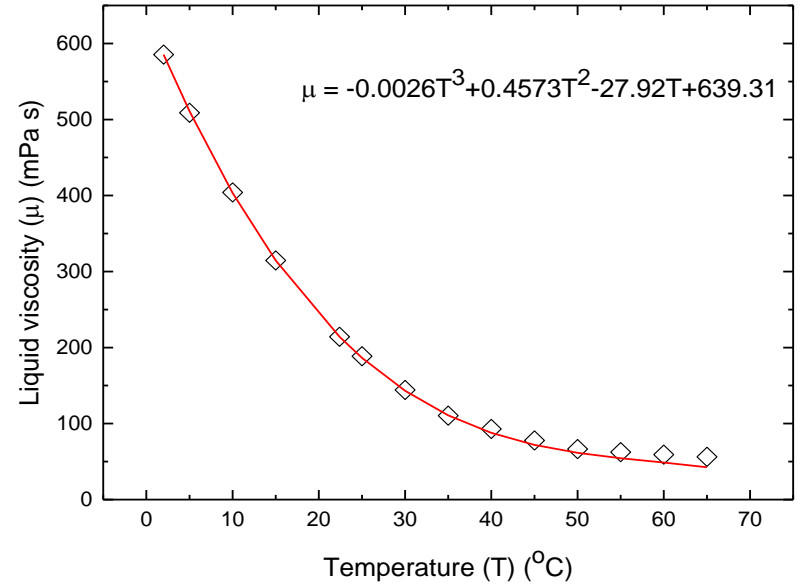

(a)

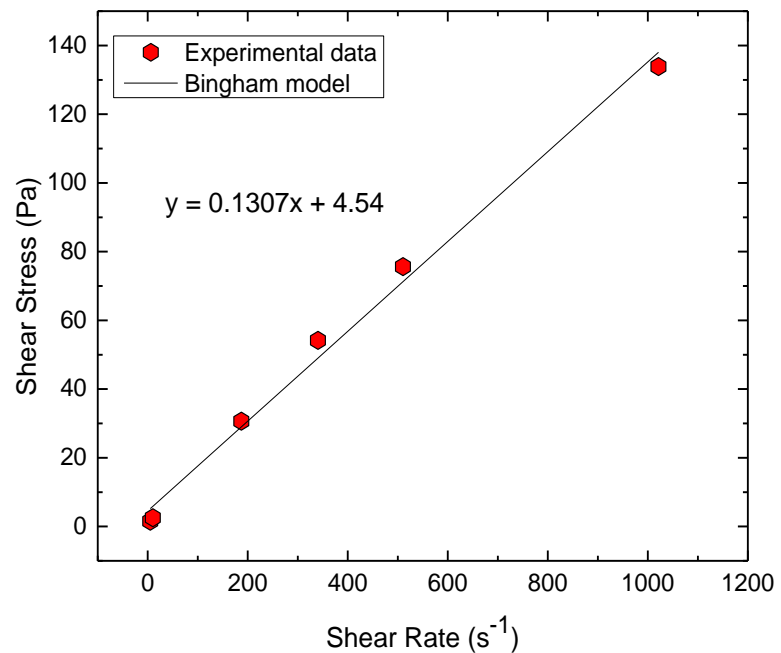

(b)

Figure 2. Properties of liquid used in the experiment: (a) variation of liquid viscosity with temperature for two-phase high viscosity experiments (b) rheological properties of the liquid

The test section (Figure 1) is a pipe of length $10.6 \mathrm{~m}$ and an ID of $0.060 \mathrm{~m}$. The viewing section consists of an acrylic tube with a length of $7 \mathrm{~m}$. Stainless steel pipes of lengths $1.1 \mathrm{~m}$ and $2.5 \mathrm{~m}$ respectively are fixed at each end of the acrylic tube. Pressure, temperature and pressure differential sensors, as well as quick closing valves and other devices are installed on the stainless-steel sections of the pipe. The distance between the two quick closing valves is $9.5 \mathrm{~m}$. The distance between the differential pressure transducers is $8 \mathrm{~m}$. Control of the devices as well as extraction of data is done directly online at the control center. Details of the measuring equipment utilized for the experiment are presented in Table 3. Air constituted the gas phase while oil was used as the liquid phase. The fluid properties used in the experiment are presented in Table 4.

Compressed air and white oil constituted the gas and liquid phases respectively. The oil density was 854 $\mathrm{kg} / \mathrm{m}^{3}$ at $20^{\circ} \mathrm{C}$ with a surface tension of $0.0287 \mathrm{~N} / \mathrm{m}$. Variations in density and surface tension of the oil 
with temperature was small enough to assume it is negligible. Increase in viscosity was achieved by decreasing temperature. The behaviour of the oil viscosity versus temperature is as shown in Figure $2 a$. The oil utilized was non-Newtonian in nature and its viscosity was measured using a Brookfield Viscometer (DV-3T) was used to obtain the shear stress and shear strain rheological data shown in the plot (Figure 2b).

\subsection{Experimental procedure and measurement}

For this study, a constant liquid flow rate was maintained, while the gas flow rate is adjusted. When the system was deemed steady (approximately 15 minutes from the start of the experiment), the experimental flow pattern was observed and recorded. Except for liquid holdup, all other experimental data was recorded every 5 seconds for 3 minutes, and finally the average value of each measurement parameter was obtained. Each complete test took approximately 30 minutes depending on the time required to reach steady-state. After the data recording was completed, the quick closing valves (2 Limit Switch Box APL-210 mechanical actuators which can be actuated simultaneously with a single switch) were closed trapping fluids flowing in the test section. The quick closing valves have a response time is $0.3-0.5 \mathrm{~s}$. Liquid holdups are measured by using a $9.5 \mathrm{~m}$ longitudinal pipe section. For accurate measurement of liquid holdup, the trapped air-oil mixture was allowed to settle for 5-10 minutes to facilitate draining of the liquid into a measuring cylinder. Liquid holdup was estimated by calculating the volume of the liquid, $V_{v}$ and dividing it by the total volume of pipe-section, $V_{t}$. Mathematically, this estimation can be expressed as (Eq. 1):

$$
H_{l}=\frac{V_{v}}{V_{t}}
$$

Gas void fraction is either obtained directly using cross-sectionally averaged data or from liquid holdup data. There is a clear distinction between cross-sectionally averaged- and volumetric gas void fraction. Crosssectionally averaged gas void fraction can be obtained using advanced measuring devices including Wire Mesh Sensor (WMS) and Electrical Capacitance Tomography (ECT) while the volumetric gas void fraction is extracted from liquid holdup data using quick closing values (QCVs). Methods to obtain gas void fraction data are adequately detailed by Wu et al. (2017)

QCVs have been employed to measure liquid holdup (gas void fraction) (Bhagwat and Ghajar, 2012; Cioncolini and Thome, 2012; Xue et al., 2016) for several studies reported on gas void fraction. Further, some reports indicate that there is very little difference between gas void fraction values obtained using different methods. For instance, Viera et al. (2015) compared the liquid holdup results obtained by Yuan (2011) and Guner (2012) using QCVs for $v_{s g}$ values ranging from 10 to $40 \mathrm{~m} / \mathrm{s}$ and his experiments using WMS, the same flow conditions as well as liquid viscosities from 1 to $40 \mathrm{mPa}$ s. Their results showed that 
similar results could be obtained from both methods. For this study, values of gas void fraction were obtained using QCVs.

Gas void fraction can also be obtained using a number of methods including tomography, linearized x-ray systems (Jones and Zuber, 1975), neutron radiography and image processing (Mishima and Hibiki, 1996), gamma ray systems (Schmidt et al., 2008) and the quick-closing valve technique. For this study the gas void fraction was obtained using the quick closing value. Reports indicate that, the shut-in procedure is one of the most reliable method to measure holdup in multiphase flow systems (Oddie et al., 2003) with excellent repeatability in the obtained liquid holdup measurements. The technique has been employed by previous authors including Yamaguchi and Yamazaki (1982) and Caetano et al. (1992).

Flow patterns were visualized directly and also observed using a Canon Xtra NX4-S1 high-speed camera capable with a pixel resolution of resolution of $1024 \times 1024$ up to 3000 frames per second (fps). The maximum frame rate is $50,000 \mathrm{fps}$ with a reduced resolution. Videos and pictures of the flow pattern were obtained and used for analysis during the study. The range of measurements taken during the experiments is presented in Table 5.

For experiments in this study, the camera was located at $L / D=133$, at this location, the flow is considered to be fully developed based on a survey of similar experiments in the literature. Fully developed annular flow pattern in vertical pipes has been observed at L/D values lower than ours by a number of researchers including Wongwises and Kongkiatwanitch (2001) (L/D = 41), Aliyu et al. (2017) (L/D = 46), Fore and Dukler (1995) (L/D = 69), Zangana (2011) (L/D = 66), Skopich et al. (2015) (L/D = 59-92), and Van der Meulen (2012) $(L / D=87)$. Shearer and Nedderman (1965) conducted some experiments with an $L / D=133$. It can be assumed, therefore, that the selected L/D ratio represents a sufficient flow development length.

\subsection{Void fraction determination and validation}

In this section, all mathematical expressions used to derive values for parameters used for this study are presented and discussed. Experimental data is used to estimate the required parameters. The experimental gas void fraction data was estimated using the expression (Eq. 2):

$$
\alpha=1-H_{l}
$$

where $\alpha$ and $H_{l}$ represent gas void fraction and liquid holdup respectively.

Efforts were made to ensure that the holdup measured was accurate. To achieve this, the holdup was measured three times for each experiment and the average value used for calculation. Comparison with 
the reported data of Schmidt et al.(2008) (Figure 3) was an additional measure to demonstrate the accuracy of the experiment. Schmidt et al.(2008) determined gas void fraction by utilizing signals from a gamma-ray densitometer consisting of $C_{s}^{137}$ radiation source with strength of $10 \mathrm{GBq}$ on one side of the pipe and a detection unit on the opposite side. In this study gas void fraction was obtained using quick closing valves. The QCV used had very good closing times at less than $0.5 \mathrm{~s}$ so trapping time had limited effect on the void fraction measurement. Again, the liquid viscosities employed by Schmidt et al.(2008) in their study (900$7000 \mathrm{mPa}$ s) are far higher than that of this study (100 - $580 \mathrm{mPa}$ s). Further, while air consists of the gas phase in this study, nitrogen gas was employed by Schmidt et al.(2008). Finally, there are also slight differences in pipe diameters used. This study employed slightly bigger pipe $(0.06 \mathrm{~m})$ than Schmidt et al.(2008) (0.0545 m) did. Quite unfortunately, the experiment did not follow the measurement regime of the other data sources employed therefore, very few points coincided with those of our experiment. Additionally, there are few data points available at the conditions at which the experiment was conducted, hence only a limited number of experimental data points can be presented. Despite these differences, it is found that majority of the experimental data falls within the $\pm 20 \%$ error band. It can therefore be concluded that the measured data for this study is reasonably accurate.

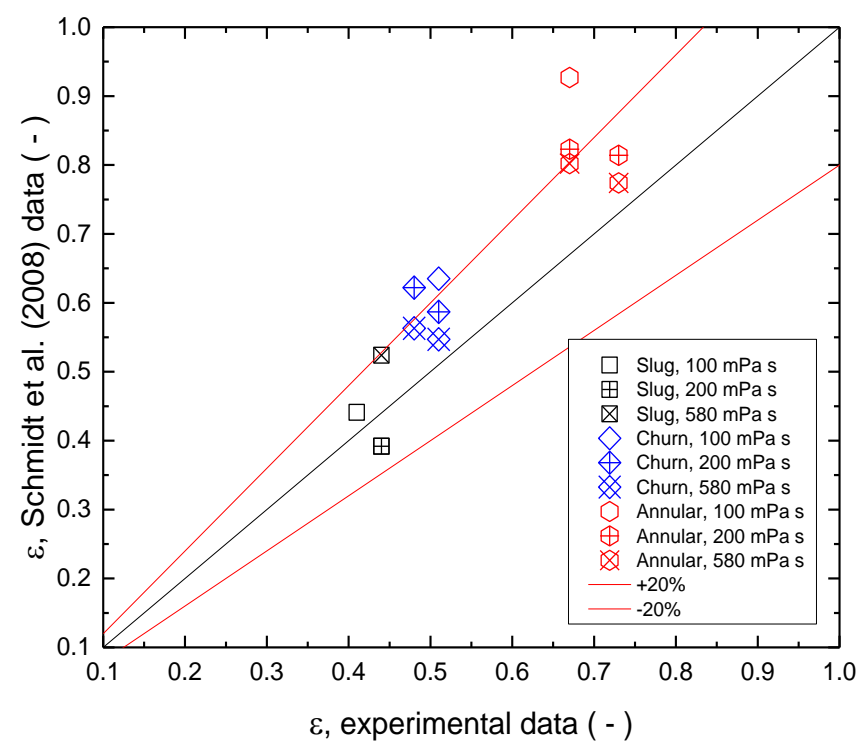

Figure 3. Comparison of the current experimental gas void fraction with the experimental data of Schmidt et al. (2008)

\subsection{Experimental database}

The experimental database used for the study consists of a total of 148 data points (Table 5), 104 data points from the current experiments and 44 data points from the experiments of Schmidt et al. (2008) who employed nitrogen and Luviskol mixtures for their study. The experimental data points have a liquid 
viscosity ranging from 100 to $580 \mathrm{mPa}$ s while that of the experimental data of Schmidt et al. (2008) ranges from 980 to $6680 \mathrm{mPa}$ s. The void fraction data utilized for this study can be considered well-distributed from low (0.144) to high values (1.0) hence spanning over all possible ranges for slug, churn and annular flow regimes.

Table 5. Range of experimental data used for the study

\begin{tabular}{lll}
\hline Parameter & Current Study & Schmidt et al. (2008) \\
\hline Number of data points & 104 & 44 \\
Pipe diameter $(\mathrm{m})$ & 0.06 & 0.054 \\
Two-phase flow quality $(x)$ & $0.0098-0.7766$ & $0.0012-0.8159$ \\
Void fraction & $0.14-1.0$ & $0.17-0.77$ \\
Density ratio $\left(\rho_{l} / \rho_{g}\right)$ & 701.24 & $459.87-1030.2$ \\
Liquid viscosity $(\mathrm{mPa} \mathrm{s})$ & $100-580$ & $980-6680$ \\
Mass Flux $(\mathrm{kg} / \mathrm{s})$ & $0.051-0.552$ & $0.019-7.434$ \\
\hline
\end{tabular}

\section{Results and Discussion}

\subsection{Flow patterns}

For different flow conditions, slug, churn and annular flows were observed at different liquid viscosities respectively. It was observed that variations in superficial gas and liquid velocities constitute the major drivers of transition from one flow regime to the other. The flow conditions at which the flow regimes occurred for various liquid viscosities have been presented in Table 6 .

Table 6. Range of flow conditions and the related flow patterns observed during the current experiment

\begin{tabular}{|c|c|c|c|c|c|c|}
\hline & $100 \mathrm{mPa} s$ & & $200 \mathrm{mPa} s$ & & $580 \mathrm{mPa} \mathrm{s}$ & \\
\hline$v_{s l}(\mathrm{~m} / \mathrm{s})$ & $v_{s g}(\mathrm{~m} / \mathrm{s})$ & $\begin{array}{c}\text { Flow } \\
\text { pattern }\end{array}$ & $v_{s g}(\mathrm{~m} / \mathrm{s})$ & $\begin{array}{c}\text { Flow } \\
\text { pattern }\end{array}$ & $v_{s g}(\mathrm{~m} / \mathrm{s})$ & $\begin{array}{c}\text { Flow } \\
\text { pattern }\end{array}$ \\
\hline 0.02 & $0.989-2.902$ & Slug & 1.01 & Slug & $0.978-2.966$ & Slug \\
\hline 0.02 & $4.93-9.894$ & Churn & $3.243-10.046$ & Churn & $4.929-14.687$ & Churn \\
\hline 0.02 & $14.744-29.482$ & Annular & $14.948-48.748$ & Annular & $19.759-29.756$ & Annular \\
\hline 0.08 & $1.035-4.957$ & Slug & - & - & - & - \\
\hline 0.08 & $10.017-19.613$ & Churn & $3.022-14.939$ & Churn & $1.003-15.378$ & Churn \\
\hline 0.08 & $24.599-68.687$ & Annular & $19.883-48.992$ & Annular & $20.249-99.72$ & Annular \\
\hline 0.15 & 1.08 & Slug & $1.003-2.913$ & Slug & 1.015 & Slug \\
\hline 0.15 & $2.88-14.798$ & Churn & 4.954-19.785 & Churn & $3.002-14.844$ & Churn \\
\hline 0.15 & $19.694-49.382$ & Annular & $24.603-49.212$ & Annular & 20.149-67.43 & Annular \\
\hline
\end{tabular}




\subsubsection{Slug flow}

Slug flow was characterized by Taylor bubbles followed by a liquid slug (Figure 4). Increase in slug frequency was observed with increase in superficial gas velocity at all viscosities. However, this parameter was not measured and therefore its behaviour was not ascertained for the various viscosities. Superficial phase velocities appeared to also affect the slug structure. It was observed that at both low and high $v_{s l}$ values and a $v_{s g}$ value of $0.98 \mathrm{~m} / \mathrm{s}$, the Taylor bubbles appeared well-defined. At higher vsg values, however, the Taylor bubbles became larger and amorphous in shape. This phenomenon was previously reported by Hewakandamby et al. (2014). Taylor bubbles were surrounded by gas bubbles. Liquid viscosity was also found to exert some influence on the slug structure at various flow conditions. For instance, it was observed that the Taylor bubble exhibits different configurations with changes in liquid viscosity (Compare Figure 4a, 4e and $4 \mathrm{l}$ and also Figure 4c, $4 \mathrm{~g}$ and $4 \mathrm{k}$ ). However, more data would be required to provide general conclusions. There was also evidence of multiple flow structures (such as Figure $4 \mathrm{~g}$ ) at the same flow conditions. Sharaf et al. (2016) explains the phenomenon as evidence of the fact that flow pattern transitions are a gradual shift from the characteristics of one flow regime to the next with characteristics of both occurring simultaneously under some of the flow conditions. Sekoguchi and Mori (Wu et al., 2017) provided further evidence from their investigation which used gas-liquid flows and multiple probes. From their time-resolved signals obtained they were able to identify individual examples of structures characterizing each flow pattern.

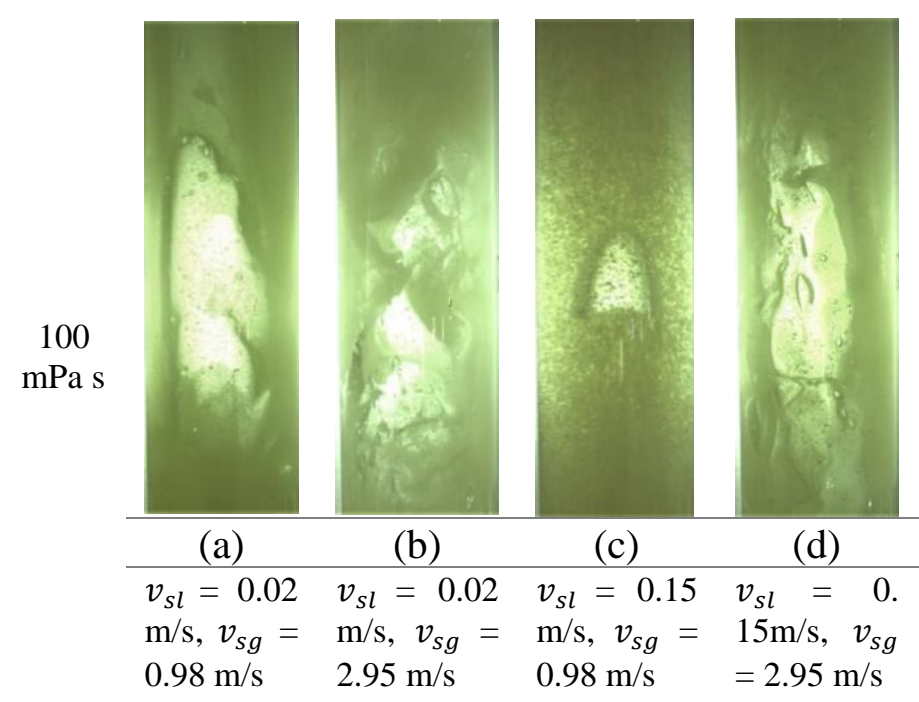




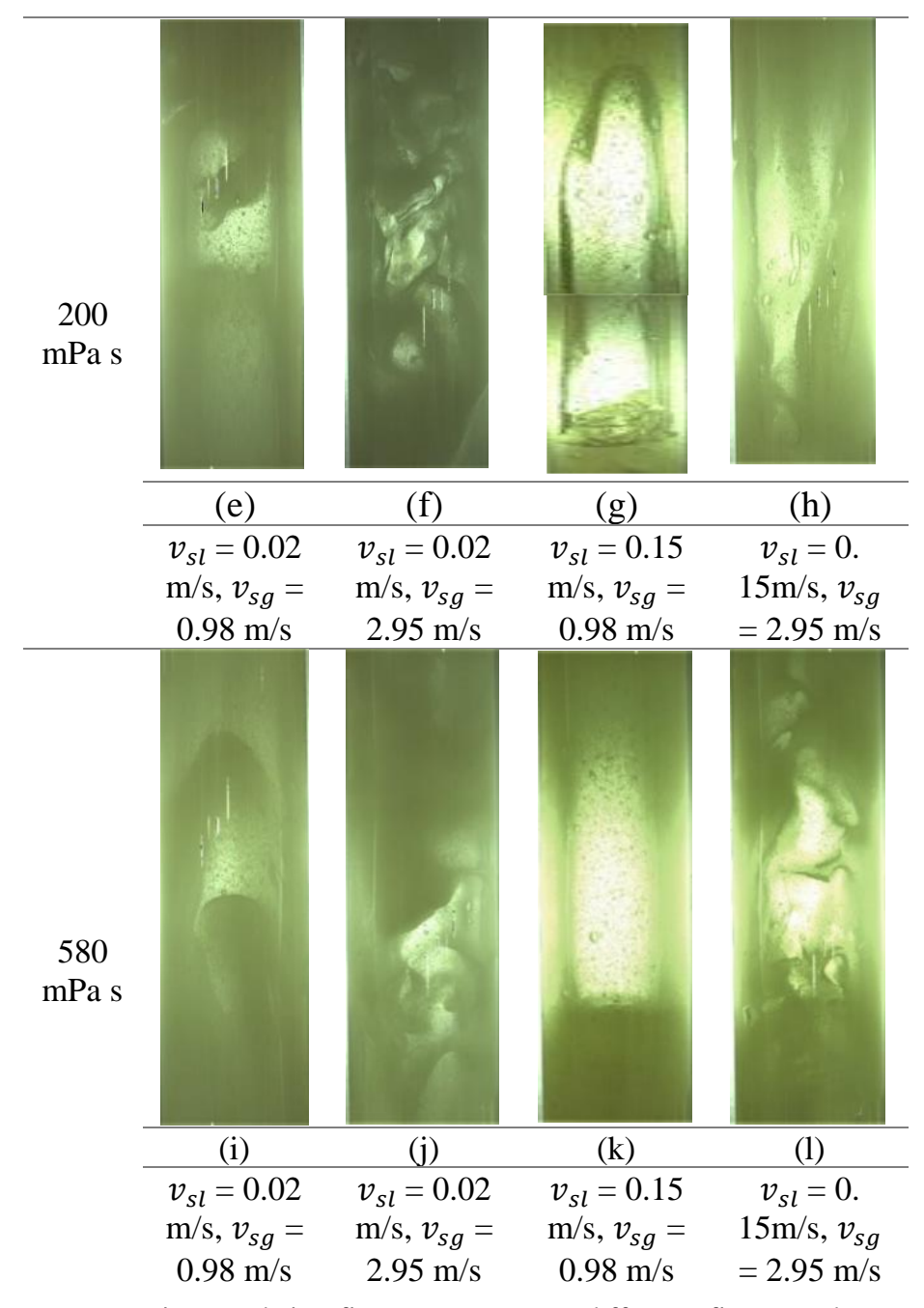

Figure 4. Observed slug flow structures at different flow conditions

\subsubsection{Churn flow}

Akin to observations reported in literature, churn flow, in this study, was characterized by high oscillation and turbulent mixing with net movement of liquid going upwards. Churn flow observed at various conditions is shown in Figure 5. The impact of superficial gas and liquid viscosities and liquid viscosities on the churn flow structures was not apparent. 

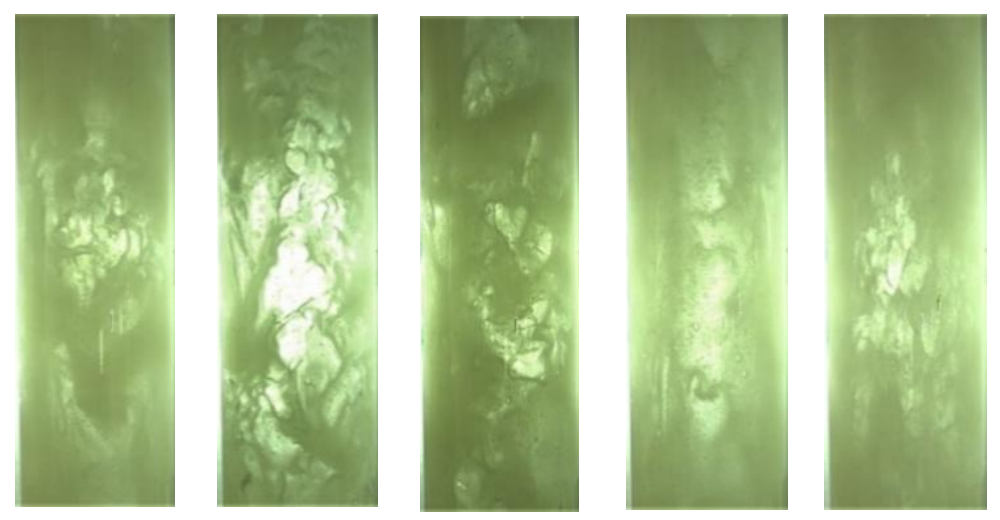

(a)

(b)

(c)

(d)

(e)

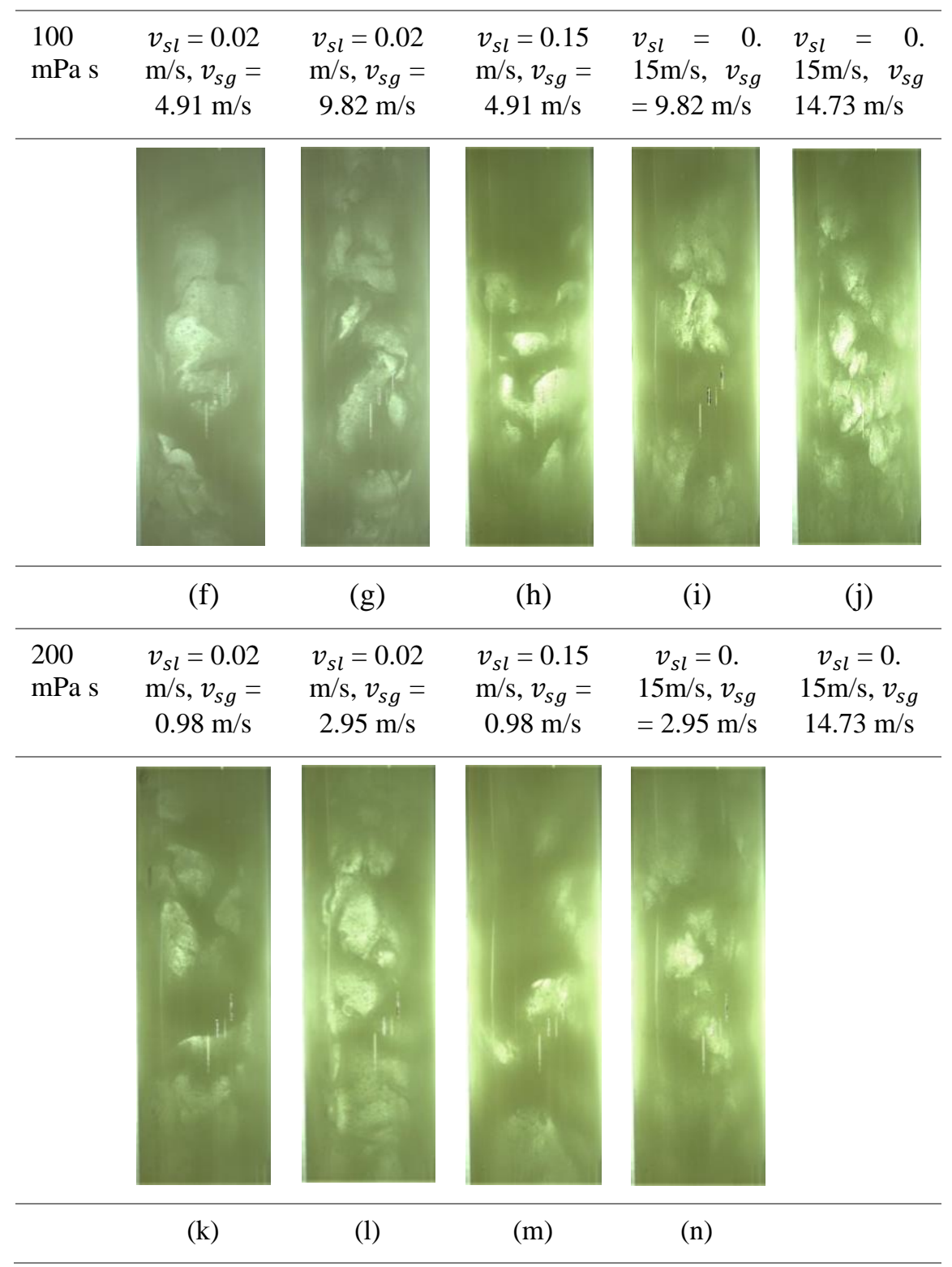




$\begin{array}{ccccc}580 & v_{s l}=0.02 & v_{s l}=0.02 & v_{s l}=0.15 & v_{s l}=0.15 \mathrm{~m} / \mathrm{s}, v_{s g} 14.73 \\ \mathrm{mPa} \mathrm{s} & \mathrm{m} / \mathrm{s}, v_{s g}= & \mathrm{m} / \mathrm{s}, v_{s g}= & \mathrm{m} / \mathrm{s}, v_{s g}= & \mathrm{m} / \mathrm{s} \\ & 0.98 \mathrm{~m} / \mathrm{s} & 2.95 \mathrm{~m} / \mathrm{s} & 0.98 \mathrm{~m} / \mathrm{s} & \end{array}$

Figure 5. Observed churn flow structures at different flow conditions

\subsubsection{Annular flow}

Highly viscous annular flows in this experiment were characterized by a high velocity gas core surrounded by liquid film (Figure 6). Film thickness was calculated from the holdup; and it was quantified in our experiments for each test point and liquid viscosity using the geometric relationship which has been used by other authors (e.g. Kaji and Azzopardi 2010):

$\delta=\frac{D_{t}}{2}\left(1-\sqrt{\varepsilon_{g}}\right)=\frac{D_{t}}{2}\left(1-\sqrt{1-H_{L}}\right)$

where $\delta, D_{t}, \varepsilon_{g}, H_{L}$ represent liquid film thickness, pipe diameter, gas void fraction and liquid holdup respectively.

Liquid film thickness was greatest at low superficial gas velocity and thinnest at high superficial gas velocity for all viscosities respectively. It appeared liquid film thickness was also influenced by liquid viscosity. It was observed that the lowest viscosity presented the least liquid film thickness and vice-versa. This phenomenon has previously been reported by Fukano and Furukawa (1998) and Alamu (2010) whose work utilized low viscosity liquids.

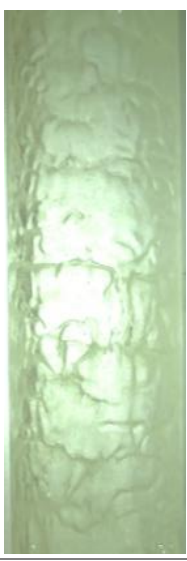

(a)

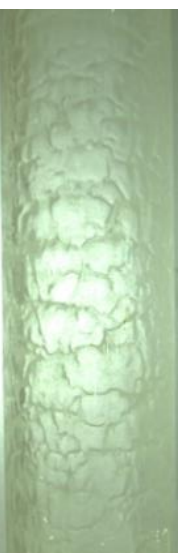

(b)

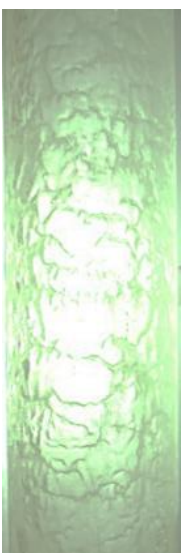

(c)

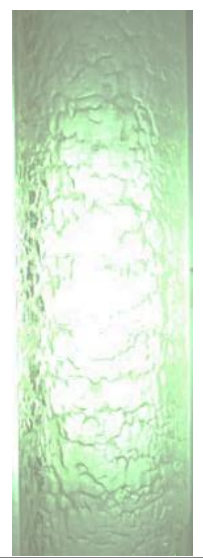

(d)

$\begin{array}{ccccc}100 \mathrm{mPa} \mathrm{s} & v_{s l}=0.02 & v_{s l}=0.02 & v_{s l}=0.15 & v_{s l}=0.15 \mathrm{~m} / \mathrm{s}, \\ & \mathrm{m} / \mathrm{s}, v_{s g}= & \mathrm{m} / \mathrm{s}, v_{s g}= & \mathrm{m} / \mathrm{s}, v_{s g}= & v_{s g}=39.29 \\ & 19.64 \mathrm{~m} / \mathrm{s} & 29.64 \mathrm{~m} / \mathrm{s} & 29.64 \mathrm{~m} / \mathrm{s} & \mathrm{m} / \mathrm{s}\end{array}$




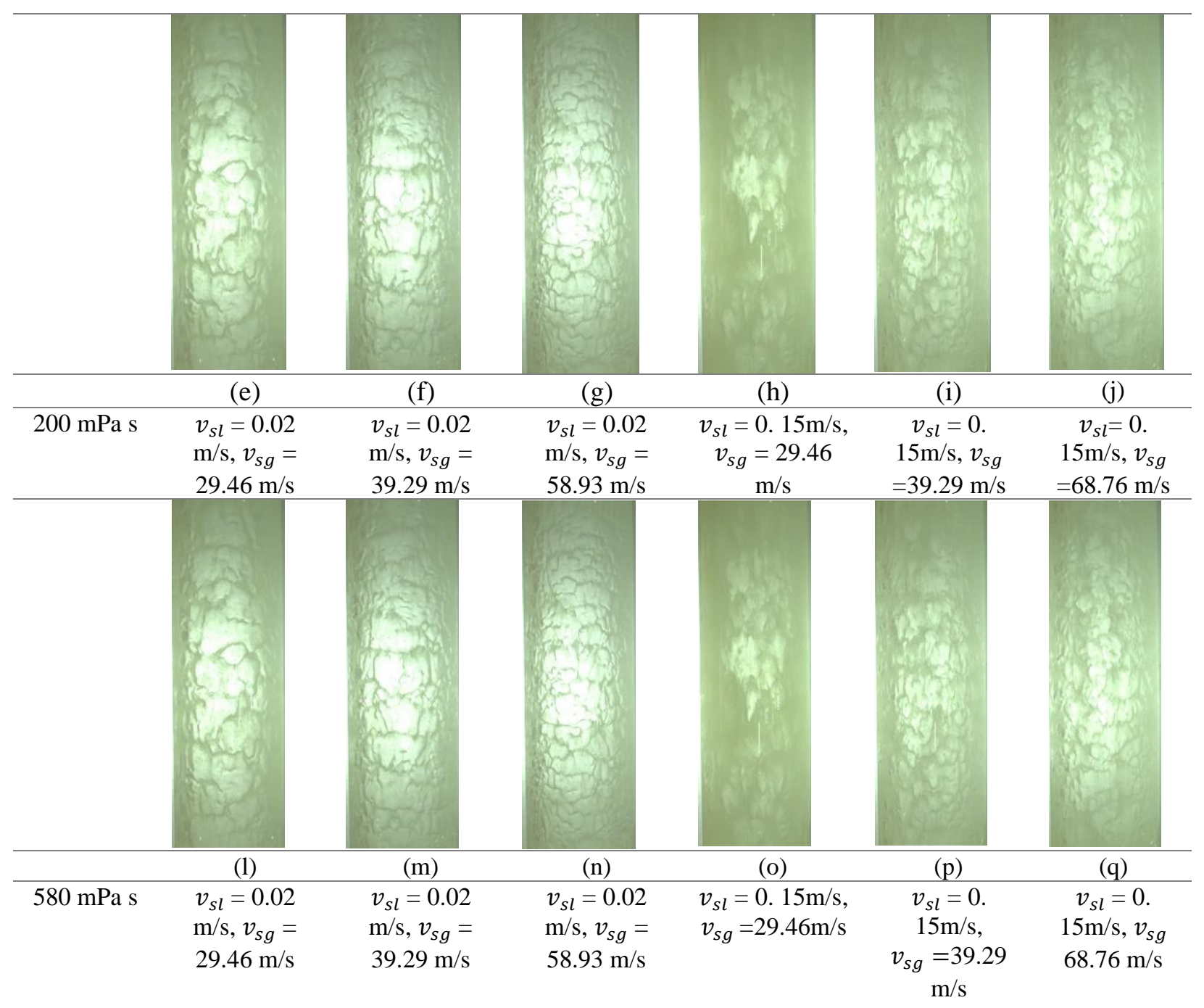

Figure 6. Observed annular flow structures at different flow conditions

\subsubsection{Flow pattern map comparison}

In this section the experimental data was superimposed on the flow pattern maps of Taitel et al. (1980) (Figure 7), Barnea (1987) (Figure 8) and Shell (Aliyu et al., 2017) (Figures 9) respectively. These flow pattern maps constitute commonly utilized maps for comparison and prediction of gas-liquid two-phase flow regimes.

The Taitel et al. (1980) flow pattern map was developed by employing different transition criteria which utilized analytical relationships for the force balance between gravity and drag forces acting at the onset of annular flow. The related theories were validated with data obtained from a 50-mm ID pipe. Unlike the Barnea (1987) flow pattern map flow regimes are clearly segregated. The theoretical (mechanistic) flow pattern map Barnea (1987) is usually used to identify the gas-liquid two-phase flows in pipes. It lumps slug 
and churn flows into one type of flow, intermittent flow. For both flow pattern maps, annular flow remains the same. Also, both employ superficial gas velocity $v_{s g}$ and superficial liquid velocity $v_{s l}$ as the ordinate and abscissa respectively.

Created by the Shell Company (Aliyu et al., 2017) for transport (charge and discharge) of combustibles, the Shell map flow pattern map is generalized by using the superficial gas and liquid Froude numbers (Eq. 3 ) as ordinate and abscissa respectively based on the feed pipe velocity and diameter. For the Shell flow pattern map, the densimetric Froude numbers employed are defined as follows:

$$
F r_{g}=v_{s g} \sqrt{\frac{\rho_{g}}{\left(\rho_{l}-\rho_{g}\right) g D}}, F r_{l}=v_{s l} \sqrt{\frac{\rho_{l}}{\left(\rho_{l}-\rho_{g}\right) g D}}
$$

In this study, the experimental data is imposed on these afore-mentioned flow pattern maps for comparison. From Figure 7(a) to (c), depicting the Taitel et al.(1980) flow pattern map, it can be observed that at all viscosities there is a slight shift in slug-churn transition boundary towards higher superficial gas velocities. Additionally, it can be observed that there is also a small shift in the churn-annular transition boundary towards higher superficial velocities. It also appears that the data points for annular flow shift away from the churn annular transition boundary towards higher viscosities. The trend is the same for all liquid viscosities under consideration. On the whole, it can be considered that the flow pattern map of Taitel et al. (1980) agrees with the experimental data. Compared with the Taitel et al. (1980) flow pattern map, the selected data points reported by Schmidt et al. (2008) appears to have very good agreement. However, from their work, the authors reported a shift towards low superficial gas velocities on the Taitel et al. (1980) flow pattern map when a higher viscosity liquid was utilized and agrees with that of Fukano and Furukawa (1998).

When the experimental data was compared with the Barnea (1987) flow pattern map, it was observed that the slug and churn experimental data agree with it (Figure 8(a) - (c)). It appears the intermittent-annular flow boundary is overpredicted for the experimental data and also for the Schmidt et al. (2008) data. However, considering that the flow pattern transition boundaries cannot be captured by a straight line, it can be concluded that the Barnea flow pattern map agrees well with the experimental data.

Examination of the Shell flow pattern map (Figures 9(a) - (c)) reveals that the Shell flow pattern map is unable to detect and properly characterize churn flow data points. The flow pattern map seems to suggest that the intermittent-annular transition flow shifts towards higher superficial velocities. The trend appears the same for the Schmidt et al. (2008) data. 
In summary, high liquid viscosity influences the flow pattern maps of Taitel et al. (1980) and Barnea (Barnea, 1987) and Shell (Aliyu et al., 2017). In all cases, it appears the slug-churn transition as well as the churn-annular transition flow patterns shift towards higher superficial velocities.

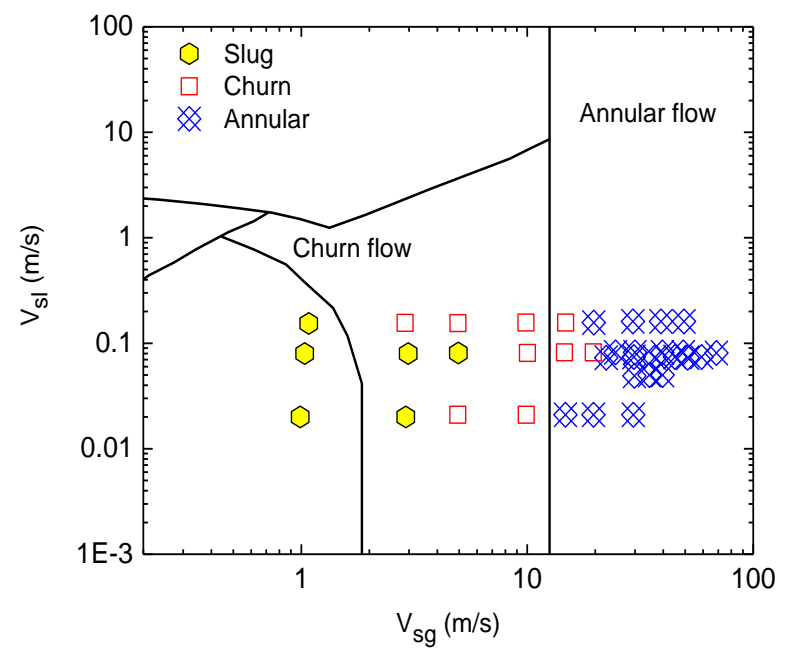

(a)

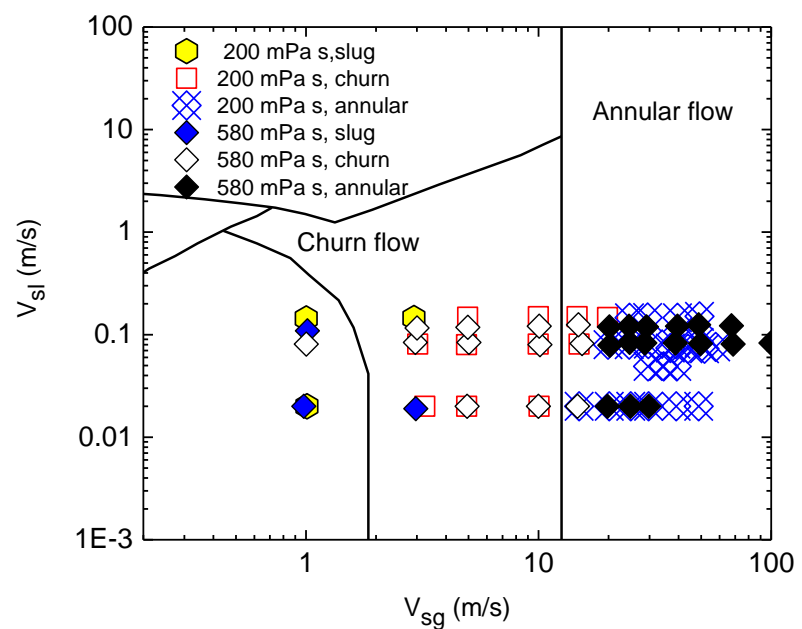

(b)

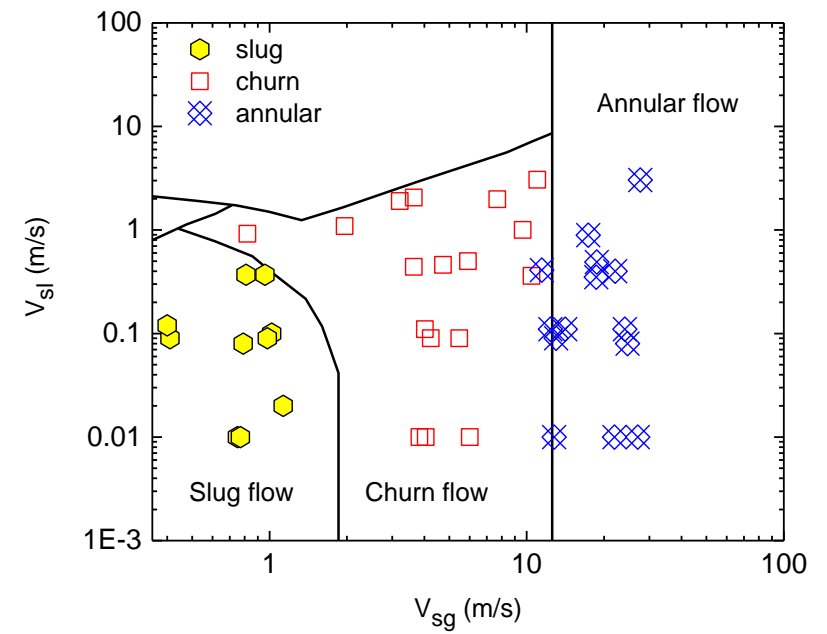

(c)

Figure 7. Comparison of our experimental data (viscosities of (a) $100 \mathrm{mPa} \mathrm{s}$, (b) 200 and $580 \mathrm{mPa}$ s) and (c) Schmidt et al. (2008) data with Taitel et al. (1980) flow pattern map

Comparison of experimental data with Taitel et al. (1980) flow pattern map: (a) our experimental data with liquid viscosity of $100 \mathrm{mPa}$ s, (b) our experimental data with liquid viscosities of 200 and $580 \mathrm{mPa}$ s, (c) Schmidt et al.'s

(2008) data 


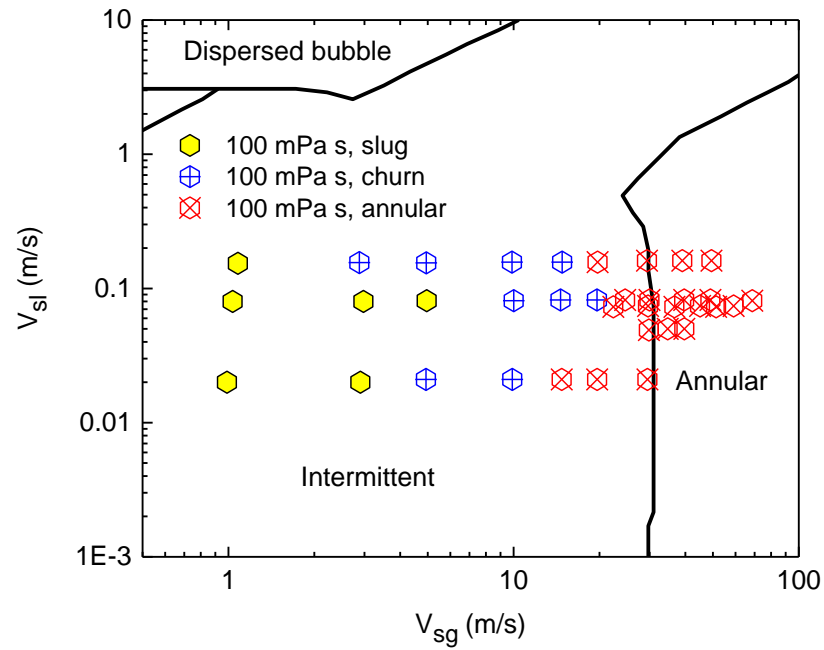

(a)

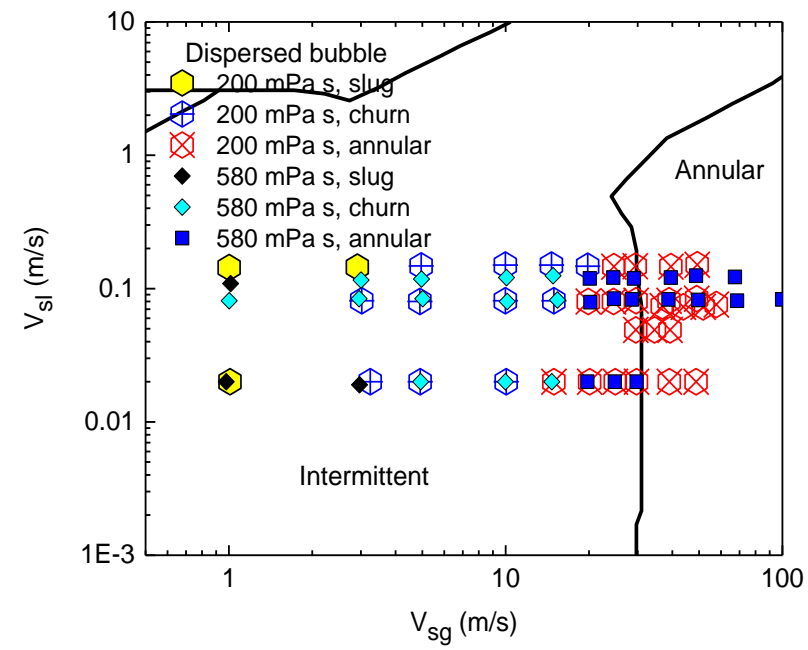

(b)

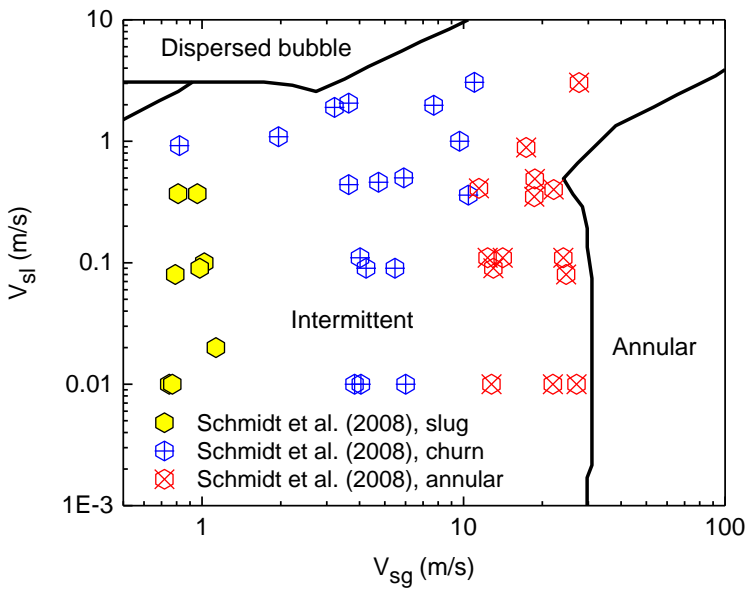

(c)

Figure 8 Comparison of experimental data (a) $100 \mathrm{mPa}$ s, (b) 200 and $580 \mathrm{mPa}$ s and Schmidt et al. (2008) with Barnea (1987) flow pattern map

Comparison of experimental data with Barnea (1987) flow pattern map: (a) our experimental data with liquid viscosity of $100 \mathrm{mPa}$ s, (b) our experimental data with liquid viscosities of 200 and $580 \mathrm{mPa} \mathrm{s}$, (c) Schmidt et al.

$$
\text { (2008) data }
$$




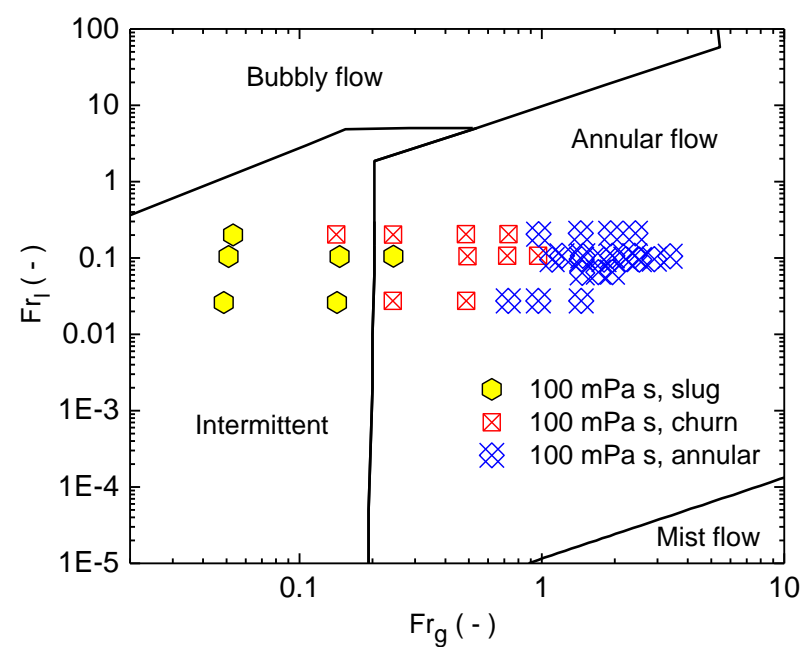

(a)

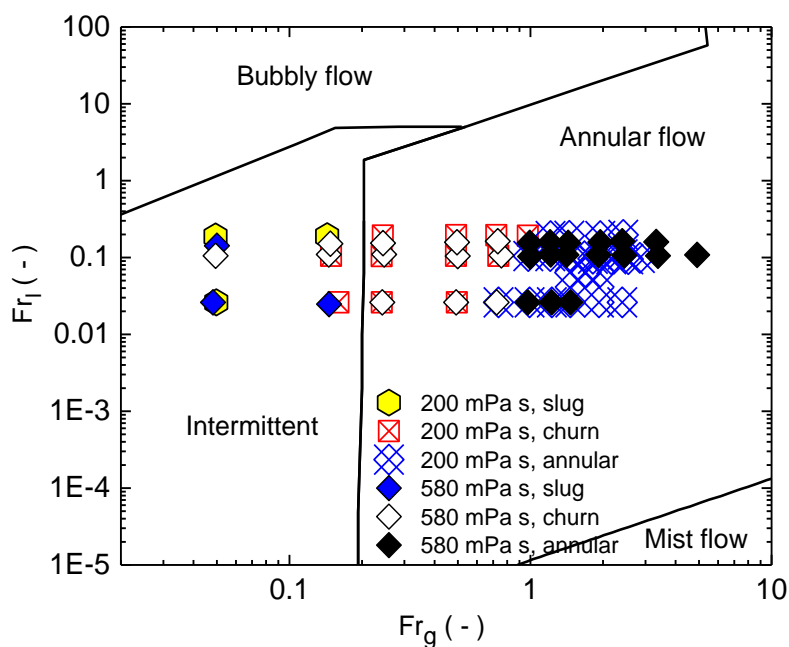

(b)

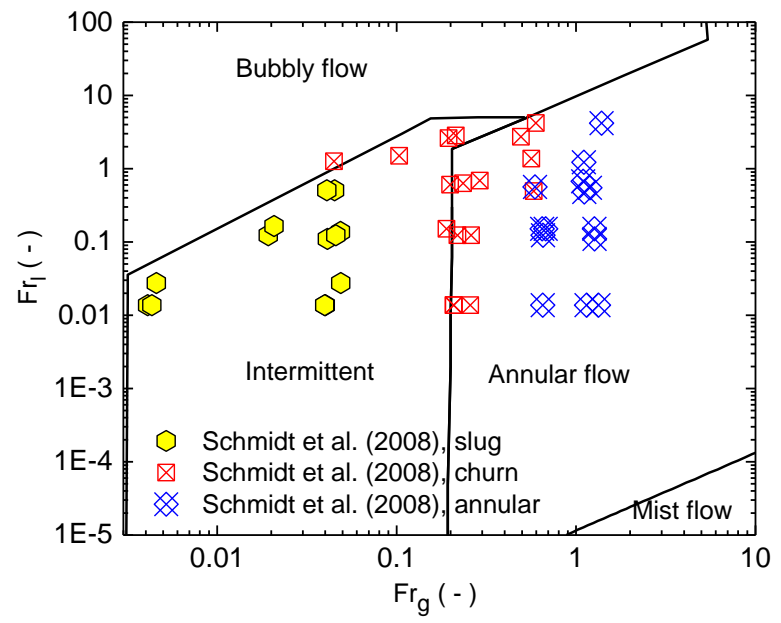

(c)

Figure 9 Comparison of experimental data (a) $100 \mathrm{mPa}$ s, (b) 200 and $580 \mathrm{mPa}$ s and Schmidt et al. (2008) with Shell (2001) flow pattern map

Comparison of experimental data with Shell (2001) flow pattern map: (a) our experimental data with liquid viscosity of $100 \mathrm{mPa}$ s, (b) our experimental data with liquid viscosities of 200 and $580 \mathrm{mPa}$ s, (c) Schmidt et al.'s (2008) data

\subsection{Void fraction and gas volumetric fraction}

Gas volumetric flow fraction is defined as the ratio of the gas volumetric flow rate to the total volumetric flow. This can be mathematically expressed as (Eq.4) (Bhagwat and Ghajar, 2012):

$$
\beta=\frac{v_{s g}}{v_{s g}+v_{s l}}
$$

By definition, the gas volumetric flow fraction is also referred to as the homogeneous void fraction with the assumption that there is no slip between the two phases. In the case for no slip, the void fraction is equal 
to the gas volumetric flow fraction, that is $\alpha=\beta$. However, due to significant density differences between the two phases, there is significant slip between the two phases, hence in practice, $\alpha \neq \beta$.

Figure 10 (a) to (c) show the variation of void fraction with gas volumetric flow fraction for air-water mixtures (Bhagwat and Ghajar, 2012), current experimental data with liquid viscosities of 100, 200 and 580 mPa s as well as the reported data of Schmidt et al. (2008) respectively. In the present analysis, it was observed that the void fraction is always less than the gas volumetric flow fraction, that is $\alpha<\beta$ at all viscosities. For viscosities between 100 and $580 \mathrm{mPa}$ s, it is observed that the void fraction decreases with increasing liquid viscosity. At highly viscous flows (represented by the Schmidt et al. (2008)), however, it appears the decrease is lower than that described. Bhagwat and Ghajar (2012) report a similar phenomenon for air-water mixtures. Perhaps, this is an indication that the phenomenon is not peculiar to higher and highly viscous flows or vice-versa. A comparison with their observation shows that the underprediction is less at air-low viscous liquid mixtures.

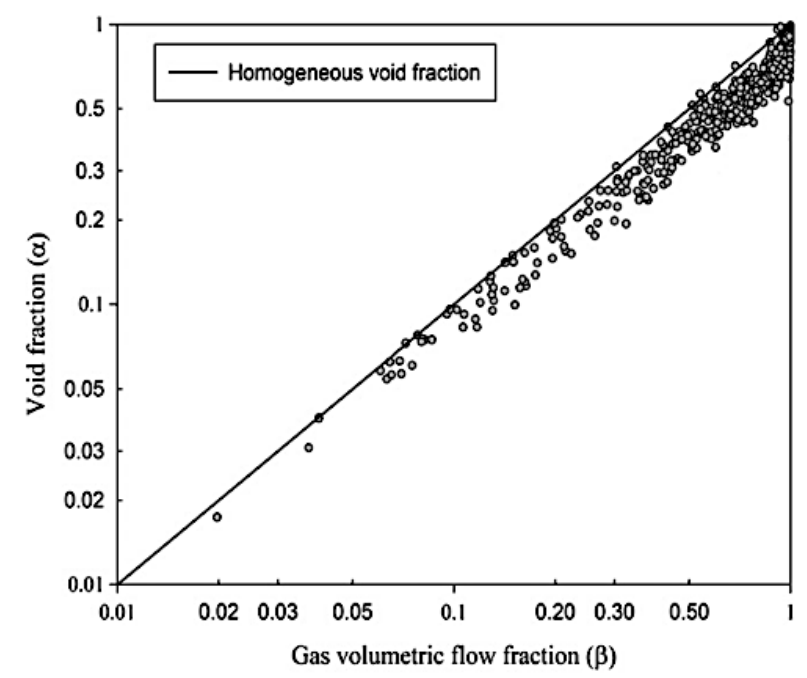

(a)
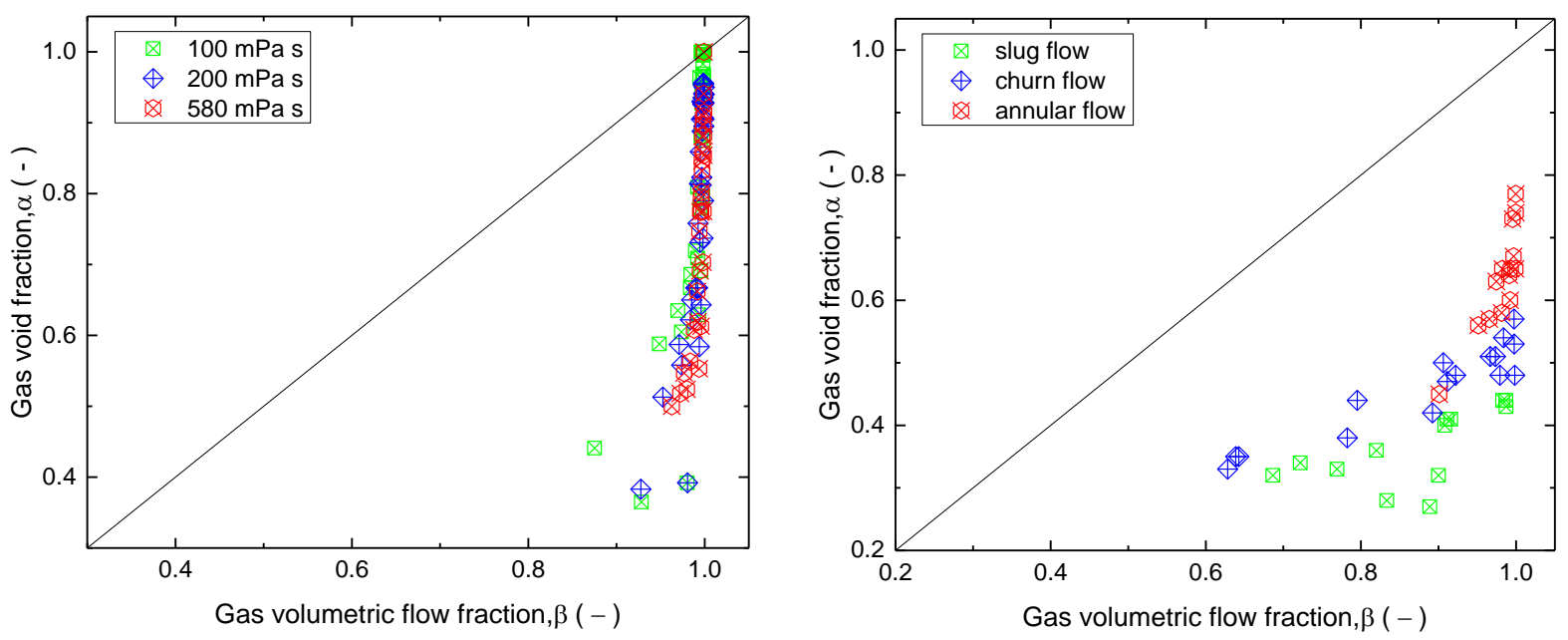
(b)

(c)

Figure 1 Void fraction vs gas volumetric flow fraction for vertical upward two-phase flow data: (a) reported by Bhagwat and Ghajar, (2012), (b) current experimental data with liquid viscosities of 100, 200 and $580 \mathrm{mPa}$ s and (c) reported data of Schmidt et al. (2008)

\subsubsection{Variation of gas void fraction with respect to flow pattern}

Figure 11 shows the variation of gas void fraction with respect to flow pattern and phase flow rates at constant $v_{s l}$ values of $0.02 \mathrm{~m} / \mathrm{s}$ and $0.15 \mathrm{~m} / \mathrm{s}$ respectively. It can be seen that void fraction changes significantly with the flow pattern. It can be observed that low void fractions are associated slug flow. As gas superficial velocity increases, a corresponding increase is observed in void fraction. Additionally, changes in flow pattern are observed where flow pattern transits from slug flow through churn flow to annular flow. Similar observations were previously reported by Ghajar and Bhagwat (2013) for their work which utilized air-water mixtures. Comparatively lower values for annular flow were observed for higher viscosities as reported by Schmidt et al. (2008) whose work utilized liquid viscosities ranging from 900 $7000 \mathrm{mPa}$ s (Figure 12).

It is noted that, akin to the case of air-water/ air-low liquid viscosities, there is a rapid increase in gas void fraction, even with the small changes in superficial gas velocity; whereas for annular flows small changes are observed, even for large increases in superficial gas velocity. Bhagwat and Ghajar (Ghajar and Bhagwat, 2013) noticed that the trend in variation of the void fraction with change in the flow patterns occur for void fraction around $\alpha=0.7$. It appears that for higher viscous flows (experimental data), there is a shift to higher void fraction of around $\alpha=0.8$. This study buttresses the suggestion by Bhagwat and Ghajar (Ghajar and Bhagwat, 2013) about the need for a correlation sensitive to changes in superficial gas velocity and predicts void fraction accurately within the of the steep slope typically for $0 \leq \alpha \leq 0.7$. Perhaps, for cases of higher viscous flows the range may be extended $0 \leq \alpha \leq 0.8$. It is however interesting to note that at highly viscous flows, the gas void fraction at which such changes are occurring appear to reduce to void fractions below 0.7. More data may be required to accurately establish this.

Further, compared to the report of Ghajar and Bhagwat (2013) it can be observed that there are differences in the phenomenon under discussion. Flow pattern and flow pattern transitions appear to occur at higher superficial gas velocities in the high liquid viscosity case. Churn covers a relatively expanded range and froth flow is not observed. 


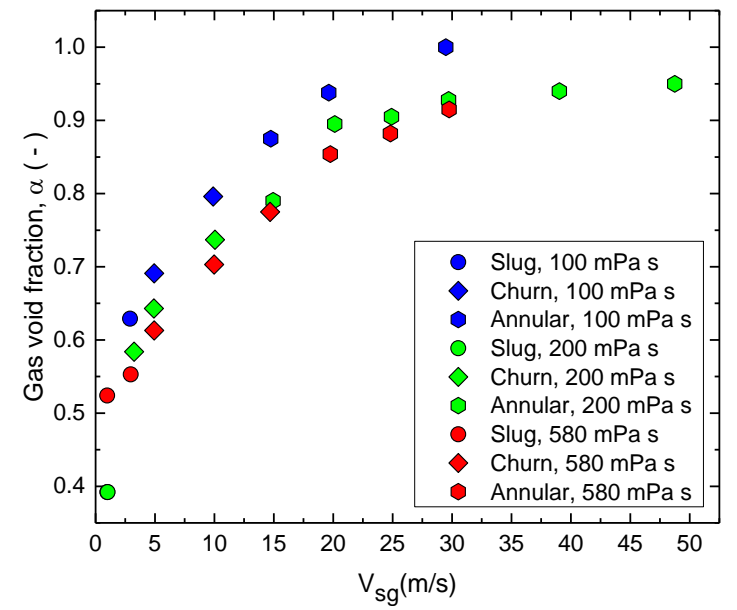

(a)

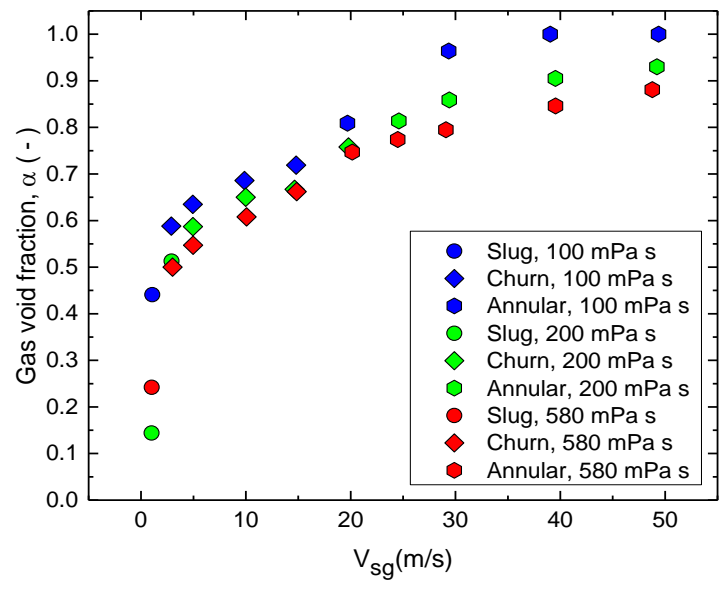

(b)

Figure 2. Variation of gas void fraction with respect to flow pattern and phase flow rates at $v_{s l}$ value of (a) 0.02 $\mathrm{m} / \mathrm{s}$ and (b) $0.15 \mathrm{~m} / \mathrm{s}$

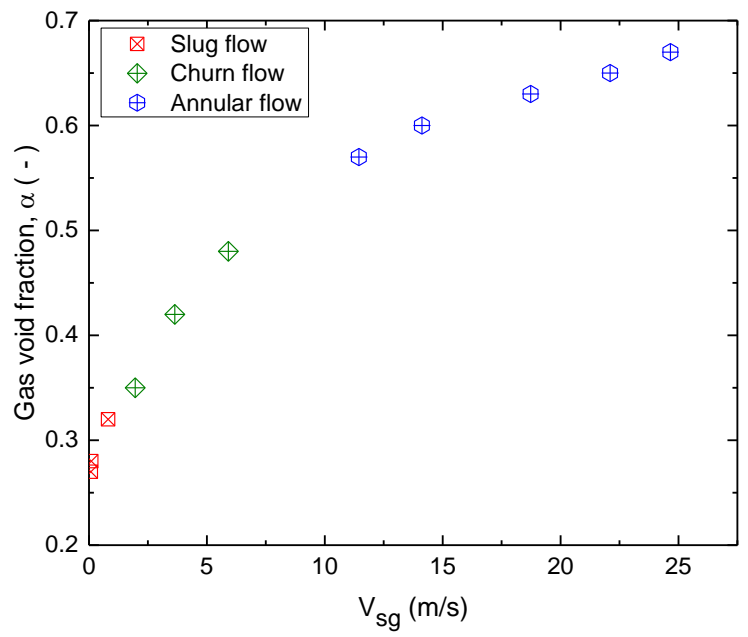

Figure 3. Variation of gas void fraction with respect to flow pattern and selected phase flow rates (Schmidt et al.,2008)

\subsubsection{Effect of superficial gas velocity on gas void fraction}

The variation of gas void fraction with superficial gas velocity for liquid viscosities of 100, 200 and $580 \mathrm{mPa}$ $\mathrm{s}$ is presented in Figures 11. Figure 12 shows a similar plot for selected phase flow rates for the Schmidt et al. (2008) data. It can be observed that gas void fraction increases as superficial gas velocity increases at all liquid viscosities. This phenomenon is attributable to the inability of the quantity and velocity of the liquid to counter the effects of the high gas velocity (Szalinski et al., 2010). The phenomenon could also be attributed to reduction in liquid film of the viscous phase adjacent to the wall causing higher holdup and less void distribution across the cross-section of the pipe (Alamu, 2010; Parsi et al., 2015b; Vieira et al., 
2015). Similar observations have been previously reported by Alamu (2010), Szalinski et al. (2010), Vieira et al. (2015), and Parsi et al. (2015a) whose works employed low liquid viscosities.

\subsubsection{Effect of superficial liquid velocity on gas void fraction}

The variation of gas void fraction with superficial gas velocity for $v_{s l}$ values of 0.02 and $0.15 \mathrm{~m} / \mathrm{s}$ is shown in Figure 13(a) and (b) respectively. From the Figures, it can be observed that increases in superficial liquid velocity decreases the gas void fraction. This trend is similar across all viscosities considered in the study. It is also noted that the phenomenon is present at low viscosities (Fig. 13). It also appears the influence of superficial liquid velocity diminishes as it increases with increasing liquid viscosity.

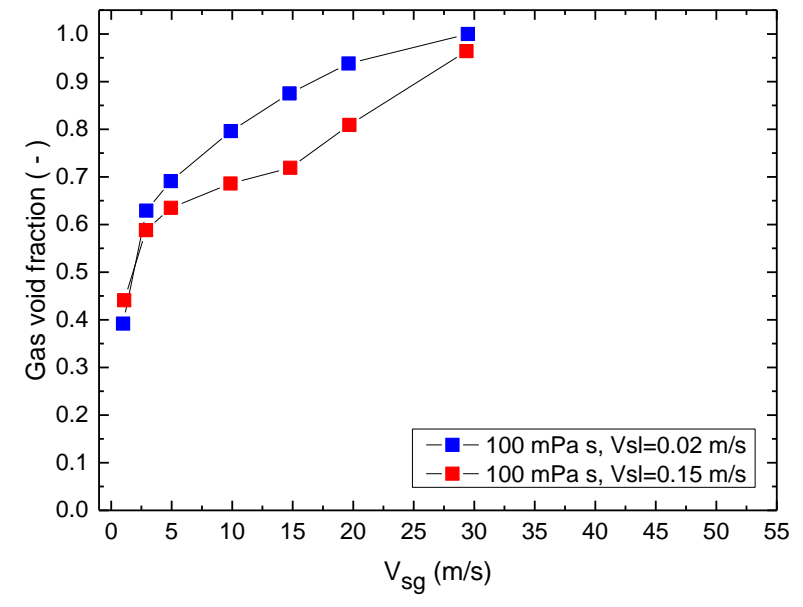

(a)

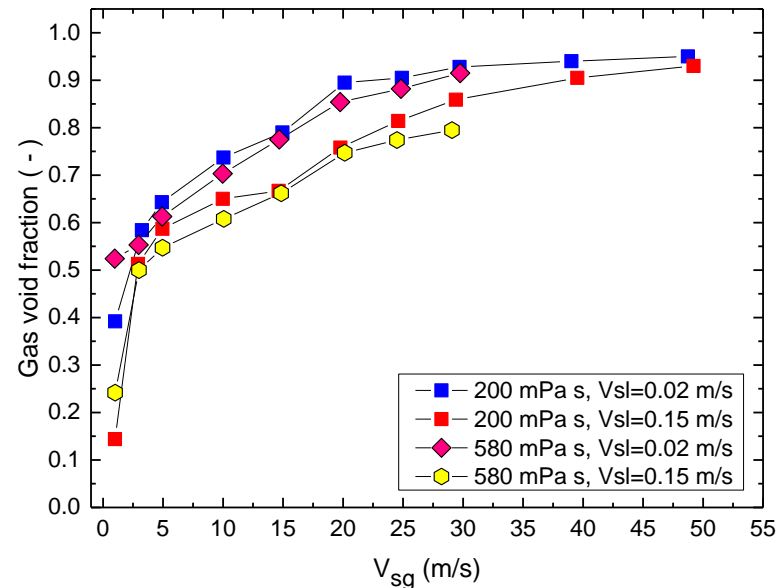

(b)

Figure 4. Variation of gas void fraction with superficial gas velocity for liquid viscosities of (a) $100 \mathrm{mPa} \mathrm{s}$, (b) $200 \mathrm{mPa}$ $s$ and $580 \mathrm{mPa} s$ at $v_{s l}$ values of 0.02 and 0.15 respectively

\subsubsection{Effect of liquid viscosity on gas void fraction}

Variation of gas void fraction with superficial gas velocity is presented for liquid velocities of $0.02 \mathrm{~m} / \mathrm{s}$ and $0.15 \mathrm{~m} / \mathrm{s}$ for respectively for experimental liquid viscosities of 100, 200 and $580 \mathrm{mPa} \mathrm{s}$ in Figure 14. The reported data of Hewakandamby et al. (2014) (16.2 mPa s), Szalinski et al. (2010) (5.2 mPa s) and Parsi et al. (2015a) (40 mPa s) are also superimposed on the plots of the experimental data.

From the Figures 14(a) and (b), it can be observed that gas void fraction decreases with increasing liquid viscosity. This can be attributed to increased shear stresses which lead to liquid accumulation and hence reduced gas void fraction (Al-Ruhaimani et al., 2017). Additionally, liquid viscosity influences liquid drop entrainment. Increased viscosity leads to decreased liquid droplet entrainment which also increases liquid 
accumulation and hence reduced gas void fraction. It appears the phenomenon is not restricted to lower viscosities. Similar observations have been previously reported by Al-Ruhaimani et al.(2017), Alamu (2010), Szalinski et al. (2010), Vieira et al. (2015), and Parsi et al. (2015a) whose works employed low liquid viscosities.

Again, it appears that the effect of liquid viscosity on gas void fraction is not significant at low superficial gas velocities representing the slug flow region (occurring at $v_{s g}<4 \mathrm{~m} / \mathrm{s}$ for liquid viscosities of 100 and $200 \mathrm{mPa} s$ and $v_{s g}<5 \mathrm{~m} / \mathrm{s}$ for $580 \mathrm{mPa} \mathrm{s}$ ). Within the churn flow range (occurring at $v_{s g}<4 \mathrm{~m} / \mathrm{s}<$ $10 \mathrm{~m} / \mathrm{s}$ for liquid viscosities of 100 and $200 \mathrm{mPa}$ s and $v_{s g}<5 \mathrm{~m} / \mathrm{s}<$ approximately $15 \mathrm{~m} / \mathrm{s}$ for $580 \mathrm{mPa}$ s), it is observed that the effect of liquid viscosity on gas void fraction declines liquid viscosity increases for both low and high superficial liquid velocities. It is important to note that the additional data was obtained with different pipe diameters. This suggests that the effect of diameter may also have a negligible effect on gas void fraction at higher liquid viscosities. The effect of liquid viscosity on gas void fraction is found to be significant for all viscosities at higher superficial gas and liquid velocities (which represent the annular flow region).

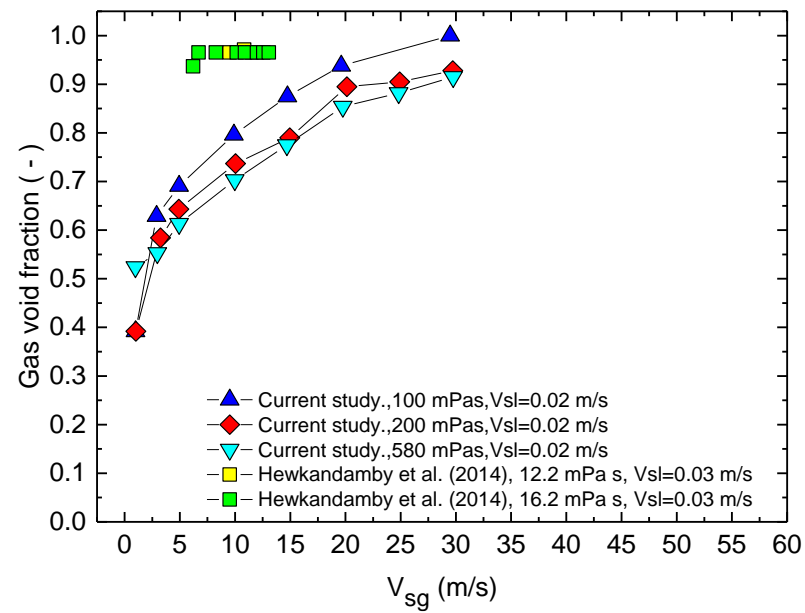

(a)

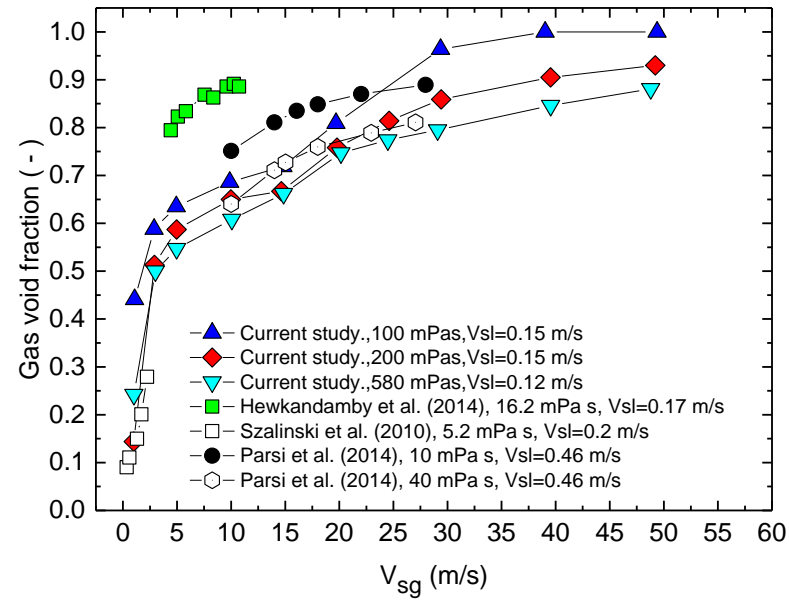

(b)

Figure 5. Variation of gas void fraction with superficial gas velocity for superficial liquid velocities of: (a) $0.02 \mathrm{~m} / \mathrm{s}$, and (b) $0.15 \mathrm{~m} / \mathrm{s}$ respectively 


\subsection{Comparison of correlation predictions with experimental data}

\subsubsection{Comparison of correlation predictions with overall data}

One hundred and fifteen (115) correlations were initially identified and slated for evaluation in this study. Preliminary analysis revealed that 12 correlations could not be evaluated over the entire database because they required values for system pressure which was provided in the reported data of Schmidt et al. (2008). While the performance of three correlations were found to be extremely unsatisfactory. Hence, in this study, 100 correlations were evaluated using the combined experimental data as well as data reported by Schmidt et al. (2008). It is noteworthy that the slip ratio and drift flux correlations presented by Schmidt et al. (2008) are also evaluated for the first time in this study. All correlations considered for this study have been listed Table A1 in the appendix. Table A2, also located in the appendix, lists the correlations which could not be evaluated over the entire database. Out of this number, 47 correlations exhibited satisfactory performances. A summary of these correlations has been presented in Table A3 in the appendix.

The analysis commences with the comparison of the predictions of correlations with the overall data in order to identify the best performing correlations. Further, comparison of the predictions of correlations are evaluated at different viscosities, different void fraction ranges and flow pattern. This is to facilitate investigation the behaviour of the selected best performing correlations at these conditions and also compare their performances with correlations designed for those conditions. Based on the results obtained, the best performing correlations are identified and presented.

Table 7. Results of the correlations that compared satisfactorily with the entire experimental database.

\begin{tabular}{|c|c|c|c|c|c|}
\hline Author & & $\pm 10 \%$ & $\pm 15 \%$ & $\pm \mathbf{2 0} \%$ & RMS* \\
\hline Hibiki and Ishii (1996) A & General & 87.34 & 93.92 & 97.97 & 9.09 \\
\hline Flanigan (1959) & General & 52.70 & 65.54 & 69.59 & 29.77 \\
\hline Bestion (1985) & General & 56.76 & 66.89 & 79.73 & 27.93 \\
\hline Schmidt et al. (2008) II & Drift flux & 30.41 & 41.89 & 56.76 & 23.76 \\
\hline
\end{tabular}

One hundred correlations considered in this analysis were compared with the experimental database. A summary of relevant information about them as well as the sources from which information was obtained is presented in Table A1. Out of the 100 correlations, the performance of 4 correlations were found to be satisfactory with a root-mean-square (RMS) error of less than $30 \%$. Of these, the drift model of Schmidt et 
al. (2008), reported in this work as Schmidt et al. (2008) II, is the only drift flux model. The rest are general models (Table 7).

Only the correlations presented by Hibiki and Ishii (2003) (annular flow) and Bestion (1990) satisfy the full dictates of the criteria; which are for the correlations to present an RMS value of less than $30 \%$ and also predict at least $85 \%$ and $75 \%$ of the data points within the $\pm 20 \%$ and $\pm 15 \%$ error bands respectively. The Bestion (1990) correlation predicts approximately $79 \%$ of the experimental data with less than $30 \%$ error to meet the criteria. It can be observed that the Flanigan correlation presents a good performance but it is not enough to meet the requirements.

It can be observed that of the two expressions, the annular flow-based drift flux correlation presented by Hibiki and Ishii (2003) presents the better performance. It is worthy to note that its predictions exceed the requirements of the criteria, predicting the highest number of experimental within all error indices respectively. In addition, its prediction error, measured using RMS, is extremely low; two times less than the error of Bestion (1990). This makes it a far more efficient correlation compared to the Bestion (1990) correlation. For the overall comparison of void fraction correlations with experimental data from $0<\alpha<$ 1, it can be concluded that the Hibiki and Ishii (2003) correlation is the best correlation.

The assessment done so far has examined the overall performances of the void fraction correlations with the combined experimental data. Considering that the overall performance neglects the strengths and weakness of the correlations in specific ranges of void fraction, further analysis is conducted to examine their performance at different viscosities. After that, the experimental data is also examined at four void fraction ranges: $0-0.25,0.25-0.5,0.5-0.75,0.75-1.0$. There is very little data for the $0-0.25$ range while the data points for the 0.75-1.0 dominate the database. Absolute reliance on the overall comparison of correlations and experimental results, therefore, could lead to biased interpretations. Examining correlations at these void fraction ranges will facilitate identification of correlations with higher accuracies in targeted void fraction range.

\subsubsection{Comparison of correlation predictions at different viscosities}

Correlation predictions were compared with the experimental data at viscosities of 100, 200, $580 \mathrm{mPa} \mathrm{s}$ and the data reported by Schmidt et al. (2008). Results of the evaluation is presented in Table 8. The main variable considered in this study and flow regimes (inherently superficial velocity ranges) were considered in the analyses and comparisons. Other variables that have been shown in other studies to be important are pipe size, pipe orientation (horizontal, inclined or vertical) and flow direction (upwards or downwards). 


\subsubsection{Comparison of correlation predictions at $100 \mathrm{mPa} \mathrm{s}$}

The top three correlations are those of Hibiki and Ishii (2003) (annular flow), Flanigan (1958) and Fauske (1961). Of the three, the Hibiki and Ishii (2003) correlation presents the best performance, predicting more than $90 \%$ of the experimental data points at each error index. Predictions of this correlation are achieved with low prediction errors (RMS=4.65). The second-best position is occupied by the correlation presented by Flanigan (1958) which predicted approximately $80 \%$ of the experimental data within the $10 \%$ error band and progressively predicted more than $80 \%$ of the experimental data within the $15 \%$ and $20 \%$ error bands respectively. Its prediction error can be deemed reasonable (almost three times the error of the former). The third position is occupied by the correlation of Fauske (1961) which predicted $77.78 \%$ of the experimental data within the $10 \%$ error index. The correlation was also found to present a similar performance as Flanigan (1958) in the 15\% error band. The annular flow-dependent correlation of Beggs (1972), Jowitt et al. (1984) and Dimentiev et al. (1959) (listed in order of decreasing performance in the 15\% error band) also performed well, predicting approximately $80 \%$ of the experimental data.

Mention can also be made of the correlations of Baroczy (1966), Takeuchi et al. (1992), Bestion (1990), Nicklin and Davidson (1962), Ohkawa and Lahey (Godbole, 2009) and Smith (1969) who do not make it to the top five but present good performances. These correlations predict at least $70 \%$ of the database in the $15 \%$ error index. It was also observed that their predictions are achieved with reasonably low prediction errors. The highest prediction error (RMS=31.85) is presented by the correlation of Takeuchi et al. (1992).

We note that viscosity is the main variable considered in this study - its effect on prediction models and flow regimes (inherently by the superficial velocity ranges). Other variables that can be important are pipe orientation (horizontal, inclined or vertical) and flow direction (upwards or downwards). They are not considered in this study. All the correlations considered here are for vertical upwards flow.

Table 8. Comparison of correlation predictions at different viscosities

\begin{tabular}{lccccc}
\hline \multicolumn{1}{c}{ Author } & $\mathbf{\pm 1 0} \%$ & $\mathbf{\pm 1 5} \%$ & $\mathbf{\pm 2 0} \%$ & $\mathbf{\pm 3 0} \%$ & RMS \\
\hline 100 mPa s & & & & & \\
\hline Hibiki and Ishii (2003) Annular & 94.4 & 97.2 & 100 & 100 & 4.65 \\
\hline Flanigan (1958) & 80.56 & 83.33 & 88.89 & 91.67 & 13.78 \\
\hline Fauske (1961) annular & 77.78 & 83.33 & 88.89 & 94.44 & 18.39 \\
\hline Beggs (1972) Annular & 72.22 & 83.33 & 86.11 & 97.22 & 14.44 \\
\hline Jowitt et al. (1984) & 25.00 & 80.56 & 88.89 & 91.67 & 13.86 \\
\hline Dimentiev et al. (1959) & 61.11 & 80.56 & 97.22 & 100 & 11.30 \\
\hline 200 mPa s & & & & & \\
\hline Hibiki and Ishii (2003) A & 91.89 & 94.59 & 97.29 & 97.29 & 10.58 \\
\hline Flanigan (1958) & 70.27 & 83.78 & 86.49 & 97.29 & 16.48 \\
\hline Bestion (1985) & 75.68 & 81.08 & 86.49 & 91.89 & 15.17 \\
\hline Hart et al. (1989) & 56.76 & 81.08 & 81.08 & 83.78 & 23.88 \\
\hline
\end{tabular}




\begin{tabular}{lccccc}
\hline Fauske (1961) annular & 67.57 & 75.67 & 78.38 & 89.19 & 20.06 \\
\hline 580 mPa s & & & & & \\
\hline Hibiki and Ishii (2003) Annular & 93.55 & 93.55 & 93.55 & 96.77 & 9.79 \\
\hline Kataoka and Ishii (1987) & 61.29 & 90.32 & 96.77 & 96.77 & 13.19 \\
\hline Turner and Wallis (1965) & 67.74 & 83.87 & 90.32 & 100 & 11.98 \\
\hline Flanigan (1958) & 25.81 & 80.65 & 83.87 & 96.77 & 15.69 \\
\hline Bestion (1985) & 61.29 & 74.19 & 93.55 & 96.77 & 15.22 \\
\hline Schmidt et al. (2008) data & & & & & \\
\hline Schmidt et al. (2008) II DF & 77.27 & 88.64 & 93.18 & 95.45 & 10.77 \\
\hline Hibiki and Ishii (2003) Annular & 68.18 & 81.82 & 93.18 & 100 & 10.20 \\
\hline Bhagwat and Ghajar (2013) & 63.64 & 79.55 & 88.63 & 93.18 & 16.23 \\
\hline Beattie and Sugawara (1986) & 52.27 & 75.00 & 79.54 & 90.91 & 15.92 \\
\hline
\end{tabular}

\subsubsection{Comparison of correlation predictions at $200 \mathrm{mPas}$}

When the data obtained using a liquid viscosity of $200 \mathrm{mPa}$ s was used, the top three correlations consist of those of Hibiki and Ishii (2003) (Annular), Flanigan (1958) and Dimentiev et al. (1959). The annular flow dependent -correlation of Hibiki and Ishii (2003) predicts approximately 91\% of the experimental data within the $10 \%$ error band. The number of accurate predictions increase to $94.59 \%$ and $97.29 \%$ within the $15 \%$ and $20 \%$ error indices. It can also be seen predictions are also made with low prediction errors (RMS=10.58). This is followed by the correlations of Flanigan (1958) and Dimentiev et al. (1959). Both correlations presented similar performances within the $10 \%$ and $15 \%$ error indices, predicting $70.27 \%$ and 83.78\% of experimental data respectively. Within the $20 \%$ error index, the Dimentiev et al. (1959) correlation is found to be better than that of Flanigan (1958). However, in terms of prediction errors, the Flanigan (1958) correlation is a better choice because of its lower prediction errors (RMS=16.48).

The Bestion (1990) correlation occupies the third-best position. Its predictions are higher than those of Flanigan (1958) within the 10\% error band but its performance deteriorates as the error band increases, predicting approximately $80 \%$ and $86.49 \%$ of experimental data within the $15 \%$ and $20 \%$ error bands respectively. The Bestion (1990) correlation is only superior to the Flanigan (1958) within the 10\% error band and exhibits a similar performance in the $20 \%$ error index. In terms of prediction errors (RMS=15.17) it offers a better performance than that of Flanigan (1958).

The correlations of Hart et al. (1989) and Fauske (1961) also present a good performance. The Hart et al. (1989) correlation appears to be the fourth-best correlation predicting at least $80 \%$ of the database within the $15 \%$ and $20 \%$ error indices respectively. The correlation by Fauske (1961) is however better than that of Hart et al. (1989) in terms of prediction errors. The former has a lower prediction error (RMS=20.06) than the latter (RMS=23.88). 


\subsubsection{Comparison of correlation predictions at $580 \mathrm{mPa} \mathrm{s}$}

At the viscosity of $580 \mathrm{mPa} \mathrm{s}$, only five correlations made satisfactory predictions. These include the correlations of Hibiki and Ishii (2003) (annular flow), Flanigan (1958), Turner and Wallis (1965), Bestion (1990) and Kataoka and Ishii (1987). The annular flow correlation of Hibiki and Ishii (2003) is found to present the highest prediction within the 10\%,15\% and 20\% error indices respectively. It predicts at least $90 \%$ of the experimental data within these error indices with the lowest prediction errors (RMS $=9.79$ ). This makes it the best correlation in this viscosity. This is followed by the correlation of Kataoka and Ishii (1987) which predicts $90.32 \%$ of the experimental data within the $15 \%$ error band. In terms of low prediction errors, the Turner and Wallis (1965) correlation is better than that of Kataoka and Ishii (1987) though it occupies third place. The Bestion (1990) correlation occupies the fifth position, predicting at least $70 \%$ of the experimental data within 15\% error index. It can be seen that predictions errors of all correlations are below $20 \%$.

\subsubsection{Comparison of correlation predictions with Schmidt et al. (2008) data}

Four correlations were found to predict the experimental data of Schmidt et al. (2008) satisfactorily. These include the correlations of Schmidt et al. (2008) II, Hibiki and Ishii (2003) (Annular), Bhagwat and Ghajar (Ghajar and Bhagwat, 2013) and Beattie and Sugawara (Bhagwat and Ghajar, 2014). It is noted that the performance of all the correlations improve as the error indices increase. The drift flux correlation of Schmidt et al. (2008) is found to be the best performing correlation in terms of percentage of predicted points with the $10 \%, 15 \%$ and $20 \%$ error bands where it predicts $77.27 \%, 88.67 \%$ and $93.18 \%$ respectively. These predictions are made with low prediction errors (RMS=10.77). The excellent performance exhibited by the correlation can be attributed to the fact that it is developed based on the experimental data. A slip ratio correlation (Schmidt et al. (2008) I) developed by the same author, also based on the experimental data, does not give a satisfactory performance.

The Hibiki and Ishii (2003) (annular flow (A)) correlation predicts $68.16 \%, 81.82 \%$ and $93.18 \%$ within the $10 \%, 15 \%$ and $20 \%$ error indices respectively. It can be seen from Table 8 that the annular flow correlation by Hibiki and Ishii (2003) exhibits a similar performance with the Schmidt et al. (2008) correlation. Within the 30\% error index, it is observed that the Hibiki and Ishii (2003) (Annular) model presents a better performance than the Schmidt et al. (2008) II correlation. It is also important to note that while both present low prediction errors (measured using RMS values) the Hibiki and Ishii (2003) (Annular) correlation has a slight edge over the Schmidt et al. (2008) II correlation. The third best correlation is that of Bhagwat and Ghajar (Ghajar and Bhagwat, 2013) which predict more than $70 \%$ and $80 \%$ in the $15 \%$ and $20 \%$ error 
indices respectively. Its best performance is within the $30 \%$ error index where it predicts slightly more than $90 \%$ of the experimental data. Further, its prediction errors are comparatively low (RMS=16.23). The Beattie and Sugawara (Bhagwat and Ghajar, 2014) correlation presents more than $70 \%$ of the experimental data in the $15 \%$ and $20 \%$ error indices. The performance of this correlation is the lowest compared to those previously mentioned. Therefore, this correlation occupies the fourth-best position. With the exception of the Schmidt et al. (2008) II correlation, the performance of the rest correlations can be deemed excellent considering that they were developed based on much less gas-lower liquid viscosities.

The findings of the evaluation using the Schmidt et al. (2008) II data support the findings of Godbole et al. (2009). In his work, none of the correlations he assessed could satisfactorily predict the experimental data. The difference, in this study, lies in the fact that the five correlations, found to present satisfactory performances were not part of his investigation. Contrary to his conclusion, this study demonstrates the capacity of some existing correlations to excellently predict higher and highly viscous experimental data for gas void fraction.

\subsubsection{Comparison of correlation predictions at different void fraction ranges}

\subsubsection{Comparison of correlation predictions at void fraction range $\mathbf{0}<\boldsymbol{\alpha} \leq \mathbf{0 . 2 5}$}

In previous comparison, previous authors (Bhagwat and Ghajar, 2012; Godbole et al., 2011) observed that at this void fraction range, the percentage error with respect to measured data is high compared to other ranges; partly as a result of rapid increases in void fraction at low superficial gas velocity. A similar observation was observed in this study. However, there was very little data available for analysis. Analysis of such data would be insignificant and may present false results. Hence, no analysis was carried out for this void fraction range.

\subsubsection{Comparison of correlation predictions at void fraction range $\mathbf{0 . 2 5}<\boldsymbol{\alpha} \leq \mathbf{0 . 5}$}

The results of the evaluation for this range are shown in Figure 15. Only two correlations were identified to meet the criterion. These were the correlations of Hibiki and Ishii (2003) and Schmidt et al. (2008) II (drift flux). The Hibiki and Ishii (2003) correlation predicts 39.4\%, $81.81 \%$ and $81.8 \%$ in the $10 \%, 15 \%$ and $20 \%$ respectively while the Schmidt et al. (2008) II correlation predicts $60.6 \%, 81.81 \%$ and $84.8 \%$ in the $10 \%, 15 \%$ and $20 \%$ respectively. The correlations predict the experimental data with low prediction errors and reasonable overprediction. The Hibiki and Ishii (2003) correlation presents the lower prediction error with an RMS value of $16.98 \%$ while the Schmidt et al. (2008) II presents an RMS value of $38.91 \%$. It can be observed that at the all the selected indices, the Schmidt et al. (2008) II outperforms the Hibiki and Ishii 
(2003) correlation. The edge presented by the Schmidt et al. (2008) II correlation can be attributed the fact that it was developed based on the experimental data.

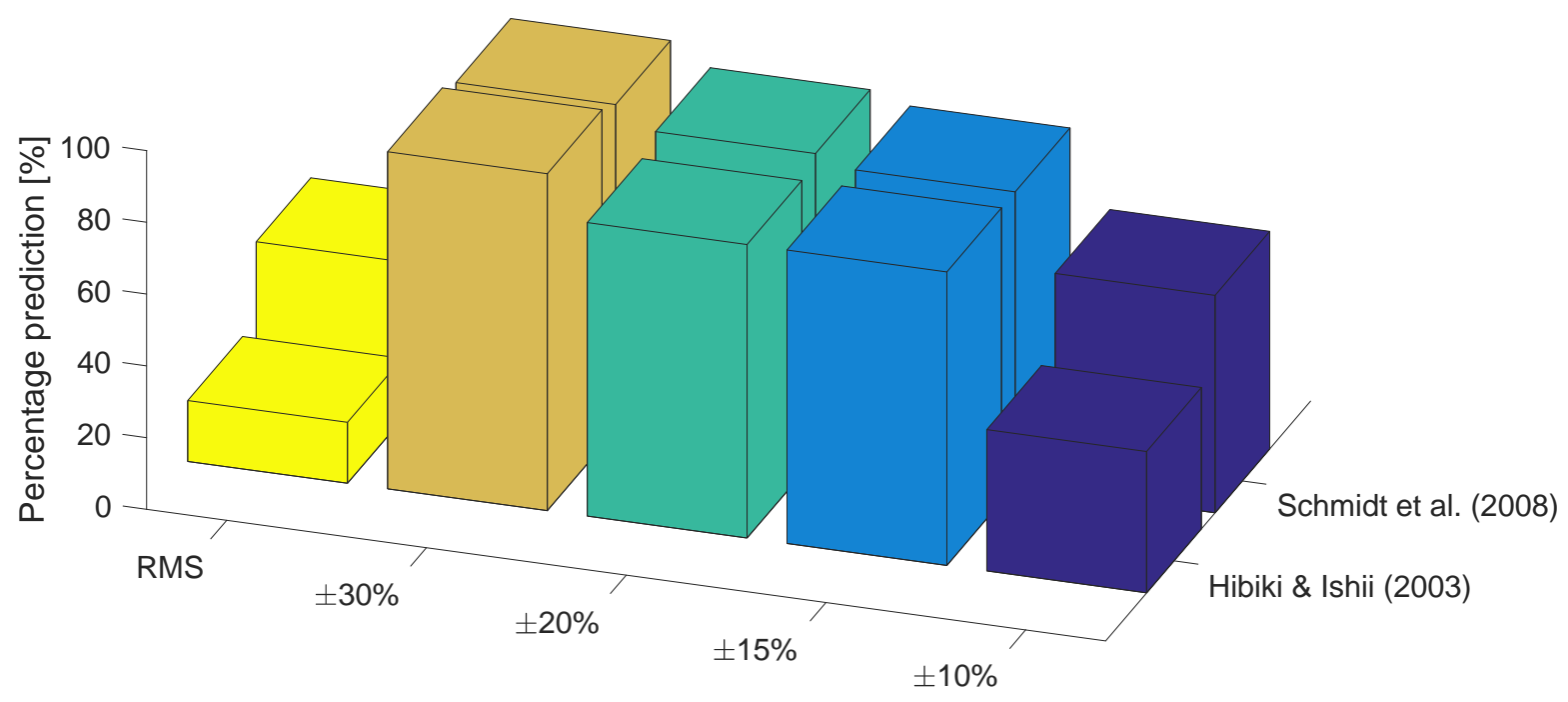

Figure 6 Results of top performing correlations for the $0.25<\alpha \leqslant 0.5$ range

\subsubsection{Comparison of correlation predictions at void fraction range $\mathbf{0 . 5}<\boldsymbol{\alpha} \leq \mathbf{0 . 7 5}$}

Within the void fraction range of $0.5<\alpha \leq 0.75$ (Figure 16), the five best correlations observed include that of Bhagwat and Ghajar (Ghajar and Bhagwat, 2013), Schmidt et al. (2008) II, Hibiki and Ishii (2003), Mishima and Hibiki (1996) and Beattie and Sugawara (1986). The performance of the latter two are not presented in Figure 16. The Bhagwat and Ghajar (Ghajar and Bhagwat, 2013) correlation predicts 74.1\%, $98.15 \%$ and $100 \%$ of the experimental data within the $10 \%, 15 \%$ and $20 \%$ respectively. The Schmidt et al. (2008) II correlation also predicts $50.0 \%, 68.52 \%$ and $98.15 \%$ of the experimental data within the $10 \%, 15 \%$ and $20 \%$ respectively. The Hibiki and Ishii correlation (2003) A is also found to predict $96.29 \%$ in the $10 \%$ error index and then 100\% of the experimental data within the $15 \%$ and $20 \%$ error indices respectively. Investigation of the RMS values show that its prediction errors are the lowest (RMS=6.88\%). This makes it the best correlation within this range. This performance is followed closely by that of Bhagwat and Ghajar (Ghajar and Bhagwat, 2013) (RMS=8.66) and then Schmidt et al. (2008) II (RMS=11.57). 


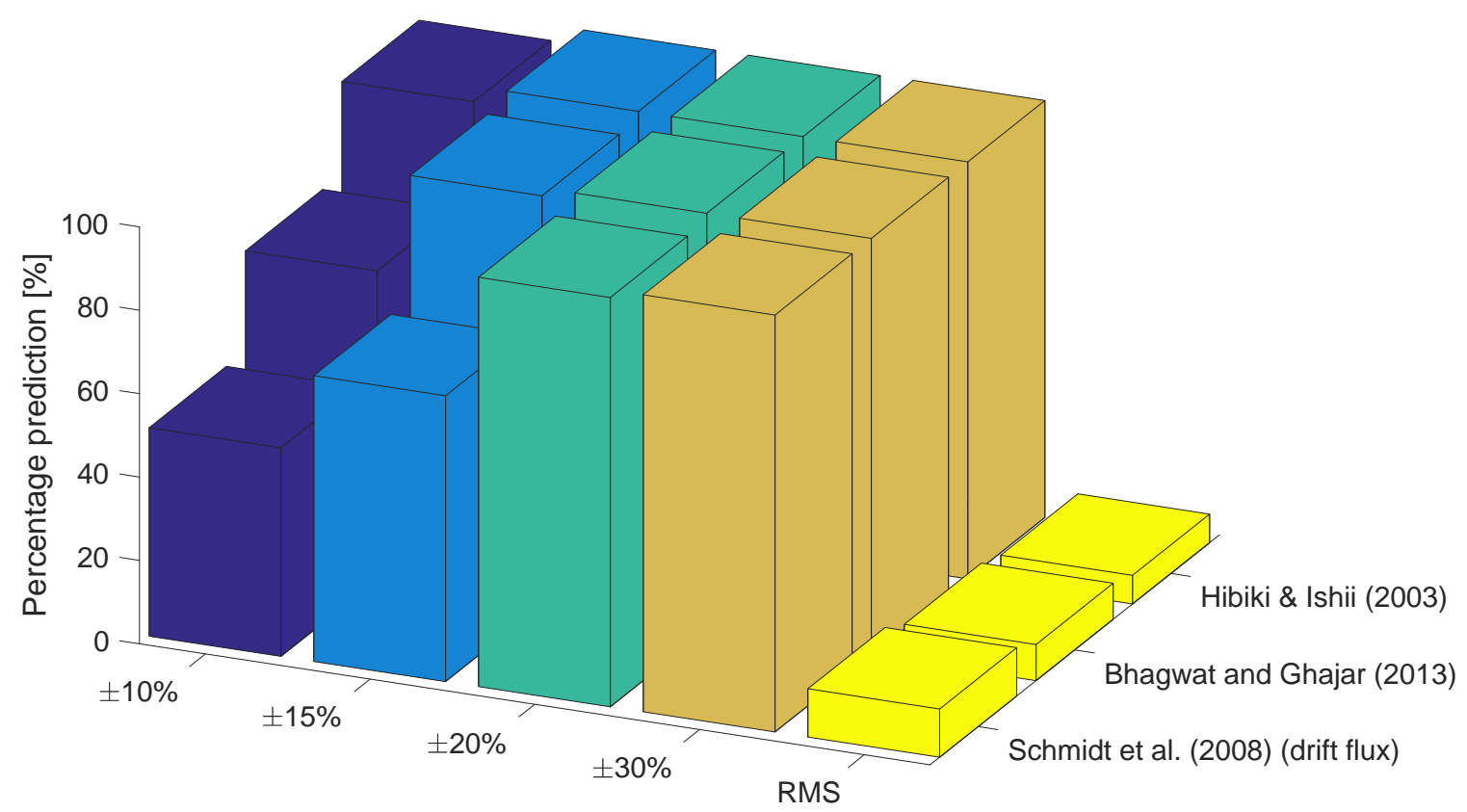

Figure 7 Results of top performing correlations for the $0.5<\alpha \leq 0.75$ range

Though the correlations of Mishima and Hibiki (1996) and Beattie and Sugawara (Bhagwat and Ghajar, 2014) do not appear in the top three, their performances are noteworthy. Both present improved performances as the error indices increase, finally predicting accurately $100 \%$ of the experimental data within the $30 \%$ error index. However, the latter presents better improvement than the former below the error index of 30\%. The Beattie and Sugawara (Bhagwat and Ghajar, 2014) predicts 33.3\%, 75.93\% and 92.6\% of the experimental data within the 10\%,15\% and 20\% respectively while the Mishima and Hibiki (1996) correlation predicts $55.6 \%, 64.81 \%$ and $85.2 \%$ of the experimental data within the $10 \%, 15 \%$ and $20 \%$ respectively. The related prediction errors for the two correlations are found to be comparatively higher than those of the top three. The Mishima and Hibiki (1996) correlation presents the lower of the two with an RMS value of $12.57 \%$ while the Beattie and Sugawara correlation presents an RMS value of $13.37 \%$. The Bestion (1990) correlation presents a good performance, however, per the criterion, its performance is not high enough to make it appear in the top three.

\subsubsection{Comparison of correlation predictions at void fraction range $\mathbf{0 . 7 5}<\boldsymbol{\alpha} \leq \mathbf{1}$. 0}

10 correlations were found to meet the criteria for this void fraction range (Table 9). These include (arranged in order of performance within the 10\% error index) those of Hibiki and Ishii (1996), Ishii (1975), Ohkawa and Lahey (Godbole, 2009), Lahey and Moody (1977), Flanigan (1958), Bestion (1990), Beggs (1972), Takeuchi et al. (1992), Baroczy (1966) and Lockhart and Martinelli (1949). The correlations of Hibiki and Ishii (2003) and Ishii (1975) predict accurately all of the experimental data to share the best correlation 
in this void fraction range. It can be also be noticed that they present the least prediction errors. The Hibiki and Ishii (2003) A correlation presents to lowest in the range (RMS=1.56) and is followed closely by that of Ishii (1975).

The correlations by Ohkawa and Lahey (Godbole, 2009) as well as Lahey and Moody (1977) present similar performances, predicting $96.72 \%$ of the experimental data respectively. They occupy the position for second best correlation. It can be seen from Table 9 that they also present very low prediction errors. Of the two, the Ohkawa and Lahey (Godbole, 2009) correlation presents the lower prediction errors (RMS=4.26\%). The correlation by Lahey and Moody (1977) presents an RMS value of 6.79\%.

The third best correlation is that of Flanigan (1958) which predicts $93.4 \%$ of the experimental data within the $10 \%$ error index with an RMS value of 6.09. The Bestion (1990) correlation takes the fourth place by predicting $91.8 \%$ experimental data within 10\% error index with an RMS value of $6.25 \%$. It is clear from the results that the performance of the Hibiki and Ishii (2003) A correlation is superior to that of Bestion (1990) at this void fraction range.

The correlation of Lockhart and Martinelli (1949) is found with the comparatively lowest number of predicted experimental data points (81.96\%) within the $10 \%$ error index. Its performance is similar to that of the Baroczy (1966) correlation. It appears the position of the Lockhart and Martinelli (1949) correlation is emphasized by the prediction errors (7.79\%) which is slightly more than that of Baroczy (1966) which presents an RMS value of $7.60 \%$.

Table 9. Results of top performing correlations for the $0.75<\alpha \leq 1.0$ range.

\begin{tabular}{lccccc}
\hline \multirow{2}{*}{ Correlations } & \multicolumn{4}{c}{ Percentage of points within } & RMS \\
\cline { 2 - 5 } & $\mathbf{\pm 1 0 \%}$ & $\mathbf{\pm 1 5 \%}$ & $\mathbf{\pm 2 0 \%}$ & $\mathbf{\pm 3 0 \%}$ & \\
\hline Hibiki and Ishii (2003) (A) & 100 & 100 & 100 & 100 & 1.56 \\
Ishii (1977b) & 100 & 100 & 100 & 100 & 1.98 \\
Ohkawa and Lahey (1980) & 96.72 & 100 & 100 & 100 & 4.26 \\
Lahey and Moody (1977) & 96.72 & 100 & 100 & 100 & 6.79 \\
Takeuchi et al. (1992) & 83.61 & 100 & 100 & 100 & 6.07 \\
Flanigan (1958) & 93.44 & 100 & 100 & 100 & 6.09 \\
Bestion (1985) & 91.80 & 100 & 100 & 100 & 6.25 \\
Beggs (1972) & 88.53 & 98.36 & 100 & 100 & 6.51 \\
Baroczy (1966) & 81.97 & 95.08 & 98.36 & 100 & 7.60 \\
Lockhart and Martinelli (1949) & 81.96 & 93.44 & 98.36 & 100 & 7.79 \\
\hline
\end{tabular}




\subsection{Comparison of correlation predictions with data at different flow patterns}

Slug, churn and annular flows were the main flow patterns observed during the experiment. Data obtained and used for this evaluation is obtained based on these flow regimes. The data is augmented with the data of Schmidt et al. (2008) which is also based on these flow regimes.

\subsubsection{Comparison of correlation predictions with slug flow data}

A total of 25 data points in the slug flow regime were utilized for comparison in this study (Figure 17). The void fraction range for the experimental data was $0.144-0.667$. The slug-regime specific correlations evaluated in this study include those of Nicklin and Davidson (1962), Ellis and Jones (1965), Sylvester (1987), Kataoka and Ishii (1987), Gomez et al. (2000) (as reported by Woldesemayat and Ghajar,(2007)), Bonnecaze et al. (1971), Beggs (1972) and Kabir and Hasan (1990). The results indicate, however, that performances of these correlations were not satisfactory.

The top three correlations identified to present satisfactory performances include those of Hibiki and Ishii 2003) (Annular), Schmidt et al. (2008) II and Beattie and Sugawara (Bhagwat and Ghajar, 2014) (Figure 17). With the exception of the Schmidt et al. (2008) correlation which is based on the drift flux model, the other two are general equations. The drift flux correlation of Schmidt et al. (2008) is found to perform as well as the Hibiki and Ishii (2003) (Annular) correlation, in terms of experimental data predicted in the 20\% error index. Both predict $92 \%$ of the experimental data points in the error index under consideration. However, in terms of prediction errors, measured using RMS values, the Hibiki and Ishii (2003) (Annular) correlation is the better of the two and the best in the range, with an RMS value of $16.52 \%$. The third best correlation is that of Beattie and Sugawara (Bhagwat and Ghajar, 2014) with 84\% of experimental data predicted with the $20 \%$ error index with an RMS value of $45.45 \%$. The prediction errors presented by the correlations of Schmidt et al. (2008) and Beattie and Sugawara (Bhagwat and Ghajar, 2014) can be considered reasonable. 
Close prediction capabilities were demonstrated by other correlations including those of Jowitt et al. (1984), Pearson et al. (2016) and Mattar and Gregory (1974) which predict 76\%, 72\% and 72\% of the experimental data within the $20 \%$ error index respectively.

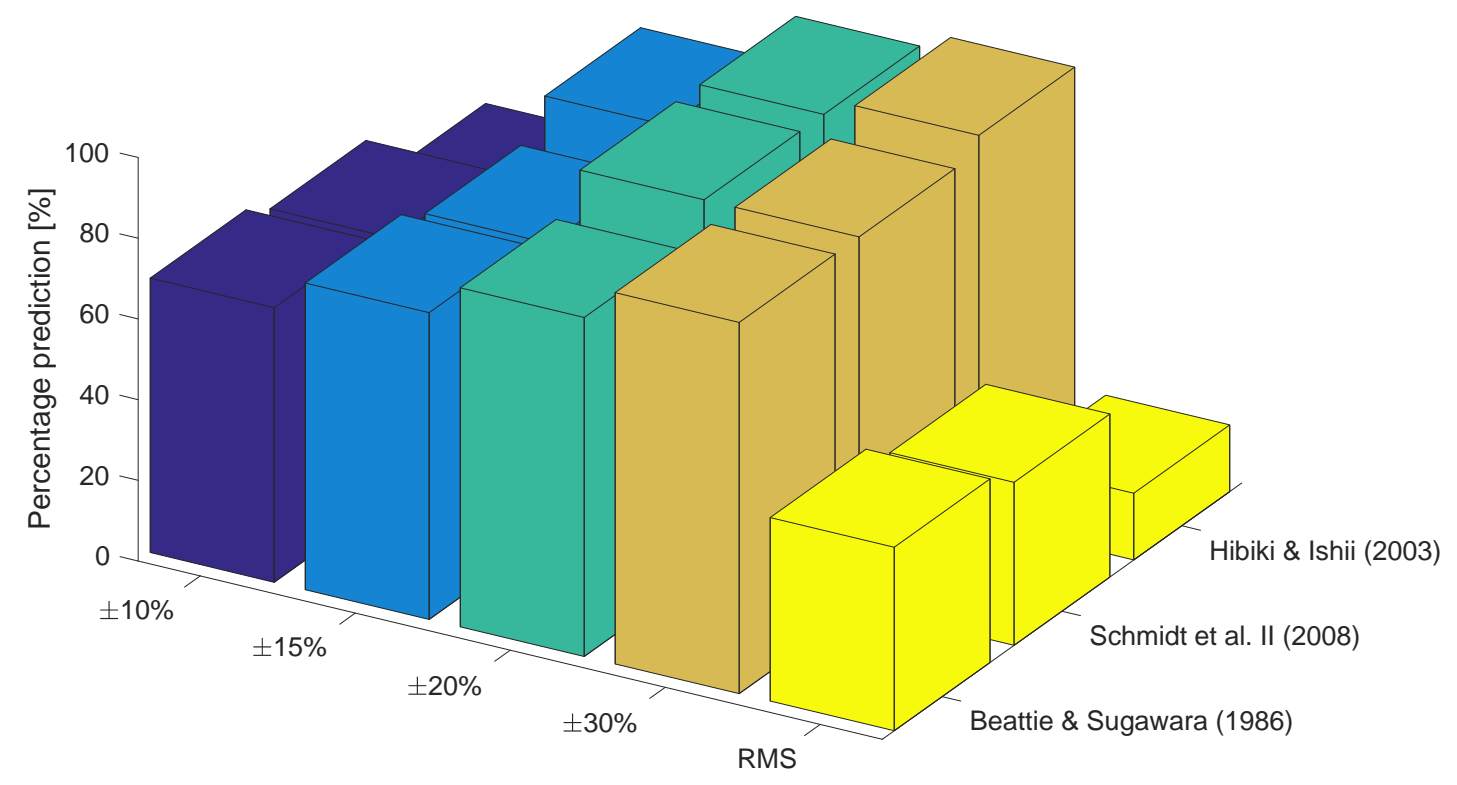

Figure 8. Comparison of correlation predictions with slug flow data

\subsubsection{Comparison of correlation predictions with churn flow data}

Forty-nine data points were utilized in this assessment. Results from are evaluation are presented in Table 10. The churn flow specific correlations considered for evaluation include those of Kabir and Hasan (1990) and Tangesdal et al. (1999). The performances of these correlations were found to be unsatisfactory.

Table 10. Comparison of correlation predictions with churn flow data

\begin{tabular}{lccccc}
\hline Correlations & \multicolumn{3}{c}{ Percentage of points within } & \multirow{2}{*}{ RMS } \\
\cline { 2 - 5 } & $\mathbf{\pm 1 0 \%}$ & $\mathbf{\pm 1 5 \%}$ & $\mathbf{\pm 2 0 \%}$ & $\mathbf{\pm 3 0 \%}$ & \\
\hline Hibiki and Ishii (2003) & 83.67 & 89.79 & 95.92 & 97.96 & 10.00 \\
Bhagwat and Ghajar (2013) & 69.39 & 93.88 & 97.96 & 97.56 & 18.34 \\
Beattie and Sugawara (1986) & 48.98 & 73.47 & 87.76 & 95.92 & 18.89 \\
Bestion (1985) & 55.10 & 67.35 & 85.71 & 91.83 & 18.73 \\
Schmidt et al. (2008) drift flux & 42.86 & 69.39 & 81.63 & 95.92 & 19.65 \\
Proposed drift flux correlation & 55.10 & 77.55 & 89.79 & 97.98 & 13.55 \\
Proposed slip ratio correlation & 77.55 & 87.76 & 95.92 & 95.92 & 21.24 \\
\hline
\end{tabular}


Within the 20\% error index, 5 correlations meet the requirement (Table 10). These include the correlations of Bhagwat and Ghajar (Ghajar and Bhagwat, 2013), Hibiki and Ishii (2003), Beattie and Sugawara (Bhagwat and Ghajar, 2014), Bestion (1990) and the drift flux correlation of Schmidt et al. (2008). These correlations predict 97.96\%, 95.92\%, 87.76\%, 85.71\% and $81.63 \%$ respectively. It can also be observed that the prediction errors presented by these correlations are also relatively lower compared to those for the slug flow regime. The least is presented by the Hibiki and Ishii (2003) (Annular) correlation with an RMS value of $10 \%$ while the highest is presented by the drift flux correlation of Schmidt et al. (2008) with an RMS value of 19.65\%. The Bestion (1990) correlation occupies the fourth place in this regime. It is noted that compared to the performance of the Hibiki and Ishii (2003) (Annular) correlation, the latter is superior.

\subsubsection{Comparison of correlation predictions with annular flow data}

For this evaluation, considering that annular falls within the $0.75<\alpha<1.0$ range and predictions within this regime is comparatively better than the others, the same criteria is used. 73 data points were utilized. Generally, predictions within this flow regime were found to be more accurate than others. The performances of 36 correlations found to meet the requirement are presented in Table A7 in the Appendix.

12 annular flow-dependent existing correlations were used for this assessment. These include those of Lockhart and Martinelli (1949), Fauske (1961), Smith (1969), Zivi (1964), Tandon (1985), Chen (1986), Yao and Sylvester (1987), Kabir and Hasan (1990), Beggs (1972) and Gomez et al. (2000). The performance of Lockhart and Martinelli (1949), Zivi (1964), Tandon (1985), Chen (1986), Kabir and Hasan (1990) as well as Yao and Sylvester (1987) performed appreciably well but could not meet the criteria. The correlations by Fauske (1961), Smith (1969), Beggs (1972) and Gomez et al. (2000) presented similar performances within the $20 \%$ error index.

The best performance among these correlations, within the $20 \%$ error index, was presented by the Fauske (1961) correlation which predicted $86.30 \%$ of the experimental data. This was followed by the Gomez et al. (2000) and Beggs (1972) correlations which predicted $84.93 \%$ of the experimental data. The least predictions were made by Smith (1969) correlation, predicting $80.82 \%$ of the data. It is found that their performances compare well with other correlations evaluated for this study. Despite their good performances, none of these correlations appeared in the top three set of correlations.

The top three correlations identified include the correlations by Hibiki and Ishii (2003) (Annular), Lahey and Moody (1977) and Hart et al. (1989). All the correlations are general in nature. The Hibiki and Ishii (2003) (Annular) and Lahey and Moody (1977) correlations predict 100\% of the experimental data within the $20 \%$ 
error index. However, the Hibiki and Ishii (2003) (Annular) correlation proves to be the better of the two, considering that it predicts $100 \%$ of the experimental data points even within the $10 \%$ error index and with the lowest prediction errors (RMS=1.24\%). The Lahey and Moody (1977) correlation also shows a relatively good performance within the $10 \%$ and $15 \%$ error index, predicting almost $70 \%$ and at least $80 \%$ of the experimental data points respectively. The Hart et al. (1989) correlation occupies the third position having predicted at least $89 \%$ of the experimental data points. it can be noticed, that despite this performance, its prediction errors are comparatively much higher than the first two yet satisfactory. From the Table, it can be observed that several correlations perform better the latter two correlations. However, lack of improvement as the error indices increase prevent them from making it to the top.

The Bestion (1990) correlation, one of two overall best correlations, occupies the fourth position, predicting $87.67 \%$ of the experimental data with a low prediction error (RMS $=5.31 \%$ ). The performances of 30 other correlations of different characteristics are presented in Table A7 in the appendix. It was observed that the performances are very good with very low prediction errors.

\subsubsection{Summary}

From the discussion, two correlations, that of Hibiki and Ishii (2003) (Annular) and Bestion (1990) were identified as the overall best and second best when the entire database was used to evaluate the 100 correlations. Subsequent analysis of the selected correlations at void fraction ranges of $0.25-0.5,0.5-$ 0.75, 0.75 -1.0 indicated revealed that the Hibiki and Ishii (2003) (Annular) correlation exhibits a good performance at all ranges. In the $0.25-0.5$ as well as the $0.75-1.0$ ranges respectively, it was found to exhibit the best performance. It was also found to have a better performance than the Bestion (1990) correlation in all the ranges considered. Finally, it was observed that the Hibiki and Ishii (2003) (Annular) correlation outperformed the both the flow pattern - specific as well as other correlations which met the criteria when its predictions were compared with those of the experimental data. It is also important to note that its performance was better than that of Bestion (1990) in all cases. Therefore, it can be concluded that the overall best correlation for gas void fraction prediction in highly viscous upward flows is that of Hibiki and Ishii (2003) (Annular) while the second best is Bestion (1990). A pictorial assessment of these correlations is presented in Figures 18 and 19 respectively. 


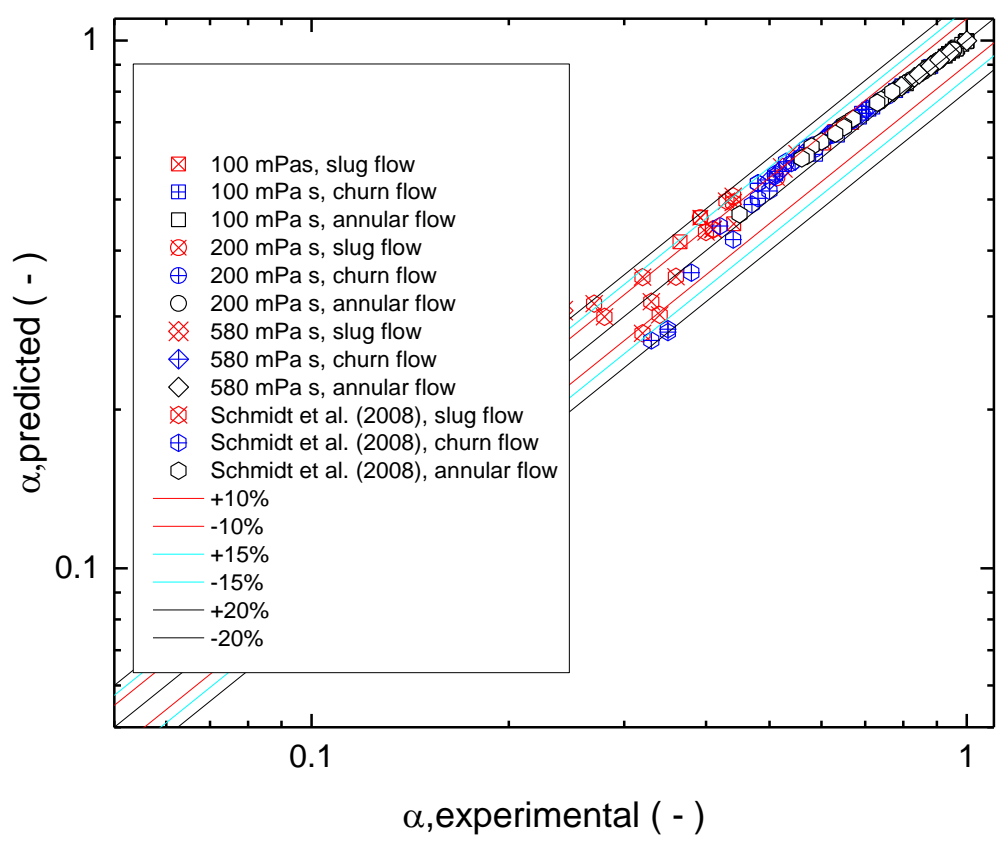

Figure 9. Comparison of predictions of Hibiki and Ishii (2003 A) with entire evaluation database

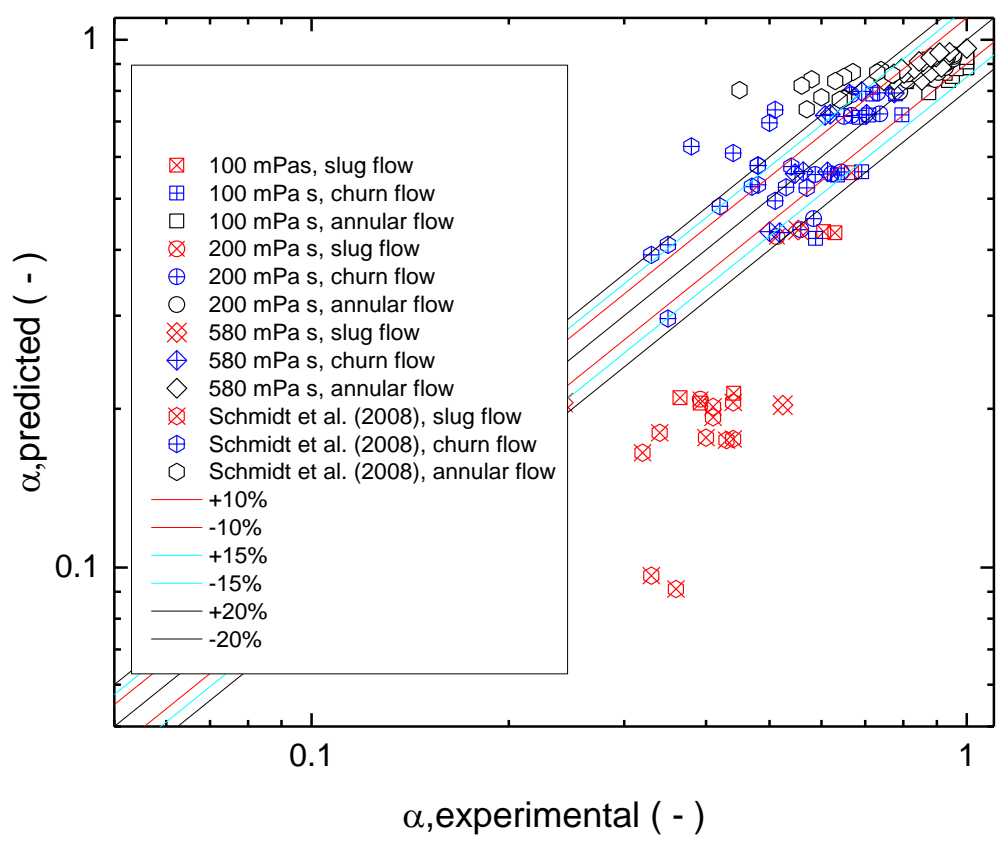

Figure 19. Comparison of predictions of Bestion (1985) with entire evaluation database 


\subsection{Proposed flow regime-dependent correlations}

It was observed that no churn flow - dependent correlation could accurately predict the combined experimental database. For annular flow, quite a few were able to predict accurately. In pursuit for higher accuracies, new correlations, based on experimental data, were developed for churn and annular flow regimes. The drift flux and slip ratio approaches were employed for correlation development. The performance of both correlations for the flow regimes were first compared with each other and also compared with those of existing correlations. As can be seen, the drift flux and slip ratio methods have been extensively used in literature for the development of gas void fraction correlations (Bhagwat and Ghajar, 2014)

The general drift flux method defined by Zuber and Findlay (1965) is expressed as (Eq. 5):

$$
\alpha=\frac{v_{s g}}{C_{o} v_{m}+v_{d}}
$$

where $v_{s g}, C_{o}, v_{m}$ and $v_{d}$ represent superficial gas velocity, distribution parameter, mixture velocity and

drift velocity respectively. $C_{o}$ can be obtained by plotting $\left(\frac{v_{s g}}{\varepsilon}=v_{g}\right)\left(v_{g}\right.$ : velocity of the gas) as the ordinate and $\left(C_{o} v_{m}+v_{d}\right)$ as the abscissa. From this relation, $C_{o}$ is estimated as the slope and the drift velocity as the intercept.

The general approach for slip ratio correlations suggest that the slip can be a function of flow conditions as well as some fluid properties. Some authors employed varied combinations of ratios of wetness fraction $(1-x)$ and $x$, the quality or dryness fraction, ratio of gas flow rate to the total flow rate, densities of gas and liquid phases as well as ratios of viscosities of the liquid and gas phases to determine the gas void fraction. The combined product of the ratios of wetness fraction $(1-x)$ and $x$, the quality or dryness fraction, densities of gas and liquid phases as well as ratios of viscosities of the liquid and gas phases was introduced and is known as the Martinelli parameter. Butterworth (Schmidt et al., 2008) generalized the slip as a function of these ratios expressed as (Eq. 6):

$$
\alpha=\left[1+A\left(\frac{1-x}{x}\right)^{a}\left(\frac{\rho_{g}}{\rho_{l}}\right)^{b}\left(\frac{\mu_{l}}{\mu_{g}}\right)^{c}\right]^{-1}
$$

where $\mathrm{A}$ is a constant and $\mathrm{a}, \mathrm{b}$ and $\mathrm{c}$ are coefficients. The correlation is so structured to account for fluid properties including the wetness and dryness fractions, fluid densities and viscosities. 


\subsubsection{Proposed correlation for prediction of gas void fraction in highly viscous churn flows}

\subsubsection{Drift flux correlation}

A new drift flux correlation for developed for the combined churn flow data. $C_{o}$ was initially determined for the various viscosities. It was observed that except for the Schmidt et al. (2008) data which had a value of approximately 1.9, and $100 \mathrm{mPa} s$ which had a value of 1.12, the rest of the data at liquid viscosities of 200 and 580 had a value of 1.24. A value of approximately 1.2 was obtained when the entire data was considered (Figure 20).

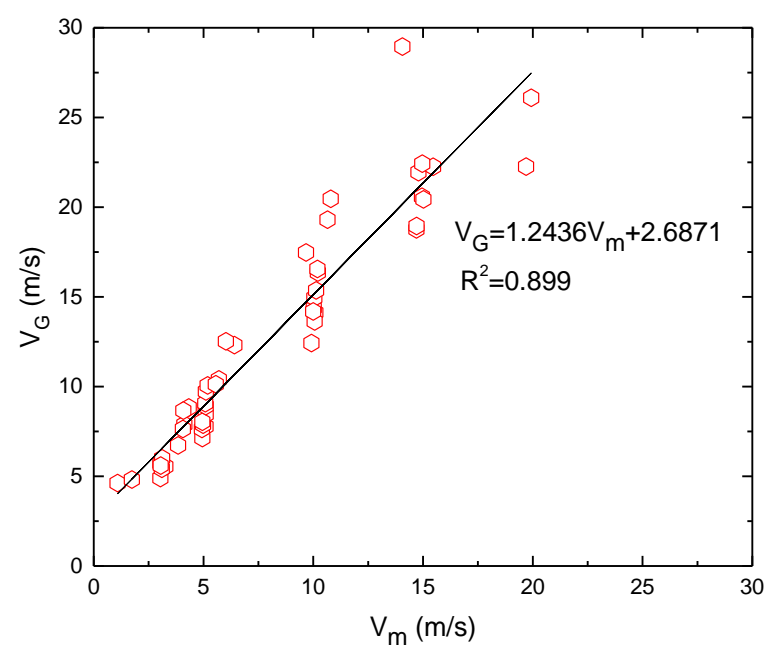

Figure 10. Gas velocity vs superficial gas velocity for churn flow data

When the values were substituted in Equation 5, the resulting equation can be written as (Eq. 7):

$$
\alpha=\frac{v_{s g}}{1.2436 v_{m}+2.6871}
$$

where the 1.2436 and 2.6871 are values for $C_{o}$ and $v_{d}$ respectively. A pictorial assessment is presented in Figure 21(a). Hence, for the highly viscous churn flow data, a drift flux correlation expressed as Equation 7 is proposed for accurate prediction of gas void fraction.

\subsubsection{Slip ratio correlation}

The general equation (Eq. 6) was used, where $A$ is a constant and $a, b$ and $c$ are coefficients determined by fitting the experimental data. To obtain the constants, the method of non-linear least squares, a powerful technique, easily implemented in Microsoft Excel was employed.

To do this, Eq. (6) was re-written as follows: 


$$
r_{i}=(\alpha)_{\exp , i}-\left(\left[1+A\left(\frac{1-x}{x}\right)^{a}\left(\frac{\rho_{g}}{\rho_{l}}\right)^{b}\left(\frac{\mu_{l}}{\mu_{g}}\right)^{c}\right]^{-1}\right)_{\text {pred }, i}
$$

where $r$ is the residual being the difference between each experimental point $(\exp , i)$ and the corresponding predicted point (pred,i). Though difficult to achieve as a result of random errors present in experimental measurements, an ideal value of $r_{i}=0$ is desired. There is no closed form solution for Eq. (8) and an infinite number of solutions can be obtained. Therefore, the best values for the constants are those that present the minimum value of the sum of squares of the residual $S$ across the entire experimental database. This is obtained by solving the non-linear least squares minimization problem as follows (Eq. 9):

$$
\min S=\sum_{i=1}^{N} r_{i}^{2}=\sum_{i=1}^{N}\left\{(\alpha)_{e x p, i}-\left(\left[1+A\left(\frac{1-x}{x}\right)^{a}\left(\frac{\rho_{g}}{\rho_{l}}\right)^{b}\left(\frac{\mu_{l}}{\mu_{g}}\right)^{c}\right]^{-1}\right)_{p r e d, i}\right\}^{2}
$$

where $\mathrm{N}$ is the number of datapoints in the databank. Eq. (9) is solved iteratively using the Gauss-Newton deterministic algorithm embedded in the Solver add-in available in Microsoft Excel. Initial values for the constants were provided. Efforts were made to ensure these values were as realistic as possible with a view to facilitate easy convergence of the algorithm and also to obtain a solution with realistic coefficients. Using the experimental data as well as data obtained from Schmidt et al. (2008), the following expression (Eq. 10) was obtained after the algorithm was implemented.

$$
\alpha=\left[1+3 \times 10^{-3}\left(\frac{1-x}{x}\right)^{0.27}\left(\frac{\rho_{g}}{\rho_{l}}\right)^{-0.36}\left(\frac{\mu_{l}}{\mu_{g}}\right)^{0.212}\right]^{-1}
$$

Evaluation of the predictions of Equation 10 (Figure 21b) indicates the performance of the correlation is good and has good agreement with the experimental data. Equation 10 therefore is proposed for gas void fraction prediction in highly viscous churn flows.

The results of evaluation reveal that, in terms of percentage of data points predicted, the slip ratio is a better correlation. It predicts $77.55 \%, 87.76 \%$ and $95.92 \%$ of experimental data within the $10 \%, 15 \%$ and $20 \%$ error indices, compared the $55.10 \%, 77.55 \%$ and $89.79 \%$ predicted by the drift flux correlation within the same indices. On the other hand, in terms of prediction errors, it found that the drift flux correlation $(\mathrm{RMS}=13.55)$ is better compared to the slip ratio correlation (RMS=21.24).

In terms of percentage of points predicted, within the 10\% error index, the Hibiki and Ishii (2003) (Annular) correlation is still found to be the most efficient correlation. This is followed by the proposed slip ratio correlation that of Bhagwat and Ghajar (Ghajar and Bhagwat, 2013) respectively. The proposed drift flux 
correlation is found to exhibit similar performances as the Bestion correlation. Within the $15 \%$ error index, the Bhagwat and Ghajar (Ghajar and Bhagwat, 2013) correlation presents the best performance, followed by that of Hibiki and Ishii (2003) (Annular). The proposed slip ratio and drift flux correlations occupy the third and fourth places respectively. When comparison is made within the $20 \%$ error index, it is observed that the Bhagwat and Ghajar (Ghajar and Bhagwat, 2013) correlation maintains its performance and retains the top position. The second place, however, is shared by both the Hibiki and Ishii (2003b) (Annular) and proposed slip ratio correlations while the third best performance is exhibited by the proposed drift flux correlation.

When the correlations are ranked in terms of error predictions, it is found that the Hibiki and Ishii (2003) A correlations presents the least correlation. This is followed by that of the proposed drift flux correlation and the Bhagwat and Ghajar (Ghajar and Bhagwat, 2013). The proposed slip ratio occupies the fourth position with comparatively the largest prediction error.

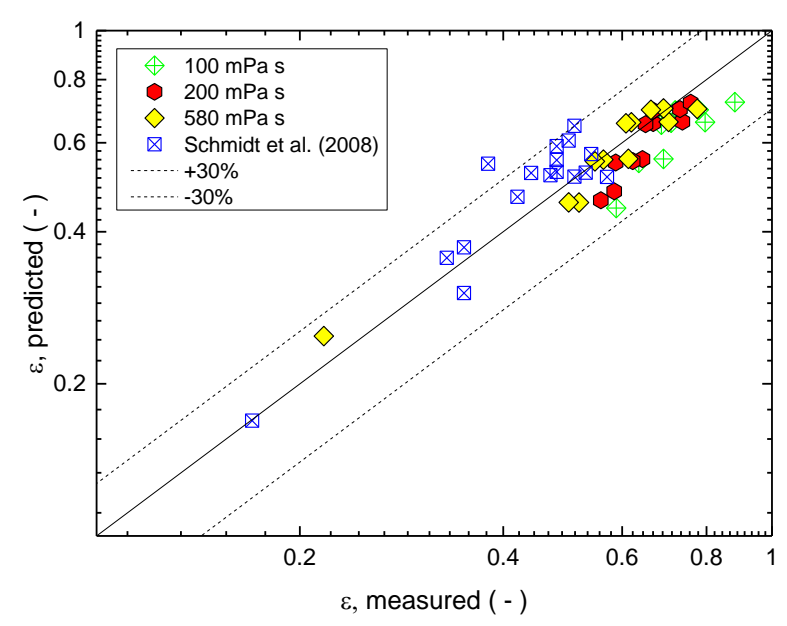

(a)

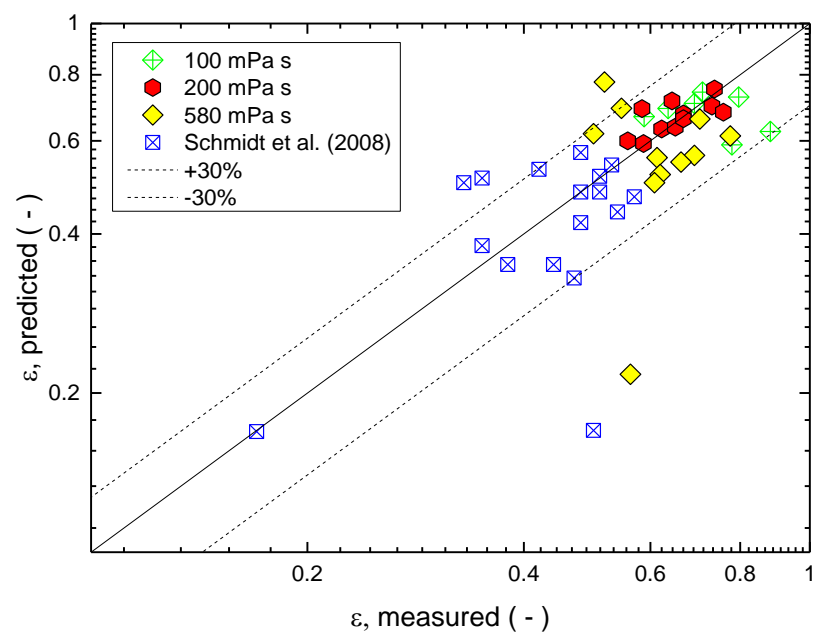

(b)

Figure 11. Performance of new correlations based on (a) drift flux and (b) slip ratio methods for highly viscous churn flow data

\subsection{Proposed correlation for prediction of gas void fraction in highly viscous annular flows}

Two correlations were also developed for the an nular flow. The previously applied methodologies were employed.

\subsubsection{Drift flux correlation}

For the development of a drift flux correlation, Equation (5) was adopted. Here, Co was estimated to be 0.9026 and $v_{d}$ obtained was 7.7333. As is noted, the $v_{d}$ value is quite high. This is normal and is 
characteristic of annular flows where generally $v_{d}=\operatorname{Fr} \sqrt{g D}, F r>1$. Substituting the values, Equation 5 becomes Eq. 11 as follows:

$$
\alpha=\frac{v_{s g}}{0.9026 v_{m}+7.7333}
$$

Evaluation of the predictions of Equation 11 is found to agree well with the experimental data (Figure 22a).

\subsubsection{Slip ratio correlation}

The slip ratio method was also employed to develop a new correlation for a correlation for gas void fraction in highly viscous annular flows. Regression analysis, using the experimental data as well as data obtained from Schmidt et al.(2008) yields the following correlation (Equation 12):

$$
\alpha=\left[1+7 \times 10^{-5}\left(\frac{1-x}{x}\right)^{0.4}\left(\frac{\rho_{g}}{\rho_{l}}\right)^{-0.363}\left(\frac{\mu_{l}}{\mu_{g}}\right)^{0.5119}\right]^{-1}
$$

It can be observed that the correlations obtained are within the range of values presented by previous authors. A comparison of the proposed correlation with the top five correlations earlier identified is presented in Table A7. A pictorial assessment is presented in Figure 22b.

Based on the results obtained, Equation 12 is proposed as a flow regime dependent correlation for prediction of gas void fraction in upward highly viscous annular flows in vertical pipes.

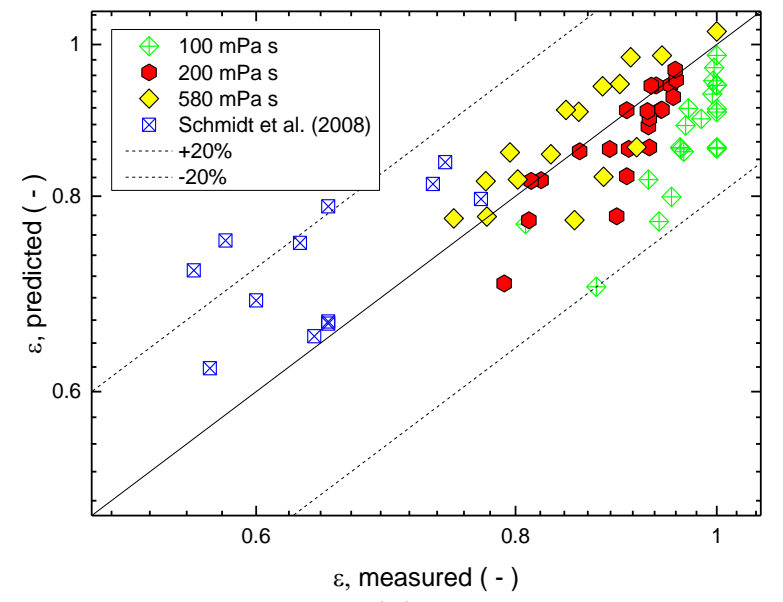

(a)

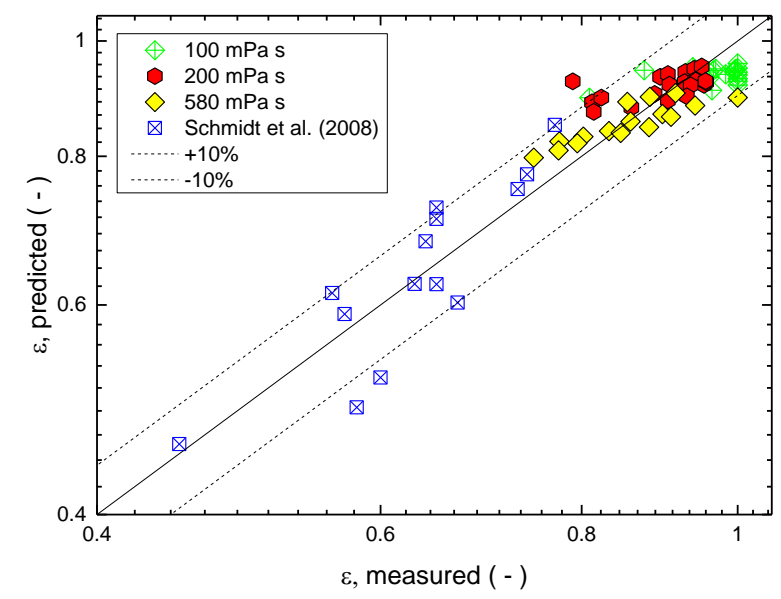

(b)

Figure 12. Performance new correlations based on (a) drift flux and (b) slip ratio methods for highly viscous annular flow data

When both correlations are compared, it is found that the slip ratio correlation better than the correlation based on the drift flux approach. The slip ratio correlation predicts at least $90 \%$ of the experimental data 
points within the $10 \%$ error index, $98.63 \%$ within the $15 \%$ error index and accurately predicts $100 \%$ of the data points when the other error indices are considered. Its predictions are also observed to be low (RMS=4.29). The drift flux model, on the other hand, predicts slightly more than $70 \%$ of the experimental data within the $10 \%$ error band, $87.67 \%$ within the $15 \%$ error index, and $96.15 \%$ and $98.63 \%$ in the $20 \%$ and $30 \%$ error index respectively with an RMS value of $6.59 \%$.

When the performance of the new correlations is made with others presented in Table A4 in the Appendix, it is found that, within the 10\% error index, the Hibiki and Ishii (2003) (Annular) presents the best performance. This is followed by the correlation presented by Ishii (1975). Finally, the third-best position is occupied by proposed slip ratio correlation (Eq.12). The proposed drift flux correlation (Eq.11) performs well but does not make it to the top three. Within the $15 \%$ error index, the slip ratio and drift flux models occupy the second and third-best performing positions respectively while the Lahey and Moody (1977) correlation occupies the fourth best performing correlation. The Hibiki and Ishii (2003) correlation remains the best within the $20 \%$ error index. However, it shares the position with the correlation by Lahey and Moody (1977) and the proposed slip correlation. The drift flux correlation, therefore occupies the second position.

In terms of prediction errors, though the prediction errors are very low, the slip ratio occupies the fourth position, with the correlations of Hibiki and Ishii (2003), Ishii (1975) and Ohkawa and Lahey (1980) correlations occupying the first, second and third positions respectively.

\section{Conclusions}

In this study, a review of gas void fraction behaviour and prediction has been carried out in this study. An experiment was carried out to obtain higher viscous data in vertical pipes. Viscosity range of the liquid used was between 100 and $580 \mathrm{mPa}$ s. The data was combined with the reported data of Schmidt et al. (2008) to extend the viscosity range for the experiment to $7000 \mathrm{mPa}$ s. The combined data was used to evaluate 100 existing gas void correlations reported in literature.

The results show that liquid viscosity significantly affects prediction of gas void fraction. Few correlations could satisfactorily predict gas void fraction data obtained using highly viscous liquids in vertical pipes. It was observed that even for some of the best performing correlations, their performances diminish with increase liquid viscosity.

Though they were developed with lower liquid viscosities, it is found that the correlations by Hibiki and Ishii (2003) and Bestion (1990) present excellent performances when they are evaluated with the overall data. 
It is noted from the onset that of the two, the Hibiki and Ishii (2003) correlation has the better performance. Further analysis, by comparison of their performance at different conditions, shows that the Hibiki and Ishii (2003) correlation remains consistent, predicting the highest number of the data points in all the error indices considered. Considering its superior performance, it is concluded that, with respect to this study, the Hibiki and Ishii (2003) correlation is the best correlation.

Based on the experimental data, two new flow-regime-dependent (drift flux and slip ratio) correlations were proposed for prediction of gas void fraction in the churn flow regime. The results showed that the predictions of both correlations agreed with experimental data. Further, the performance of the slip ratio correlation is better than that based on the drift flux approach with respect to percentage of predicted data points. The proposed drift flux correlation was found to be better in terms of prediction error. When compared to the top performing correlations, it is found that the new slip ratio correlation presents a better performance than the correlations of Bhagwat and Ghajar (Ghajar and Bhagwat, 2013) within the 10\% error index. In the $15 \%$ and $20 \%$ error index, the trend was opposite. However, its performance was similar to that of the Hibiki and Ishii correlation within the $20 \%$ error index. The performance of the proposed drift flux correlation only made it to the top three within the $20 \%$ error index. When prediction error was used as the criterion, the drift flux correlation was only second to the correlation by Hibiki and Ishii (2003). The prediction errors of the slip correlation were comparatively larger.

The same approach is employed to develop correlations for annular flow. Here, though higher performances are observed, like previously, the performance of the slip ratio correlation is found to be better than that of the drift flux correlation. Compared the top performing existing correlations, in terms of percentage of experimental data predicted, the results showed that the slip ratio correlation was second only to the correlation of Hibiki and Ishii within the $10 \%$ and $15 \%$ error indices. Within the $20 \%$ error index, its performance was similar to that of Hibiki and Ishii. The performance of the proposed drift flux equation trailed that of the proposed slip correlation.

\section{Conflict of interest}

The authors declare no conflict of interest.

\section{Nomenclature}

$C_{o} \quad$ distribution parameter

$D$ diameter (m)

$F_{r} \quad$ Froude number 


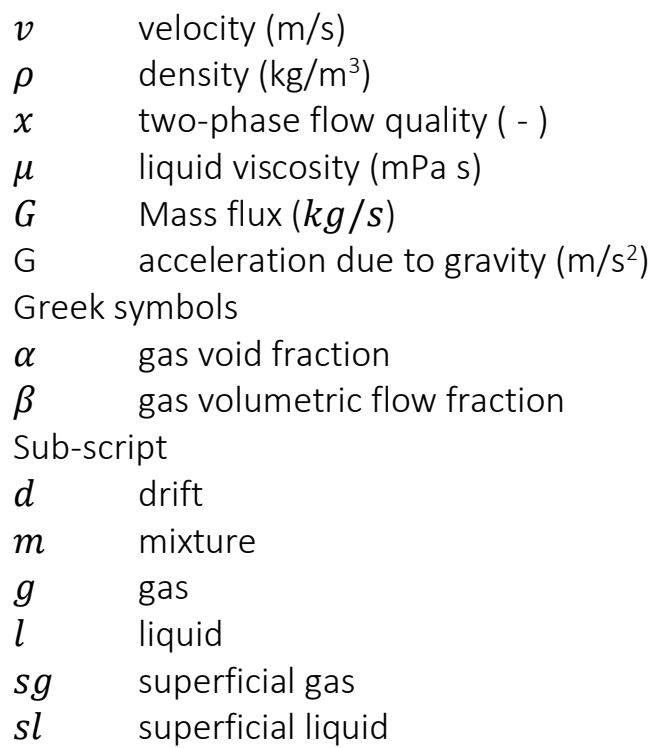

\section{Acknowledgement}

This work was supported by National Science and Technology Major Project of the Ministry of Science and

Technology of China under grant number 2017ZX05030-003-005.

\section{References}

Abdul-Majeed, G.H., 1996. Liquid holdup in horizontal two-phase gas-liquid flow. J. Pet. Sci. Eng. 15, 271280. https://doi.org/10.1016/0920-4105(95)00069-0

Abdulkadir, M., Hernandez-Perez, V., Lowndes, I.S., Azzopardi, B.J., Brantson, E.T., 2014a. Detailed analysis of phase distributions in a vertical riser using wire mesh sensor (WMS). Exp. Therm. Fluid Sci. 59, 32-42. https://doi.org/10.1016/j.expthermflusci.2014.07.010

Abdulkadir, M., Hernandez-Perez, V., Lowndes, I.S., Azzopardi, B.J., Dzomeku, S., 2014b. Experimental study of the hydrodynamic behaviour of slug flow in a vertical riser. Chem. Eng. Sci. 106, 60-75. https://doi.org/10.1016/j.ces.2013.11.021

Agrawal, S.S., Gregory, G.A., Gorier, G.W., 1973. An analysis of horizontal stratified two- phase flow in pipes. Can. J. Chem. Eng. 51, 280-286.

Ahmadi, M.A., Shadizadeh, S.R., Shah, K., Bahadori, A., 2016. An accurate model to predict drilling fluid density at wellbore conditions. Egypt. J. Pet. 1-10. https://doi.org/10.1016/j.ejpe.2016.12.002

Ahmadi, M.A., Zendehboudi, S., James, L.A., Elkamel, A., Dusseault, M., Chatzis, I., Lohi, A., 2014. New tools to determine bubble point pressure of crude oils: Experimental and modeling study. J. Pet. Sci. Eng. 123, 207-216. https://doi.org/10.1016/j.petrol.2014.08.018

Al-Naser, M., Elshafei, M., Al-Sarkhi, A., 2016. Artificial neural network application for multiphase flow patterns detection: A new approach. J. Pet. Sci. Eng. 145, 548-564. https://doi.org/10.1016/j.petrol.2016.06.029

Al-Ruhaimani, F., Pereyra, E., Sarica, C., Al-Safran, E.M., Torres, C.F., 2017. Experimental Analysis and Model Evaluation of High-Liquid-Viscosity Two-Phase Upward Vertical Pipe Flow. SPE J. 22, 0712- 
0735. https://doi.org/10.2118/184401-PA

Alamu, M.B., 2010. Investigation of periodic structures in gas-liquid flow. (Ph.D thesis). University of Nottingham.

Ali Ahmadi, M., Golshadi, M., 2012. Neural network based swarm concept for prediction asphaltene precipitation due to natural depletion. J. Pet. Sci. Eng. 98-99, 40-49. https://doi.org/10.1016/j.petrol.2012.08.011

Aliyu, A.M., Baba, Y.D., Lao, L., Yeung, H., Kim, K.C., 2017. Interfacial friction in upward annular gas-liquid two-phase flow in pipes. Exp. Therm. Fluid Sci. 84, 90-109. https://doi.org/10.1016/j.expthermflusci.2017.02.006

Almabrok, A.A., Aliyu, A.M., Lao, L., Yeung, H., 2016. Gas/liquid flow behaviours in a downward section of large diameter vertical serpentine pipes. Int. J. Multiph. Flow 78, 25-43. https://doi.org/10.1016/j.ijmultiphaseflow.2015.09.012

Ambrose, S., 2015. the Rise of Taylor Bubbles in Vertical Pipes.

Ariadji, T., Haryadi, F., Rau, I.T., Aziz, P.A., Dasilfa, R., 2014. A novel tool for designing well placements by combination of modified genetic algorithm and artificial neural network. J. Pet. Sci. Eng. 122, 69-82. https://doi.org/10.1016/j.petrol.2014.05.018

Ashena, R., Moghadasi, J., 2011. Bottom hole pressure estimation using evolved neural networks by real coded ant colony optimization and genetic algorithm. J. Pet. Sci. Eng. 77, 375-385. https://doi.org/10.1016/j.petrol.2011.04.015

Ayegba, P.O., Abdulkadir, M., Hernandez-Perez, V., Lowndes, I.S., Azzopardi, B.J., 2017. Applications of artificial neural network (ANN) method for performance prediction of the effect of a vertical $90^{\circ}$ bend on an air-silicone oil flow. J. Taiwan Inst. Chem. Eng. 74, 59-64. https://doi.org/10.1016/j.jtice.2017.02.005

Azizi, S., Ahmadloo, E., Awad, M.M., 2016a. Prediction of void fraction for gas-liquid flow in horizontal, upward and downward inclined pipes using artificial neural network. Int. J. Multiph. Flow 87, 35-44. https://doi.org/10.1016/j.ijmultiphaseflow.2016.08.004

Azizi, S., Awad, M.M., Ahmadloo, E., 2016b. Prediction of water holdup in vertical and inclined oil-water two-phase flow using artificial neural network. Int. J. Multiph. Flow 80, 181-187. https://doi.org/10.1016/j.ijmultiphaseflow.2015.12.010

Azizi, S., Karimi, H., 2015. An Artificial Neural Network Model for Predicting the Pressure Gradient in Horizontal Oil - Water Separated Flow 49, 131-141.

Baorczy, C.J., 1966. A systematic correlation for two-phase pressure drop, in: Chemical Engineering Progress Symposium Series. pp. 232-249.

Bar, N., Bandyopadhyay, T.K., Biswas, M.N., Das, S.K., 2010. Prediction of pressure drop using artificial neural network for non-Newtonian liquid flow through piping components. J. Pet. Sci. Eng. 71, 187194. https://doi.org/10.1016/j.petrol.2010.02.001

Barnea, D., 1987. A unified model for predicting flow-pattern transitions for the whole range of pipe inclinations. Int. J. Multiph. Flow 13, 1-12. https://doi.org/10.1016/0301-9322(87)90002-4

Bashiri, M., Farshbaf Geranmayeh, A., 2011. Tuning the parameters of an artificial neural network using central composite design and genetic algorithm. Sci. Iran. 18, 1600-1608. https://doi.org/10.1016/j.scient.2011.08.031 
Beggs, H.D., 1972. An experimental study of two-phase flow in inclined pipes (Ph. D. Dissertation),. University of Tulsa, Tulsa, USA. https://doi.org/10.1243/PIME

Berna, C., Escrivá, A., Muñoz-Cobo, J.L., Herranz, L.E., 2014. Review of droplet entrainment in annular flow: Interfacial waves and onset of entrainment. Prog. Nucl. Energy 74, 14-43. https://doi.org/10.1016/j.pnucene.2014.01.018

Bestion, D., 1990. The physical closure laws in the CATHARE code. Nucl. Eng. Des. 124, 229-245. https://doi.org/10.1016/0029-5493(90)90294-8

Bhagwat, S.M. (Oklahom. S.U., 2011a. STUDY OF FLOW PATTERNS AND VOID FRACTION IN VERTICAL DOWNWARD TWO PHASE FLOW, (Masters' thesis). Oklahoma State University, USA.

Bhagwat, S.M. (Oklahom. S.U., 2011b. Study of Flow Patterns and Void Fraction in Vertical Downward Two Phase Flow.

Bhagwat, S.M., Ghajar, A.J., 2014. A flow pattern independent drift flux model based void fraction correlation for a wide range of gas-liquid two phase flow. Int. J. Multiph. Flow 59. https://doi.org/10.1016/j.ijmultiphaseflow.2013.11.001

Bhagwat, S.M., Ghajar, A.J., 2012. Similarities and differences in the flow patterns and void fraction in vertical upward and downward two phase flow. Exp. Therm. Fluid Sci. 39, 213-227. https://doi.org/10.1016/j.expthermflusci.2012.01.026

Bonnecaze, R.H., Erskine, W., Greskovich, E.J., 1971. Holdup and pressure drop for two-phase slug flow in inclined pipelines. AIChE J. 17, 1109-1113. https://doi.org/10.1002/aic.690170516

Boostani, M., Karimi, H., Azizi, S., 2017. Heat transfer to oil-water flow in horizontal and inclined pipes: Experimental investigation and ANN modeling. Int. J. Therm. Sci. 111, 340-350. https://doi.org/10.1016/j.ijthermalsci.2016.09.005

Caetano, E.F., Shoham, O., Brill, J.P., 1992. Upward Vertical Two-Phase Flow Through an Annulus-Part I: Single-Phase Friction Factor, Taylor Bubble Rise Velocity, and Flow Pattern Prediction. J. Energy Resour. Technol. 114, 1. https://doi.org/10.1115/1.2905917

Chawla, J.M., 1969. Liquid content in pipes in two-phase flow of gas liquid mixtures. Chem. Eng. Technol. 41, 328-330. https://doi.org/10.1243/PIME

Chen, J.J.J., 1986. A further examination of void fraction in annular two-phase flow. Int. J. Heat Mass Transf. 29, 1760-1763. https://doi.org/10.1016/0017-9310(86)90116-X

Chexal, B., Lellouche, G., Horowitz, J., Healzer, J., 1992. A void fraction correlation for generalized applications. Prog. Nucl. Energy 27, 255-295. https://doi.org/10.1016/0149-1970(92)90007-P

Cioncolini, A., Thome, J.R., 2012. Void fraction prediction in annular two-phase flow. Int. J. Multiph. Flow 43, 72-84. https://doi.org/10.1016/j.ijmultiphaseflow.2012.03.003

Coddington, P., Macian, R., 2002. A study of the performance of void fraction correlations used in the context of drift-flux two-phase flow models. Nucl. Eng. Des. 215, 199-216. https://doi.org/10.1016/S0029-5493(01)00503-9

Czop, V., Barbier, D., Dong, S., 1994. Pressure drop, void fraction and shear stress measurements in an adiabatic two-phase flow in a coiled tube. Nucl. Eng. Des. 149, 323-333. https://doi.org/10.1016/0029-5493(94)90298-4

Diener, R., Friedel, L., 1998. Reproductive accuracy of selected void fraction correlations for horizontal and vertical upflow. Forsch. im Ingenieurwesen/Engineering Res. 64, 87-97. 
https://doi.org/10.1007/PL00010768

Dimentiev, A., Lepilin, R.S., Loginov, A.A., 1959. An investigation of hydrodynamic process of bubbling through a vapor liquid mixture of considerable height. Nauch. Dokl. Vish. Shkol-Energetica 2, 251.

Dix, G.., 1971. Vapor void fractions for forced convection with subcooled boiling at low flow rates, NEDO10491.

Dukler, A.E., Wicks, M., and Cleveland, R.G., 1964. Pressure drop and hold-up in two-phase flow Part A: A comparison of existing correlations Part B: An approach through similarity analysis. AIChE J.

Dukler, A.E., Wicks, M.I., Baker, O., Hubbard, M.G., Cleveland, R.G., 1969. Gas liquid flow in pipelines, I. Research Results. Monograph prepared on project NX-28 at The University of Houston for the American Gas Association, Inc., and the American Petroleum Institute, AGA Catalog No. L20169, New York.

Eaton, B.., 1966. The prediction of flow patterns, liquid holdup and pressure losses occurring during continuous two-phase flow in horizontal pipelines (PhD Dissertation),. The University of Texas, Austin, USA. https://doi.org/10.1243/PIME

Eaton, B.A., Knowles, C.R., Silberbrg, I.H., others, 1967. The prediction of flow patterns, liquid holdup and pressure losses occurring during continuous two-phase flow in horizontal pipelines. J. Pet. Technol. 19, 815-828. https://doi.org/10.2118/1525-PA

El-Sebakhy, E.A., 2009. Forecasting PVT properties of crude oil systems based on support vector machines modeling scheme. J. Pet. Sci. Eng. 64, 25-34. https://doi.org/10.1016/j.petrol.2008.12.006

Ellis, J.E., Jones, E.L., 1965. Symposium on Two-phase Flow, p. B101, June 21-23, Exter, England.

Emera, M.K., Sarma, H.K., 2005. Use of genetic algorithm to estimate CO2-oil minimum miscibility pressure - A key parameter in design of CO2 miscible flood. J. Pet. Sci. Eng. 46, 37-52. https://doi.org/10.1016/j.petrol.2004.10.001

Fauske, H., 1961. Critical Two-phase, Steam-water Flows, Proceedings of the 1961 Heat Transfer \& Fluid Mechanics Institute, pp. 79-89, Stanford University Press, Stanford, California.

Feili Monfared, A.E., Ranjbar, M., Nezamabadi-Pour, H., Schaffie, M., Ashena, R., 2011. Substantial improvement of the bottom-hole circulating pressure prediction by the combination of $G A$ and ANFIS. Energy Sources, Part A Recover. Util. Environ. Eff. 33, 2272-2280. https://doi.org/10.1080/15567036.2011.590849

Fernandes, R.C., Semiat, R., Dukler, A.E., 1983. Hydrodynamic model for gas-liquid slug flow in vertical tubes. AIChE J. 29, 981-989. https://doi.org/10.1002/aic.690290617

Flanigan, O., 1958. Effect of uphill flow on pressure drop in design of two-phase gathering systems. Oil Gas J. 56, 132-141.

Fore, L.B., Dukler, A.E., 1995. Droplet deposition and momentum transfer in annular flow. AIChE J. 41, 2040-2046. https://doi.org/10.1002/aic.690410904

Fukano, T., Furukawa, T., 1998. Prediction of the Effect of Liquid Viscosity on Interfacial Shear Stress and Frictional Pressure Drop in Vertical Upward Gas Liquid Annular Flow. Int. J. Multiph. Flow 24, 587603.

Ghajar, A.J., Bhagwat, S.M., 2013. Effect of void fraction and two-phase dynamic viscosity models on prediction of hydrostatic and frictional pressure drop in vertical upward gas-liquid two-phase flow. Heat Transf. Eng. 34, 1044-1059. https://doi.org/10.1080/01457632.2013.763541 
Gharbi, R.B.C., Mansoori, G.A., 2005. An introduction to artificial intelligence applications in petroleum exploration and production. J. Pet. Sci. Eng. 49, 93-96. https://doi.org/10.1016/j.petrol.2005.09.001

Godbole, P.V., 2009. Study of Flow Patterns and Void Fractions in Vertical Upward Two-Phase Flow, (Masters' thesis). Oklahoma State University, USA.

Godbole, P. V., Tang, C.C., Ghajar, A.J., 2011. Comparison of void fraction correlations for different flow patterns in upward vertical two-phase flow. Heat Transf. Eng. 32, 843-860. https://doi.org/10.1080/01457632.2011.548285

Gomez, L.E., Shoham, O., Schmidt, Z., Tulsa, U., Chokshi, R.N., Co, Z.E.T.X., Northug, T., 2000. Horizontal to Vertical Upward Flow 5-8.

Gregory, G.A., Scott, D.S., 1969. Correlation of liquid slug velocity and frequency in horizontal cocurrent gas-liquid slug flow. AIChE J. 15, 933-935. https://doi.org/10.1002/aic.690150623

Guner, M., 2012. Liquid Loading of Gas Wells with Deviations from $0^{\circ}$ to $45^{\circ}$ (M.Sc thesis). McDougall School of Petroleum Engineering, University of Tulsa, USA.

Guzhov, A.L., Mamayev, V.A., Odishariya, G.E., 1967. A Study of Transportation in Gas Liquid Systems, in: 10th International Gas Union Conference, Hamburg, Germany, June 6-10. https://doi.org/10.1243/PIME

Hamidi, M.J., Karimi, H., Boostani, M., 2018. Flow patterns and heat transfer of oil-water two-phase upward flow in vertical pipe. Int. J. Therm. Sci. 127, 173-180. https://doi.org/10.1016/j.ijthermalsci.2018.01.020

Harmathy, T.Z., 1960. Velocity of large drops and bubbles in media of infinite or restricted extent. AIChE J. 6, 281-288. https://doi.org/10.1002/aic.690060222

Hart, J., Hamersma, P.J., Fortuin, J.M.H., 1989. Correlations predicting frictional pressure drop and liquid holdup during horizontal gas-liquid pipe flow with a small liquid holdup. Int. J. Multiph. Flow 15, 947964. https://doi.org/10.1016/0301-9322(89)90023-2

Hasan, A.R., Kabir, C.S., 1988. A Study of Multiphase Flow Behavior in Vertical Wells. SPE Prod. Eng. 3, 263-272. https://doi.org/10.2118/15138-PA

Hernandez Perez, V., Azzopardi, B.J., Kaji, R., da Silva, M.J., Beyer, M., Hampel, U., 2010. Wisp-like structures in vertical gas-liquid pipe flow revealed by wire mesh sensor studies. Int. J. Multiph. Flow 36, 908-915. https://doi.org/10.1016/j.ijmultiphaseflow.2010.08.002

Hewakandamby, B.N., Kanu, A.U., Kouba, G., Azzopardi, B.J., 2014. FEDSM2014-21314, in: Proceedings of the ASME 2014 4th Joint US-European Fluids Engineering Division Summer Meeting FEDSM2014 August 3-7, 2014, Chicago, Illinois, USA. pp. 1-8.

Hibiki, T., Ishii, M., 2003a. One-dimensional drift-flux model and constitutive equations for relative motion between phases in various two-phase flow regimes. Int. J. Heat Mass Transf. 46, 4935-4948. https://doi.org/10.1016/S0017-9310(03)00322-3

Hibiki, T., Ishii, M., 2003b. One-demensional drift-flux model for two-phase flow in a large diameter pipe. Int. J. Heat Mass Transf. https://doi.org/10.1016/S0017-9310(02)00473-8

Hoogendoorn, C.J., 1959. Gas-liquid flow in horizontal pipes. Chem. Eng. Sci. 9, 205-217. https://doi.org/10.1016/0009-2509(59)85003-X

Hughmark, G.A., 1965. Holdup and heat transfer in horizontal slug gas-liquid flow. Chem. Eng. Sci. 20, 1007-1010. https://doi.org/10.1016/0009-2509(65)80101-4 
Hughmark, G.A., 1962. Holdup in gas liquid flow. Chem. Eng. Prog. 58, 62-65.

Isao, K., Mamoru, I., 1987. Drift flux model for large diameter pipe and new correlation for pool void fraction. Int. J. Heat Mass Transf. 30, 1927-1939. https://doi.org/10.1016/0017-9310(87)90251-1

Ishii, M., 1975. Thermo-fluid dynamic theory of two-phase flow, NASA STI/Recon Technical Report A, 75, p.29657. https://doi.org/10.1243/PIME

Jafari, S.A., Mashohor, S., Varnamkhasti, M.J., 2011. Committee neural networks with fuzzy genetic algorithm. J. Pet. Sci. Eng. 76, 217-223. https://doi.org/10.1016/j.petrol.2011.01.006

Jones, O.C., Zuber, N., 1975. The interrelation between void fraction fluctuations and flow patterns in twophase flow. Int. J. Multiph. Flow 2, 273-306. https://doi.org/10.1016/0301-9322(75)90015-4

Jowitt, D., Cooper, C.A., Pearson, K.G., 1984. The THETIS 80\% Blocked Cluster Experiment, Part 5: Level Swell Experiments, AEEW-R 1767, AEEE Winfrith, Safety and Engineering Science Division, Winfrith UK.

Kabir, C.S., Hasan, A.R., 1990. Performance of a two-phase gas/liquid flow model in vertical wells. J. Pet. Sci. Eng. 4, 273-289. https://doi.org/10.1016/0920-4105(90)90016-V

Kawanishi, K., Hirao, Y., Tsuge, A., 1990. An experimental study on drift flux parameters for two-phase flow in vertical round tubes. Nucl. Eng. Des. 120, 447-458. https://doi.org/10.1016/00295493(90)90394-D

Kim, T.W., Aydin, T.B., Pereyra, E., Sarica, C., 2018. International Journal of Multiphase Flow Detailed flow field measurements and analysis in highly viscous slug flow in horizontal pipes. Int. J. Multiph. Flow 106, 75-94. https://doi.org/10.1016/j.ijmultiphaseflow.2018.05.005

Kora, P., Rama Krishna, K.S., 2016. Hybrid firefly and Particle Swarm Optimization algorithm for the detection of Bundle Branch Block. Int. J. Cardiovasc. Acad. 2, 44-48. https://doi.org/10.1016/j.ijcac.2015.12.001

Kora, P., Sri Rama Krishna, K., 2016. Detection of Bundle Branch Block using Bat algorithm and Levenberg Marquardt Neural Network. Smart Innov. Syst. Technol. 50, 553-561. https://doi.org/10.1007/9783-319-30933-0_55

Lahey, R.T., Moody, F.J., 1977. The thermal-hydraulics of a boiling water nuclear reactor, ANS monograph.

Levy, S., 1960. Steam Slip-Theoretical Prediction From Momentum Model. J. Heat Transfer 82, 113. https://doi.org/10.1115/1.3679890

Li, X., Miskimins, J.L., Sutton, R.P., Hoffman, B.T., 2014. Multiphase Flow Pattern Recognition in Horizontal and Upward Gas-Liquid. SPE.

Lockhart, R.W., Martinelli, R.C., 1949. Proposed correlation of data for isothermal two-phase, twocomponent flow in pipes. Chem. Eng. Prog. 45, 39-48. https://doi.org/10.1243/PIME

Malayeri, M.R., Müller-Steinhagen, H., Smith, J.M., 2003. Neural network analysis of void fraction in air/water two-phase flows at elevated temperatures. Chem. Eng. Process. Process Intensif. 42, 587597. https://doi.org/10.1016/S0255-2701(02)00208-8

Mandhane, J.M., Gregory, G.A., Aziz, K., 1975. Critical Evaluation of Holdup Prediction Methods for GasLiquid Flow in Horizontal Pipes. J. Pet. Technol. 27, 1017-1026. https://doi.org/10.2118/5140-PA

Mao, Z.S., Dukler, A.E., 1993. The myth of churn flow? Int. J. Multiph. Flow 19, 377-383. https://doi.org/10.1016/0301-9322(93)90010-R 
Marcano, N.I., 1973. Comparison of liquid holdup correlations for gas-liquid flow in horizontal pipes (MS Thesis),. The University of Tulsa, Tulsa, OK, USA. https://doi.org/10.1243/PIME

Mathure, N., 2010. STUDY OF FLOW PATTERNS AND VOID FRACTION IN HORIZONTAL TWO-PHASE FLOW ,(Masters' thesis). Oklahoma State University, USA.

Mattar, L., Gregory, G.A., 1974. Air-Oil Slug Flow In an Upward-Inclined Pipe - I: Slug Velocity, Holdup And Pressure Gradient. J. Can. Pet. Technol. 13, 69-76. https://doi.org/10.2118/74-01-07

McNeil, D.A., Stuart, A.D., 2003. The effects of a highly viscous liquid phase on vertically upward twophase flow in a pipe. Int. J. Multiph. Flow 29, 1523-1549. https://doi.org/10.1016/S03019322(03)00122-8

Mishima, K., Hibiki, T., 1996. Some characteristics of air-water two-phase flow in small diameter vertical tubes. Int. J. Multiph. Flow 22, 703-712.

Mohammadi, M., 2006. A Comprehensive Neural Network Model for Predicting Two-Phase Liquid Holdup Under Various Angles of Pipe Inclinations, in: Canadian International Petroleum Conference. Petroleum Society of Canada, pp. 1-9. https://doi.org/10.2118/2006-048

Mohammed, S.K., Hasan, A., Dimitrakis, G., Azzopardi, B.J., 2018. Churn flow in high viscosity oils and large diameter columns. Int. J. Multiph. Flow 100, 16-29. https://doi.org/10.1016/j.ijmultiphaseflow.2017.11.018

Morooka, S., Ishizuka, T., lizuka, M., Yoshimura, K., 1989. Experimental study on void fraction in a simulated BWR fuel assembly (evaluation of cross-sectional averaged void fraction). Nucl. Eng. Des. 114, 91-98. https://doi.org/10.1016/0029-5493(89)90128-3

Nicklin, D., Wilkes, J., Davidson, J., 1962. Two-phase flow in vertical tubes. Trans. Am. Inst. Chem. Eng. 40, 61-68.

Nobakht Hassanlouei, R., Firouzfar, H., Kasiri, N., Khanof, M.H., 2012. A simple mathematical model for slug liquid holdup in horizontal pipes. Sci. Iran. 19, 1653-1660. https://doi.org/10.1016/j.scient.2012.05.010

Oddie, G., Shi, H., Durlofsky, L.J., Aziz, K., Pfeffer, B., Holmes, J.A., 2003. Experimental study of two and three phase flows in large diameter inclined pipes. Int. J. Multiph. Flow 29, 527-558. https://doi.org/10.1016/S0301-9322(03)00015-6

Osman, E.A., 2004. Artificial Neural Network Models for Identifying Flow Regimes and Predicting Liquid Holdup in Horizontal Multiphase Flow. SPE Prod. Facil. 19, 33-40. https://doi.org/10.2118/86910PA

Osman, E.A., 2001. Artificial Neural Networks Models for Identifying Flow Regimes and Predicting Liquid Holdup in Horizontal Multiphase Flow, in: SPE Middle East Oil Show. Society of Petroleum Engineers, pp. 17-20. https://doi.org/10.2118/68219-MS

Oyewole, A.L., 2013. STUDY OF FLOW PATTERNS AND VOID FRACTION IN INCLINED TWO PHASE FLOW , (Masters' thesis). Oklahoma State University.

Palmer, C.M., 1975. Evaluation of inclined pipe two-phase liquid holdup correlations using experimental data (MS Thesis),. The University of Tulsa, Tulsa, OK, USA. https://doi.org/10.1243/PIME

Parrales, A., Colorado, D., Díaz-Gómez, J.A., Huicochea, A., Álvarez, A., Hernández, J.A., 2018. New void fraction equations for two-phase flow in helical heat exchangers using artificial neural networks. Appl. Therm. Eng. 130, 149-160. https://doi.org/10.1016/j.applthermaleng.2017.10.139 
Parsi, M., Vieira, R.E., Torres, C.F., Kesana, N.R., McLaury, B.S., Shirazi, S.A., Schleicher, E., Hampel, U., 2015a. On the effect of liquid viscosity on interfacial structures within churn flow: Experimental study using wire mesh sensor. Chem. Eng. Sci. 130, 221-238. https://doi.org/10.1016/j.ces.2015.03.033

Parsi, M., Vieira, R.E., Torres, C.F., Kesana, N.R., McLaury, B.S., Shirazi, S.A., Schleicher, E., Hampel, U., 2015b. On the effect of liquid viscosity on interfacial structures within churn flow: Experimental study using wire mesh sensor. Chem. Eng. Sci. 130, 221-238. https://doi.org/10.1016/j.ces.2015.03.033

Peddu, A., Chakraborty, S., Kr. Das, P., 2018. Visualization and flow regime identification of downward airwater flow through a $12 \mathrm{~mm}$ diameter vertical tube using image analysis. Int. J. Multiph. Flow 100, 1-15. https://doi.org/10.1016/j.ijmultiphaseflow.2017.11.016

Premoli, A., Francesco, D., Prima, A., 1970. An empirical correlation for evaluating two-phase mixture density under adiabatic conditions, European Two-Phase Flow Group Meeting, Milan.

Ribeiro, J.X.F., Liao, R., Aliyu, A.M., Liu, Z., 2019a. Prediction of Pressure Gradient in Two and Three-Phase Flows in Vertical Pipes Using an Artificial Neural Network Model. Int. J. Eng. Technol. Innov. 9, 155170.

Ribeiro, J.X.F., Liao, R., Aliyu, A.M., Luo, W., Liu, Z., 2019b. Experimental study of horizontal two- and three-phase flow characteristics at low to medium liquid loading conditions. Heat Mass Transf. https://doi.org/10.1007/s00231-019-02616-y

Rouhani, S.Z., Axelsson, E., 1970. Calculation of void volume fraction in the subcooled and quality boiling regions. Int. J. Heat Mass Transf. 13, 383-393. https://doi.org/10.1016/0017-9310(70)90114-6

Saemi, M., Ahmadi, M., Varjani, A.Y., 2007. Design of neural networks using genetic algorithm for the permeability estimation of the reservoir. J. Pet. Sci. Eng. 59, 97-105. https://doi.org/10.1016/j.petrol.2007.03.007

Schmidt, J., Giesbrecht, H., van der Geld, C.W.M., 2008. Phase and velocity distributions in vertically upward high-viscosity two-phase flow. Int. J. Multiph. Flow 34, 363-374. https://doi.org/10.1016/j.ijmultiphaseflow.2007.10.013

Scott, D.S., 1962. Void fraction in horizontal co current gas liquid flow. Can. J. Chem. Eng. 40, 224-230.

Sharaf, S., van der Meulen, G.P., Agunlejika, E.O., Azzopardi, B.J., 2016. Structures in gas-liquid churn flow in a large diameter vertical pipe. Int. J. Multiph. Flow 78, 88-103. https://doi.org/10.1016/j.ijmultiphaseflow.2015.09.005

Shearer, C.J., Nedderman, R.M., 1965. Pressure gradient and liquid film thickness in co-current upwards flow of gas/liquid mixtures: Application to film-cooler design. Chem. Eng. Sci. 20, 671-683. https://doi.org/10.1016/0009-2509(65)80004-5

Shippen, M.E., Scott, S.L., 2004. A neural network model for prediction of liquid holdup in two-phase horizontal flow. Spe Prod. Facil. 19, 67-76.

Skopich, A., Pereyra, E., Sarica, C., Kelkar, M., 2015. Pipe-Diameter Effect on Liquid Loading in Vertical Gas Wells. SPE Prod. Oper. 30, 164-176. https://doi.org/10.2118/164477-PA

Smith, S.L., 1969. Void fractions in two-phase flow: a correlation based upon an equal velocity head model, in: Proceedings of the Institute Mechanical Engineers, London. pp. 647-657.

Sowinski, J., Dziubinski, M., 2007. The effect of liquid viscosity on the void fraction in a two- phase gas- 
liquid flow in narrow mini-channels. Proc. Eur. Congr. Chem. Eng. 16-20.

Spedding, P.L., 1997. Holdup prediction in vertical upwards to downwards flow. Dev. Chem. Eng. Miner. Process. 5, 43-60.

Spedding, P.L., Chen, J.J.., 1984. Holdup in two phase flow. Int. J. Multiph. Flow 10.

Spedding, P.L., Chen, J.J.., 1979. Data on holdup, pressure loss and flow pattern in a horizontal tube. University of Auckland Report, Report Eng. 214, Auckland, New Zealand.

Spedding, P.L., Ferguson, M.E.., 1993. Data on horizontal and inclined \pm 50 , co-current, two phase gasliquid flow, Queen's University Belfast Report CE/1/93, Northern Ireland, UK.

Spedding, P.L., Hand, N.., 1991. Gas-liquid co-current flow data in horizontal pipes at atmospheric pressure, Queen's University Belfast Report CE/1/91, Northern Ireland, UK.

Spedding, P.L., Hand, N.P., Spence, D.R., 1989. Data on horizontal, co current, two phase gas-liquid flows, Queen's University Belfast, Report CE/1/89, Northern Ireland, UK.

Spedding, P.L., Nguyen, V.T., 1976. Data on holdup, pressure loss and flow patterns for two-phase airwater flow in an inclined pipe. University of Auckland, Report Eng. 122, Auckland, New Zealand. https://doi.org/10.1243/PIME

Sylvester, N.D., 1987. A Mechanistic Model for Two-Phase Vertical Slug Flow in Pipes. J. Energy Resour. Technol. 109, 206. https://doi.org/10.1115/1.3231348

Szalinski, L., Abdulkareem, L.A., Da Silva, M.J., Thiele, S., Beyer, M., Lucas, D., Hernandez Perez, V., Hampel, U., Azzopardi, B.J., 2010. Comparative study of gas-oil and gas-water two-phase flow in a vertical pipe. Chem. Eng. Sci. 65, 3836-3848. https://doi.org/10.1016/j.ces.2010.03.024

Taitel, Y., Bornea, D., Dukler, A., 1980. Modelling Flow Pattern Transitions for Steady Upward Gas-Liquid Flow in Vertical Tubes. AIChE J. 26, 345-354. https://doi.org/10.1002/aic.690260304

Taitel, Y., Dukler, A.E., 1976. A theoretical approach to the Lockhart-Martinelli correlation for stratified flow. Int. J. Multiph. Flow 2, 591-595. https://doi.org/10.1016/0301-9322(76)90019-7

Takeuchi, K., Young, M.Y., Hochreiter, L.E., 1992. Generalized Drift Flux Correlation for Vertical Flow. Nucl. Sci. Eng. 112, 170-180. https://doi.org/10.13182/NSE112-170

Tang, C.C., Tiwari, S., Ghajar, A.J., 2013. Effect of Void Fraction on Pressure Drop in Upward Vertical TwoPhase Gas-Liquid Pipe Flow. J. Eng. Gas Turbines Power 135, 022901. https://doi.org/10.1115/1.4007762

Tengesdal, J. Ф., Kaya, A.S., Sarica, C., 1999. Flow-Pattern Transition and Hydrodynamic Modeling of Churn Flow. SPE J. 4, 342-348. https://doi.org/10.2118/57756-PA

Ternyik, J., Bilgesu, H.I., Mohaghegh, S., 1995. Virtual Measurement in Pipes: Part 2-Liquid Holdup and Flow Pattern Correlations, in: SPE Eastern Regional Meeting. Society of Petroleum Engineers, Richardson, Texas, pp. 35-44. https://doi.org/10.2118/30976-MS

Thom, J.R.S., Street, H., 1964. J. R. S. THOM Babcock \& Wilcox Ltd., Research Station, High Street, Renfrew, Scotland (Received $16 \mathrm{c}$.

Turner, J.M., Wallis, G.B., 1965. The Separate-Cylinders Model of Two-Phase Flow, Paper No. NYO- 31146, Thayer's School Eng., Dartmouth College, Hanover, NH, USA.

Van der Meulen, G.P., 2012. Churn-annular gas-liquid flows in large diameter vertical pipes (Ph.D thesis). University of Nottingham. 
Velez-Langs, O., 2005. Genetic algorithms in oil industry: An overview. J. Pet. Sci. Eng. 47, 15-22. https://doi.org/10.1016/j.petrol.2004.11.006

Vieira, R.E., Parsi, M., Torres, C.F., McLaury, B.S., Shirazi, S.A., Schleicher, E., Hampel, U., 2015. Experimental characterization of vertical gas-liquid pipe flow for annular and liquid loading conditions using dual Wire-Mesh Sensor. Exp. Therm. Fluid Sci. 64, 81-93. https://doi.org/10.1016/j.expthermflusci.2015.02.007

Vijayan, P.K., Patil, A.P., Pilkhwal, D.S., Saha, D., Venkat Raj, V., 2000. Assessment of pressure drop and void fraction correlations with data from two-phase natural circulation loops. Heat Mass Transf. und Stoffuebertragung 36, 541-548. https://doi.org/10.1007/s002310000108

Wallis, G.B., 1969. One-Dimensional Two-phase Flow. McGraw Hill, New York.

Woldesemayat, M.A., 2006. Comparison of void fraction correlations for two-phase flow in horizontal and upward inclined flows, (MS Thesis),. Oklahoma State University, Stillwater, Oklahoma, USA.

Woldesemayat, M.A., Ghajar, A.J., 2007. Comparison of void fraction correlations for different flow patterns in horizontal and upward inclined pipes. Int. J. Multiph. Flow 33, 347-370. https://doi.org/10.1016/j.ijmultiphaseflow.2006.09.004

Wongwises, S., Kongkiatwanitch, W., 2001. Interfacial friction factor in vertical upward gas-liquid annular two-phase flow. Int. Commun. Heat Mass Transf. 28, 323-336. https://doi.org/10.1016/S07351933(01)00238-X

Wu, B., Firouzi, M., Mitchell, T., Rufford, T.E., Leonardi, C., Towler, B., 2017. A critical review of flow maps for gas-liquid flows in vertical pipes and annuli. Chem. Eng. J. 326, 350-377. https://doi.org/10.1016/j.cej.2017.05.135

Xue, Y., Cheng, L., Mou, J., Zhao, W., 2014. A new fracture prediction method by combining genetic algorithm with neural network in low-permeability reservoirs. J. Pet. Sci. Eng. 121, 159-166. https://doi.org/10.1016/j.petrol.2014.06.033

Xue, Y., Li, H., Hao, C., Yao, C., 2016. Investigation on the void fraction of gas-liquid two-phase flows in vertically-downward pipes. Int. Commun. Heat Mass Transf. 77, 1-8. https://doi.org/10.1016/j.icheatmasstransfer.2016.06.009

YAMAGUCHI, K., YAMAZAKI, Y., 1982. Characteristics of Counter current Gas-Liquid Two-Phase Flow in Vertical Tubes. J. Nucl. Sci. Technol. 19, 985-996. https://doi.org/10.1080/18811248.1982.9734247

Yao, S.C., Sylvester, N.D., 1987. A mechanistic model for two-phase annular-mist flow in vertical pipes. AIChE J. 33, 1008-1012. https://doi.org/10.1002/aic.690330613

Yin, P., Cao, X., Li, Y., Yang, W., Bian, J., 2018. Experimental and numerical investigation on slug initiation and initial development behavior in hilly-terrain pipeline at a low superficial liquid velocity. Int. J. Multiph. Flow 101, 85-96. https://doi.org/10.1016/j.ijmultiphaseflow.2018.01.004

Yuan, M., 2011. Liquid Loading of Gas Wells (M.Sc thesis). McDougall School of Petroleum Engineering, University of Tulsa, USA.

Zangana, M.. H.S., 2011. Film behaviour of vertical gas-liquid flow in a large diameter pipe (Ph.D thesis). University of Nottingham.

Zivi, S.M., 1964. Estimation of steady-state steam void fraction by means of the principle of minimum entropy production. Trans. Am. Sot. Mech. Engrs, Ser. C 86, 247-252.

Zuber, N., Findlay, J.A., 1965. Average Volumetric Concentration in Two-Phase Flow Systems. J. Heat 
Transfer 87, 453. https://doi.org/10.1115/1.3689137 


\section{APPENDIX A}

Table A1. Classification of existing correlations used for the preliminary evaluation

\begin{tabular}{|c|c|c|c|c|}
\hline \multicolumn{5}{|c|}{ Flow regime dependent correlations } \\
\hline & Author & Flow pattern & Correlation type & Source \\
\hline 1. & Ellis and Jones (1965) & Bubble flow & Drift flux & Godbole (2009) \\
\hline 2. & Beggs (1972) & Bubble flow & Empirical & Godbole (2009) \\
\hline 3. & Kabir and Hasan (1990a) & Bubble flow & Drift flux & Godbole (2009) \\
\hline 4. & Gomez et al. (2000) & Bubble flow & Mechanistic & Godbole (2009) \\
\hline 5. & Hibiki and Ishii (2002) & Bubble flow & Drift flux & Godbole (2009) \\
\hline 6. & Nicklin and Davidson (1962) & Slug flow & Drift flux & Godbole (2009) \\
\hline 7. & Ellis and Jones (1965) & Slug flow & Drift flux & Godbole (2009) \\
\hline 8. & Sylvester (1987) & Slug flow & Drift flux & Godbole (2009) \\
\hline 9. & Kataoka and Ishii (1987) & Slug flow & Drift flux & Godbole (2009) \\
\hline 10. & Gomez et al. (2000) & Slug flow & Mechanistic & Godbole (2009), Woldesemayat and Ghajar (2007) \\
\hline 11. & Bonnecaze et al. (1971) & Slug flow & K-alpha & Godbole (2009) \\
\hline 12. & Beggs (1972) & Slug flow & Empirical & Godbole (2009) \\
\hline 13. & Kabir and Hasan (1990b) & Slug flow & Drift flux & Godbole (2009) \\
\hline 14. & Kabir and Hasan (1990c) & Churn flow & Drift flux & Godbole (2009) \\
\hline 15. & Tangesdal et al. (1999) & Churn flow & Drift flux & Godbole (2009) \\
\hline 16. & Lockhart and Martinelli (1949) & Annular flow & Slip ratio & Godbole (2009) \\
\hline 17. & Fauske (1961) & Annular flow & Slip ratio & Godbole (2009) \\
\hline 18. & Smith (1969) & Annular flow & Slip ratio & Godbole (2009), Woldesemayat and Ghajar (2007) \\
\hline 19. & Zivi (1964) & Annular flow & Slip ratio & Godbole (2009) \\
\hline 20. & Tandon (1985) & Annular flow & Empirical & Godbole (2009) \\
\hline 21. & Chen (1986) & Annular flow & Semi-empirical & Godbole (2009) \\
\hline 22. & Yao and Sylvester (1987) & Annular flow & Mechanistic & Godbole (2009) \\
\hline 23. & Kabir and Hasan (1990d) & Annular flow & Semi-empirical & Godbole (2009) \\
\hline 24. & Gomez et al. (2000) & Annular flow & Semi-empirical & Godbole (2009) \\
\hline
\end{tabular}




\begin{tabular}{|c|c|c|c|c|}
\hline \multirow[t]{2}{*}{25.} & Beggs (1972) & Annular flow & & Godbole (2009) \\
\hline & & \multicolumn{3}{|c|}{ Table A2. Flow regime independent correlations / Vertical Orientation } \\
\hline & & Author & Correlation type & Source \\
\hline & 26. & Schmidt et al. (2008) I - slip ratio & Slip ratio & Schmidt et al. (2008) \\
\hline & 27. & Schmidt et al (2008) II - drift flux & Drift flux & Schmidt et al. (2008) \\
\hline & 28. & Bankoff (1960) & $K \alpha_{H}$ & Godbole (2009) \\
\hline & 29. & Nishino and Yamaguchi (1976) & Empirical & Godbole (2009) \\
\hline & 30. & Thom (1964) & Slip ratio & Godbole (2009) \\
\hline & 31. & Baroczy (1966) & Slip ratio & Godbole (2009) \\
\hline & & Neal and Bankoff (1966) & Empirical & Godbole (2009) \\
\hline & 33. & Premoli et al. (1971) & Slip ratio & Godbole (2009) \\
\hline & 34. & El-Boher et al. (1988) & Slip ratio & Godbole (2009) \\
\hline & 35. & Czop et al. (1994) & $K \alpha_{H}$ & Godbole (2009) \\
\hline & 36. & Dimentiev et al. (1959) & Empirical & Godbole (2009) \\
\hline & & Wilson et al. (1961) & Empirical & Godbole (2009) \\
\hline & 38. & Gardner (1980) I & Empirical & Godbole (2009) \\
\hline & 39. & Gardner (1980) II & Empirical & Godbole (2009) \\
\hline & 40. & $\operatorname{Dix}(1971)$ & Drift flux & Godbole (2009) \\
\hline & 41. & Mukherjee (1979) & Empirical & Godbole (2009) \\
\hline & 42. & Spedding and Chen (1984) & Slip ratio & Woldesemayat and Ghajar (2007) \\
\hline & 43. & Morooka et al. (1992) & Drift flux & Godbole (2009) \\
\hline & 44. & Takeuchi et al. (1992) & Drift flux & Godbole (2009) \\
\hline & 45 & Yamazaki and Yamaguchi (1976) & Slip ratio & Godbole (2009) \\
\hline & 46. & Sterman (1956) & Empirical & Godbole (2009) \\
\hline & 47. & Hughmark (1962) & Slip ratio & Godbole (2009) \\
\hline
\end{tabular}


Table A3. Flow regime independent correlations / Multiple orientations

\begin{tabular}{llll}
\hline & Author & Correlation type & Source \\
\hline 48. & Madsen (1975) & Slip ratio & Godbole (2009) \\
\hline 49. & Chisholm (1983) & & \\
\hline 50. & Shvarts et al. (1993) & Empirical & Godbole (2009) \\
\hline 51. & Chexal et al. (1992) & Drift flux & Wodbole (2009) \\
\hline 52. & Woldesemayat and Ghajar (2007) & Drift flux & Woldesemayat and Ghajar (2007) \\
\hline 53. & Zhao et al. (2000) & Slip ratio & Woldesemayar (2007) \\
\hline 54. & Guzhov et al. (1967) & Ko $\alpha_{H}$ & Woldesemayat and Ghajar (2007) \\
\hline 55. & Greskovich and Cooper (1975) & $K \alpha_{H}$ & Cioncolini and Thome (2012) \\
\hline 56. & Cioncolini and Thome (2012) & & Bhagwat and Ghajar (2013) \\
\hline 57. & Bhagwat and Ghajar (2013) & Drift flux &
\end{tabular}

Table A4. General correlations

\begin{tabular}{llll}
\hline & Author & Correlation type & Source \\
\hline 58. & Homogeneous & Drift flux & Godbole (2009) \\
\hline 59. & Armand (1946) & $K \alpha_{H}$ & Woldesemayat and Ghajar (2007) \\
\hline 60. & Chisholm (1983), Armand (1946) & $K \alpha_{H}$ & Woldesemayat and Ghajar (2007) \\
\hline 61. & Armand and Masena & $K \alpha_{H}$ & Woldesemayat and Ghajar (2007) \\
\hline 62. & Filimonov et al. (1957) & Drift flux & Godbole (2009) \\
\hline 63. & Rouhani and Axelsson (1970) I & Drift flux & Woldesemayat and Ghajar (2007) \\
\hline 64. & Rouhani and Axelsson (1970) II & Drift flux & Woldesemayat and Ghajar (2007) \\
\hline 65. & Chisholm (1973a) & Slip ratio & Woldesemayat and Ghajar (2007) \\
\hline 66. & Mattar and Gregory (1974) & Drift flux & Woldesemayat and Ghajar (2007) \\
\hline 67. & Kowalczewski & Ko & Woldesemayat and Ghajar (2007) \\
\hline 68. & Moussali & Empirical & Woldesemayat and Ghajar (2007) \\
\hline
\end{tabular}




\begin{tabular}{|c|c|c|c|}
\hline 69. & Sun et al. (1980) & Drift flux & Woldesemayat and Ghajar (2007) \\
\hline 70. & Lahey and Moody (1977) & Drift flux & Woldesemayat and Ghajar (2007) \\
\hline 71. & Ishii (1977b) & Drift flux & Godbole (2009) \\
\hline 72. & Ohkawa and Lahey (1980) & Drift flux & Godbole (2009) \\
\hline 73. & Yeh (1975) & Empirical & Godbole (2009) \\
\hline 74. & Jowitt et al. (1984) & Drift flux & Godbole (2009) \\
\hline 75. & Kokal and Stanislav (1989) & Drift flux & Godbole (2009) \\
\hline 76. & Bestion (1985) & & \\
\hline 77. & Spedding et al. (1990) & Empirical & Godbole (2009) \\
\hline 78. & Huq and Loth (1992) & Empirical & Godbole (2009) \\
\hline 79. & Maier and Coddington (1996) & Drift flux & Godbole (2009) \\
\hline 80. & Inoue et al. (1993) & Drift flux & Godbole (2009) \\
\hline 81. & Hamersma and Hart (1987) & Slip ratio & Woldesemayat and Ghajar (2007) \\
\hline 82. & Hart et al. (1989) & Empirical & Woldesemayat and Ghajar (2007) \\
\hline 83. & Pearson et al. (1984) & Drift flux & Azizi et al. (2016) \\
\hline 84. & Turner and Wallis (1965) & Slip ratio & Woldesemayat and Ghajar (2007) \\
\hline 85. & Petalas and Aziz (1997) & Slip ratio & Woldesemayat and Ghajar (2007) \\
\hline 86. & Hughmark (1965) & Drift flux & Woldesemayat and Ghajar (2007) \\
\hline 87. & Gregory and Scott (1969) & Drift flux & Woldesemayat and Ghajar (2007) \\
\hline 88. & Toshiba & Drift flux & Woldesemayat and Ghajar (2007) \\
\hline 89. & Flanigan (1958) & Empirical & Woldesemayat and Ghajar (2007) \\
\hline 90. & Wallis (1969) & Empirical & Woldesemayat and Ghajar (2007) \\
\hline 91. & Kawaji et al. (1987) & Empirical & Woldesemayat and Ghajar (2007) \\
\hline 92. & Spedding and Spence (1989) & Empirical & Woldesemayat and Ghajar (2007) \\
\hline 93. & Graham et al. (2001) & Empirical & Woldesemayat and Ghajar (2007) \\
\hline 94. & Loscher and Reindhart (1973) & $K \alpha_{H}$ & Woldesemayat and Ghajar (2007) \\
\hline 95. & Fujie (1964) & Slip ratio & Woldesemayat and Ghajar (2007) \\
\hline 96. & Chisholm and Liard (1958) & Empirical & Woldesemayat and Ghajar (2007) \\
\hline 97. & Hoogendorn (1959) & Empirical & Woldesemayat and Ghajar (2007) \\
\hline
\end{tabular}




\begin{tabular}{|c|c|c|c|}
\hline 98. & Minami and Brill (1987) & Empirical & Woldesemayat and Ghajar (2007) \\
\hline 99. & Abdul-Majeed (1996) & Empirical & Woldesemayat and Ghajar (2007) \\
\hline 100. & Shipley (1982) & Drift flux & Bhagwat and Ghajar (2014) \\
\hline 101. & Hibiki and Ishii (2003) B & Drift flux & Bhagwat and Ghajar (2014) \\
\hline 102. & Hikibi and Ishii (2003) S & Drift flux & Bhagwat and Ghajar (2014) \\
\hline 103. & Hibiki and Ishii (2003) A & Drift flux & Bhagwat and Ghajar (2014) \\
\hline 104. & Mishima and Hibiki (1996) & Drift flux & Bhagwat and Ghajar (2014) \\
\hline 105. & Choi et al. (2012) & Drift flux & Bhagwat and Ghajar (2014) \\
\hline 106. & Clark and Flemmer (1985) & Drift flux & Bhagwat and Ghajar (2014) \\
\hline 107. & Greskovich and Cooper (1975) & Drift flux & Bhagwat and Ghajar (2014) \\
\hline 108. & Beattie and Sugawara (1986) & Drift flux & Bhagwat and Ghajar (2014) \\
\hline 109. & Cai et al. I & Drift flux & Bhagwat and Ghajar (2012) \\
\hline 110. & Cai et al. II & Drift flux & Bhagwat and Ghajar (2012) \\
\hline 111. & Goda et al. (2003) & Drift flux & Bhagwat and Ghajar (2012) \\
\hline 112. & Steiner (1993) & Drift flux & Azizi et al. (2016) \\
\hline 113. & Sonnenburgh (1989) & Drift flux & Godbole (2009) \\
\hline 114. & Mukherjee (1979) & Empirical & Woldesemayat and Ghajar (2007) \\
\hline 115. & Yashar et al. (2001) & Slip ratio & Bhagwat and Ghajar (2014) \\
\hline
\end{tabular}

Table A5: Correlations which could not be evaluated over the entire database

\begin{tabular}{|c|c|c|c|}
\hline 1. & \multirow{6}{*}{$\begin{array}{l}\text { Bankoff (1960) } \\
\text { Shvarts et al. (1993) } \\
\text { Woldesemayat and Ghajar (2007) } \\
\text { Filimonov et al. (2007) } \\
\text { Kowalcsewski } \\
\text { Kutucuglu }\end{array}$} & 7. & Sun et al. (1980) \\
\hline 2. & & 8. & Maier and Coddington (1996) \\
\hline 3. & & 9. & Inoue et al. (1993) \\
\hline 4. & & 10. & Minami and Brill (1987) \\
\hline 5. & & 11. & Loscher and Riendhart (1973) \\
\hline 6. & & 12. & Fujie (1964) \\
\hline
\end{tabular}


Table A6: Correlations found to present satisfactory performances

\begin{tabular}{|c|c|c|c|c|}
\hline \multirow{3}{*}{$\begin{array}{l}\text { Flow regime dependent } \\
\text { correlations }\end{array}$} & \multicolumn{4}{|c|}{ FRI regime independent correlations } \\
\hline & \multirow[t]{2}{*}{ For vertical orientation } & $\begin{array}{c}\text { Multiple orientations including } \\
\text { vertical }\end{array}$ & \multicolumn{2}{|c|}{ General } \\
\hline & & & Armand (1946) & $\begin{array}{l}\text { Clark and Flemmer } \\
(1985)\end{array}$ \\
\hline Gomez et al. (2000) & $\begin{array}{l}\text { Schmidt et al. (2008) I - slip } \\
\text { ratio }\end{array}$ & $\begin{array}{l}\text { Woldesemayat and Ghajar } \\
(2007)\end{array}$ & Mattar and Gregory (1974) & $\begin{array}{l}\text { Beattie and Sugawara } \\
(1986)\end{array}$ \\
\hline \multirow[t]{2}{*}{ Hibiki and Davidson (1962) } & $\begin{array}{l}\text { Schmidt et al (2008) II - drift } \\
\text { flux }\end{array}$ & Bhagwat and Ghajar (2013) & Lahey and Moody (1977) & Cai et al. (1997) I \\
\hline & Thom (1964) & & Ishii (1977b) & Cai et al. (1997) II \\
\hline \multicolumn{5}{|l|}{ Slug flow correlations } \\
\hline & Baroczy (1966) & & Ohkawa and Lahey (1980) & $\begin{array}{l}\text { Mishima and Hibiki } \\
\text { (1996) }\end{array}$ \\
\hline Nicklin and Davidson (1962) & Czop et al. (1994) & & Jowitt et al. (1984) & \\
\hline Ellis and Jones (1965) & Dimentiev et al. (1959) & & Bestion (1985) & \\
\hline Kataoka and Ishii (1987) & $\operatorname{Dix}(1971)$ & & Hart et al. (1989) & \\
\hline Gomez et al. (2000) & Takeuchi et al. (1992) & & Pearson et al. (1984) & \\
\hline \multirow[t]{2}{*}{ Bonnecaze et al. (1971) } & & & Turner and Wallis (1965) & \\
\hline & & & Hughmark (1965) & \\
\hline Churn flow correlations & & & Gregory and Scott (1969) & \\
\hline \multirow[t]{2}{*}{ Kabir and Hasan (1990c) } & & & Toshiba & \\
\hline & & & Flanigan (1958) & \\
\hline Annular flow correlations & & & Wallis (1969) & \\
\hline Lockhart and Martinelli (1949) & & & Shipley (1982) & \\
\hline
\end{tabular}


Fauske (1961)

Smith (1969)

Gomez et al. (2000)

Beggs (1972)
Hibiki and Ishii (2003) B

Hibiki and Ishii (2003) S

Hibiki and Ishii (2003) A

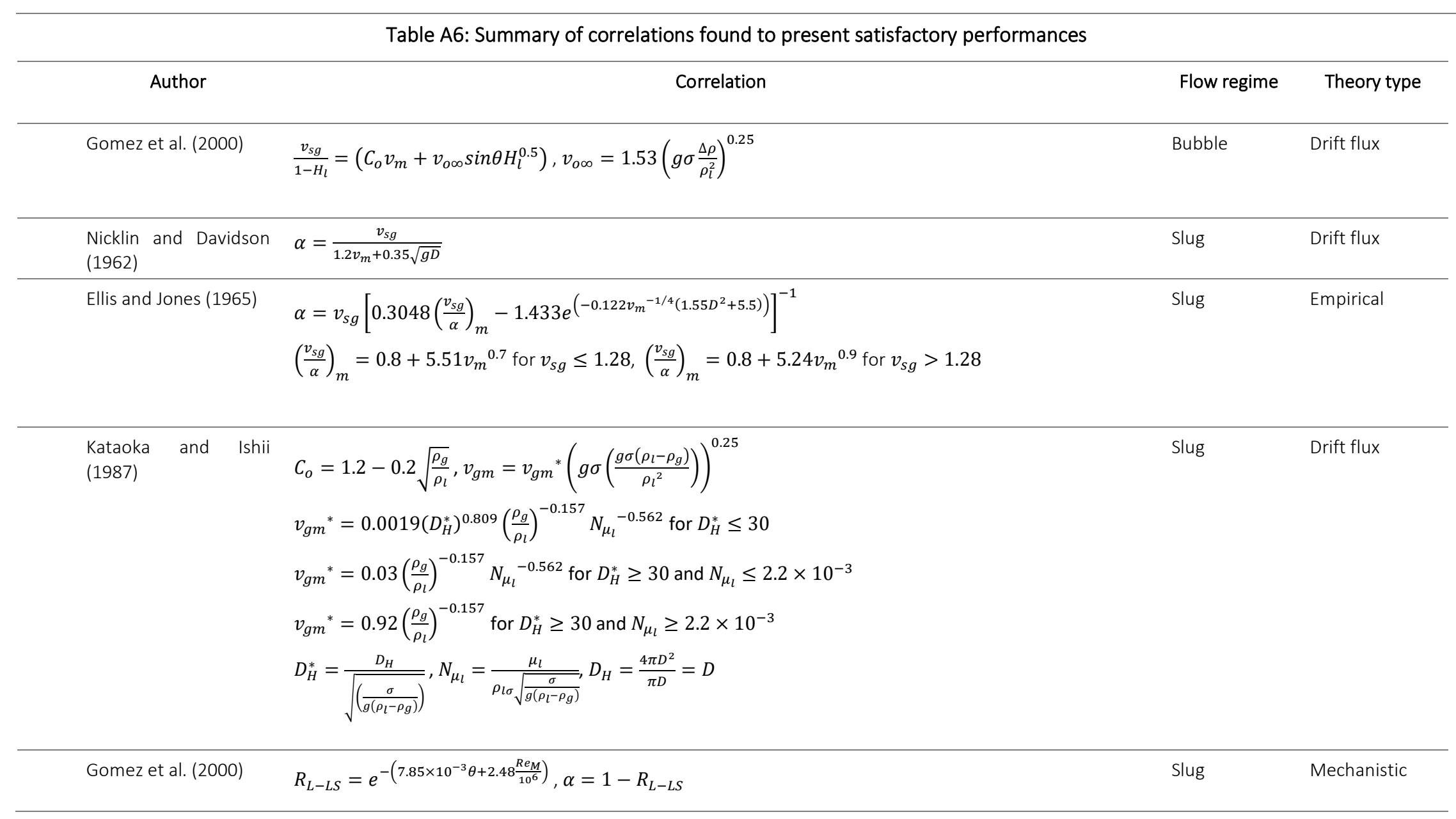




\begin{tabular}{|c|c|c|c|}
\hline $\begin{array}{l}\text { Bonnecaze et al. } \\
(1971)\end{array}$ & $\alpha=\alpha_{H}\left(1.2+\frac{0.35\left(1-\frac{\rho_{g}}{\rho_{l}}\right)}{k_{\text {Bonnecaze }} \sqrt{F r}}\right)^{-1}$ & Slug & $K \alpha_{H}$ \\
\hline Kabir and Hasan (1990) & $C_{o}=1.15, v_{g m}=0.3+0.22 \frac{D_{t}}{D_{c}}\left(\sqrt{g\left(D_{t}-D_{c}\right) \frac{\left(\rho_{l}-\rho_{g}\right)}{\rho_{l}}}\right)$ & Churn & Drift flux \\
\hline $\begin{array}{ll}\text { Lockhart } & \text { and } \\
\text { Martinelli (1949) }\end{array}$ & $\alpha=\left(1+0.28\left(\frac{1-x}{x}\right)^{0.64}\left(\frac{\rho_{g}}{\rho_{l}}\right)^{0.36}\left(\frac{\mu_{l}}{\mu_{g}}\right)^{0.07}\right)^{-1}$ & Annular & Slip ratio \\
\hline Fauske (1961) & $\alpha=\left(1+\left(\frac{1-x}{x}\right)\left(\frac{\rho_{g}}{\rho_{l}}\right)^{0.5}\right)^{-1}$ & Annular & Slip ratio \\
\hline Smith (1969) & $\begin{array}{l}\alpha=\left[1+\frac{\rho_{g}}{\rho_{l}}\left(\frac{1-x}{x}\right)\left(k_{\text {Smith }}+\left(1-k_{\text {Smith }}\right)\right) \sqrt{\left.\frac{\left(\frac{\rho_{g}}{\rho_{l}}+k_{\text {Smith }}\left(\frac{1-x}{x}\right)\right)}{1+k_{\text {Smith }}\left(\frac{1-x}{x}\right)}\right]}\right. \\
k_{\text {Smith }}=0.4\end{array}$ & Annular & Slip ratio \\
\hline Gomez et al. (2000) & $\alpha=\frac{v_{s g}}{v_{s g}+E V_{s l}}, E=1-e^{(-0.125(\phi-1.5))}, \phi=10^{4} v_{s g} \mu_{g} \frac{\sqrt{\frac{\rho_{g}}{\rho_{l}}}}{\sigma}$ & Annular & Mechanistic \\
\hline Beggs (1972) & $\begin{array}{l}\frac{\alpha(\theta)}{\alpha(O)}=1+C_{\text {Beggs,annular }}\left[\sin (1.8 \theta)-\frac{1}{3} \sin ^{3}(1.8 \theta)\right] \\
C_{\text {Beggs,annular }}=\left(1-\lambda_{l}\right) \ln \left[0.011 \lambda_{l}{ }^{-3.7680} N_{F R}^{0.0978} N_{L V}^{-1.6140}\right] \\
\alpha(O)=\frac{0.980 \lambda_{l}^{0.4846}}{N_{F R}^{0.0868}}, N_{L V}=1.938 v_{S l}\left(\frac{\rho_{l}}{g \sigma}\right)^{0.25}, N_{F R}=\frac{v_{m}^{2}}{g D}\end{array}$ & & \\
\hline Schmidt et al. (2008) I & $\begin{array}{l}S=1+1.95\left(\frac{\mu_{l}}{\mu_{o}}\right) \psi^{0.749}, \psi=\frac{v_{g}}{v_{l}}, \mu_{o}=1 P a s \\
\alpha=\frac{\psi}{S+\psi}\end{array}$ & & Slip ratio \\
\hline Schmidt et al (2008) II & $C_{o}=1.218 v_{m}^{-0.246}+1, v_{g m}=0$ for $\mu_{l}=1-7 \mathrm{Pas}$ & & Drift flux \\
\hline Thom (1964) & $\alpha=\left(1+\left(\frac{1-x}{x}\right)\left(\frac{\rho_{g}}{\rho_{l}}\right)^{0.89}\left(\frac{\mu_{l}}{\mu_{g}}\right)^{0.18}\right)^{-1}$ & & Slip ratio \\
\hline Baroczy (1966) & $\alpha=\left(1+\left(\frac{1-x}{x}\right)^{0.74}\left(\frac{\rho_{g}}{\rho_{l}}\right)^{0.65}\left(\frac{\mu_{l}}{\mu_{g}}\right)^{0.13}\right)^{-1}$ & & Slip ratio \\
\hline
\end{tabular}




\begin{tabular}{|c|c|c|}
\hline Czop et al. (1994) & $\alpha=-0.285+1.097 \alpha_{H}$ & $K \alpha_{H}$ \\
\hline Dimentiev et al. (1959) & $\begin{array}{l}\alpha=1.07 v_{g}^{0.8} D_{H}^{*-0.25}\left(\frac{\rho_{g}}{\rho_{l}-\rho_{g}}\right)^{-0.23} \text { for } v_{g}\left(\frac{\rho_{g}}{\rho_{l}-\rho_{g}}\right)^{-0.5} \leq 3.7 \\
\alpha=1.9 v_{g}^{0.34} D_{H}^{*-0.25}\left(\frac{\rho_{g}}{\rho_{l}-\rho_{g}}\right)^{0.09} \text { for } v_{g}\left(\frac{\rho_{g}}{\rho_{l}-\rho_{g}}\right)^{-0.5}>3.7\end{array}$ & Drift flux \\
\hline $\operatorname{Dix}(1971)$ & $C_{o}=\frac{v_{s g}}{v_{m}}\left(1+\left(\frac{v_{s l}}{v_{s g}}\right)^{\left(\frac{\rho g}{\rho_{l}}\right)}\right), v_{g m}=2.9\left(\frac{\left(\rho_{l}-\rho_{g}\right) g \sigma}{\rho_{l}^{2}}\right)^{0.25}$ & Drift flux \\
\hline Takeuchi et al. (1992) & $\begin{array}{l}C_{o}=1.11775+0.45881 \alpha-0.57656 \alpha^{2} \\
v_{g m}=F_{\text {Takeuchi }} C_{o}\left(1-C_{o} \alpha\right)\left(\frac{\sqrt{\frac{g D\left(\rho_{l}-\rho_{g}\right)}{\rho_{l}}}}{m_{\text {Takeuchi }}^{2}+C_{o} \alpha \sqrt{\frac{\rho_{l}}{\rho_{g}}-m_{\text {Takeuchi }}^{2}}}\right) \\
F_{\text {Takeuchi }}=\sqrt{\frac{k_{\text {Takeuchi }}^{2}}{D_{\text {Takeuchi }}}} k_{\text {Takeuchi }}=\sqrt{D_{\text {Takeuchi }}, \min \left(\frac{1}{2.4}, \frac{10.24}{D_{\text {Takeuchi }}}\right)}, \\
D_{\text {Takeuchi }}=D \sqrt{g\left(\frac{\rho_{l}-\rho_{g}}{\sigma}\right)}\end{array}$ & Drift flux \\
\hline $\begin{array}{l}\text { Woldesemayat and } \\
\text { Ghajar (2007) }\end{array}$ & $\alpha=v_{s g}\left[\left(1+\left(\frac{v_{s l}}{v_{s g}}\right)^{\left(\frac{\rho_{g}}{\rho_{l}}\right)^{0.1}}\right)+2.9\left(\frac{g D \sigma(1+\cos \theta)\left(\rho_{l}-\rho_{g}\right)}{\rho_{l}^{2}}\right)^{0.25}(1.22+1.22 \sin \theta)^{\frac{P_{\text {atm }}}{P_{\text {system }}}}\right]^{-1}$ & Drift flux \\
\hline $\begin{array}{l}\text { Bhagwat and Ghajar } \\
\text { (2013) }\end{array}$ & $\begin{array}{l}C_{o}=\left(\frac{1}{(1+\cos \theta)^{1.25}}\right)^{(1-\alpha)^{0.5}}+0.18\left(\frac{v_{s l}}{v_{s l}+v_{s g}}\right)^{0.1} \\
v_{g m}=R(0.35 \sin \theta+0.54 \cos \theta) \sqrt{\left(\frac{g D\left(\rho_{l}-\rho_{g}\right)}{\rho_{l}}\right)}(1-\alpha)^{-0.5 \sin \theta}\end{array}$ & \\
\hline Armand (1946) & $\alpha=0.833 \alpha_{H}$ & Drift flux \\
\hline $\begin{array}{l}\text { Mattar and Gregory } \\
\text { (1974) }\end{array}$ & $\alpha=\frac{v_{s g}}{1.3 v_{m}+0.7}$ & Drift flux \\
\hline
\end{tabular}




\begin{tabular}{|c|c|c|}
\hline $\begin{array}{l}\text { Lahey and Moody } \\
\text { (1977) }\end{array}$ & $\begin{array}{l}C_{o}=1.13, v_{g m}=2.9\left(\frac{\left(\left(\rho_{l}-\rho_{g}\right) g \sigma\right)^{0.25}}{\sqrt{\rho_{l}}}\right) \text { for } \alpha \leq 0.65 \\
C_{o}=\frac{1.13}{0.35}(1-\alpha), v_{g m}=2.9\left(\frac{\left(\left(\rho_{l}-\rho_{g}\right) g \sigma\right)^{0.25}}{\sqrt{\rho_{l}}}\right) \frac{(1-\alpha)}{0.35} \text { for } \alpha>0.65\end{array}$ & Drift flux \\
\hline Ishii (1977b) & $\begin{array}{l}C_{o}=\min \left(C_{01, \text { Ishii }}, C_{02, \text { Ishii }}\right), \\
C_{01, \text { Ishii }}=\left(1.2-0.2\left(\frac{\rho_{g}}{\rho_{l}}\right)^{0.5}\right)\left(1-e^{-18 \alpha}\right), C_{02, \text { Ishii }}=1+\frac{1-\alpha}{\left(0.8+4\left(\frac{\rho_{g}}{\rho_{l}}\right)^{0.5}\right)} \\
v_{g m}=\min \left(v_{g m 1, \text { Ishii }}, v_{g m 2, I s h i i}\right), v_{g m 1, I s h i i}=1.43 \frac{\left(g \sigma\left(\rho_{l}-\rho_{g}\right)\right)^{0.25}}{\sqrt{\rho_{l}}} \\
v_{g m 2, \text { Ishii }}=\frac{1-\alpha}{\alpha+\left(\frac{1+75(1-\alpha)}{\sqrt{\alpha}}\left(\frac{\rho_{g}}{\rho_{l}}\right)\right)^{0.5}}\left(Q_{m}+\left(\frac{\left(\rho_{l}-\rho_{g}\right) g D(1-\alpha)}{0.015 \rho_{l}}\right)^{0.5}\right), \\
Q_{m} \text { is the total volume rate of liquid and gas }\end{array}$ & Drift flux \\
\hline $\begin{array}{l}\text { Ohkawa and Lahey } \\
\text { (1980) }\end{array}$ & $\begin{array}{l}C_{o}=C_{\text {o1OkawaLahey }} \text { if } \alpha<X_{\text {OkawaLahey }} \\
C_{o}=\min \left(C_{\text {o10kawaLahey }}, C_{\text {o2OkawaLahey }}\right) \text { if } \alpha \geq X_{\text {OkawaLahey }} \\
v_{g m}=v_{\text {gm } 1, \text { okawaLahey }} \text { if } \alpha<X_{\text {OkawaLahey }} \\
v_{g m}=\min \left(v_{\text {gm } 1, \text { okawaLahey }}, v_{\text {gmakawaLahey }}\right) \text { if } \alpha \geq X_{\text {OkawaLahey }} \\
\text { Please refer to Godbole (2009) for full details }\end{array}$ & Drift flux \\
\hline Jowitt et al. (1984) & $\begin{array}{l}C o_{\text {jowitt }}=1+0.796 \exp \left(-0.061 \sqrt{\left(\frac{\rho_{l}}{\rho_{g}}\right)}\right) \\
v_{\text {gm, Jowitt }}=0.034\left(\sqrt{\left(\frac{\rho_{l}}{\rho_{g}}\right)}-1\right)\end{array}$ & Drift flux \\
\hline Bestion (1985) & $\begin{array}{l}C_{o}=1 \\
v_{\text {gm Bestion }}=0.188 \sqrt{\frac{g D_{H}\left(\rho_{l}-\rho_{g}\right)}{\rho_{g}}}\end{array}$ & Drift flux \\
\hline Hart et al. (1989) & $\alpha=\left[1+\left(\frac{v_{s l}}{v_{s g}}\right)\left(1+\left(108 \frac{\rho_{l}}{\rho_{g}} R e_{s l}^{-0.726}\right)^{0.5}\right)\right]^{-1}$ & General \\
\hline
\end{tabular}




\begin{tabular}{|c|c|c|}
\hline Pearson et al. (1984) & $C_{o}=1+0.796 \exp \left(-0.061 \sqrt{\frac{\rho_{l}}{\rho_{g}}}\right), v_{g m}=0.034\left(\sqrt{\frac{\rho_{l}}{\rho_{g}}-1}\right)$ & Drift flux \\
\hline $\begin{array}{l}\text { Turner and Wallis } \\
\text { (1965) }\end{array}$ & $\alpha=\left(1+\left(\frac{1-x}{x}\right)^{0.72}\left(\frac{\rho_{g}}{\rho_{l}}\right)^{0.4}\left(\frac{\mu_{l}}{\mu_{g}}\right)^{0.08}\right)^{-1}$ & Slip ratio \\
\hline Hughmark (1965) & $\alpha=v_{s g} / 1.2 v_{m}$ & Drift flux \\
\hline $\begin{array}{l}\text { Gregory and Scott } \\
\text { (1969) }\end{array}$ & $\alpha=v_{s g} / 1.19 v_{m}$ & Drift flux \\
\hline Toshiba & $\alpha=v_{s g} /\left(1.08 v_{m}+0.45\right)$ & Drift flux \\
\hline Flanigan (1958) & $\begin{array}{l}\alpha=\left(1+3.063 v_{s g}^{-1.006}\right)^{-1} \text { if } \frac{d_{1}}{D}>1 \Rightarrow \frac{d_{1}}{D}=1 \text { where } \\
d_{1} 260 \frac{\rho_{g}^{0.2}}{\left(\rho_{l}-\rho_{g}\right)^{0.7}}\left(\frac{\sigma}{g}\right)^{0.5}\end{array}$ & General \\
\hline Wallis (1969) & $\begin{array}{l}\alpha=\left(1+X_{t t}^{0.8}\right)^{-0.38} \\
X_{t t}=\left(\frac{1-x}{x}\right)^{0.9}\left(\frac{\rho_{g}}{\rho_{l}}\right)^{0.5}\left(\frac{\mu_{l}}{\mu_{g}}\right)^{0.1}\end{array}$ & General \\
\hline Shipley (1982) & $C_{o}=1.2, v_{g m}=0.24+0.35\left(\frac{v_{s g}}{v_{m}}\right)^{2} \sqrt{g D \alpha}$ & Drift Flux \\
\hline $\begin{array}{l}\text { Hibiki and Ishii (2003) } \\
\text { (Bubble) }\end{array}$ & $C_{o}=1.2-0.2 \sqrt{\frac{\rho_{g}}{\rho_{l}}}(1-\exp (-18 \alpha)), v_{g m}=1.41\left(g \sigma \frac{\Delta \rho}{\rho_{l}^{2}}\right)^{0.25}(1-\alpha)^{1.75}$ & Drift Flux \\
\hline $\begin{array}{l}\text { Hibiki and Ishii (2003) } \\
\text { (Slug) }\end{array}$ & $C_{o}=1.2-0.2 \sqrt{\frac{\rho_{g}}{\rho_{l}}}, v_{g m}=1.41\left(g \sigma \frac{\Delta \rho}{\rho_{l}}\right)$ & Drift Flux \\
\hline $\begin{array}{l}\text { Hibiki and Ishii (2003) } \\
\text { (Annular) }\end{array}$ & $C_{o}=1+\frac{(1-\alpha)}{\left(\alpha+4 \sqrt{\frac{\rho g}{\rho_{l}}}\right)}, v_{g m}=\frac{(1-\alpha)}{\left(\alpha+4 \frac{\sqrt{\rho_{g} / \rho_{l}}(\sqrt{g D \Delta \rho(1-\alpha))}}{0.015 \rho_{g}}\right)}$ & Drift Flux \\
\hline $\begin{array}{l}\text { Clark and Flemmer } \\
(1985)\end{array}$ & $C_{o}=0.934(1+1.42 \alpha), v_{g m}=1.53\left(g \sigma \frac{\Delta \rho}{\rho_{l}^{2}}\right)^{0.25}$ & Drift flux \\
\hline $\begin{array}{l}\text { Beattie and Sugawara } \\
\text { (1986) }\end{array}$ & $\begin{array}{l}C_{o}=1+2.6 \sqrt{f_{t p}}, f_{t p}=0.0716 R e_{t p}^{-0.237}+0.008 \\
v_{g m}=0.35 \sqrt{g D \frac{\Delta \rho}{\rho_{l}}}\end{array}$ & Drift flux \\
\hline
\end{tabular}




\begin{tabular}{ccc}
\hline Cai et al. (1997)। & $\alpha=\frac{v_{s g}}{1.185 v_{m}+1.53\left(g \sigma \frac{\Delta \rho}{\rho_{l}^{2}}\right)^{0.25}}$ \\
\hline Cai et al. (1997) II $\quad \alpha=\frac{v_{s g}}{1.15 v_{m}+0.345\left(g \sigma \frac{\Delta \rho}{\rho_{l}^{2}}\right)^{0.5}}$ & Drift flux flux \\
\hline $\begin{array}{l}\text { Mishima and Hibiki } \\
\text { (1996) }\end{array}$ & $C_{o}=1.2+0.51 \exp (-0.691(D / 1000)), v_{g m}=0$ \\
\hline
\end{tabular}


Table A7. Comparison of correlation predictions with annular flow data

\begin{tabular}{|c|c|c|c|c|c|}
\hline \multirow[t]{2}{*}{ Correlation } & \multicolumn{4}{|c|}{ Percentage prediction within } & \multirow[t]{2}{*}{ RMS } \\
\hline & $\pm 10 \%$ & $\pm 15 \%$ & $\pm 20 \%$ & $\pm 30 \%$ & \\
\hline Hibiki and Ishii (2003) A & 100 & 100 & 100 & 100 & 1.24 \\
\hline Lahey and Moody (1977) & 69.86 & 86.30 & 100 & 100 & 6.04 \\
\hline Hart et al. (1989) & 56.16 & 75.35 & 89.04 & 94.52 & 9.38 \\
\hline Bestion (1985) & 76.71 & 82.19 & 87.67 & 91.78 & 5.31 \\
\hline Baroczy (1966) & 73.97 & 83.56 & 87.67 & 94.52 & 6.13 \\
\hline Ishii (1977b) & 80.82 & 84.93 & 84.93 & 93.15 & 1.79 \\
\hline Ohkawa and Lahey (1980) & 76.71 & 83.56 & 84.93 & 93.15 & 3.44 \\
\hline Proposed slip ratio & 93.15 & 98.63 & 100 & 100 & 4.29 \\
\hline Takeuchi et al. (1992) & 69.86 & 79.45 & 84.93 & 87.67 & 4.85 \\
\hline Flanigan (1958) & 75.34 & 79.45 & 83.56 & 90.41 & 5.06 \\
\hline Ellis and Jones (1965) & 78.08 & 83.56 & 83.56 & 86.30 & 5.17 \\
\hline \multicolumn{6}{|l|}{ Flow patter specific } \\
\hline Gomez et al. (2000) & 69.86 & 80.82 & 84.93 & 86.30 & 7.72 \\
\hline Fauske (1961) & 68.49 & 83.56 & 86.30 & 93.15 & 6.54 \\
\hline Smith (1969) & 60.27 & 78.08 & 80.82 & 89.04 & 7.74 \\
\hline Beggs (1972) & 72.60 & 79.45 & 84.93 & 89.04 & 5.59 \\
\hline Proposed drift flux & 72.60 & 87.67 & 93.15 & 98.63 & 6.59 \\
\hline Wallis (1969) & 63.01 & 78.08 & 86.30 & 91.78 & 6.81 \\
\hline Jowitt et al. (1984) & 49.32 & 82.19 & 86.30 & 93.15 & 8.96 \\
\hline Pearson et al. (1984) & 47.95 & 82.19 & 86.30 & 93.15 & 8.96 \\
\hline Hughmark (1965) & 35.62 & 75.34 & 86.30 & 93.15 & 9.93 \\
\hline Armand (1946) & 34.25 & 79.45 & 86.30 & 93.15 & 9.95 \\
\hline Nicklin and Davidson & 35.62 & 79.45 & 86.30 & 94.52 & 10.27 \\
\hline Hibiki and Davidson (1962) & 34.24 & 84.93 & 86.30 & 94.52 & 10.29 \\
\hline Bonnecaze et al. (1971) & 38.36 & 78.08 & 86.30 & 93.15 & 10.38 \\
\hline Kabir an Hasan (1990c) & 49.32 & 78.08 & 84.93 & 93.15 & 8.70 \\
\hline Gregory and Scott (1969) & 41.09 & 78.08 & 84.93 & 93.15 & 9.44 \\
\hline Cai et al (1997) I & 47.95 & 78.08 & 84.93 & 93.15 & 9.44 \\
\hline Hibiki and Ishii (2003) B & 47.95 & 79.45 & 84.93 & 90.41 & 9.56 \\
\hline Hibiki and Ishii (2003) S & 47.95 & 73.71 & 84.93 & 90.41 & 9.89 \\
\hline Czop et al. (1994) & 31.51 & 68.49 & 84.93 & 93.15 & 11.55 \\
\hline Shipley (1982) & 34.25 & 71.23 & 84.93 & 93.15 & 10.59 \\
\hline Cai et al (1997) II & 46.58 & 79.45 & 83.56 & 91.78 & 7.75 \\
\hline Toshiba & 68.49 & 76.71 & 82.19 & 86.30 & 6.32 \\
\hline Thom (1964) & 58.90 & 71.23 & 80.82 & 91.78 & 8.51 \\
\hline Gomez et al. (2000b) & 64.38 & 65.75 & 80.82 & 95.89 & 10.94 \\
\hline
\end{tabular}

